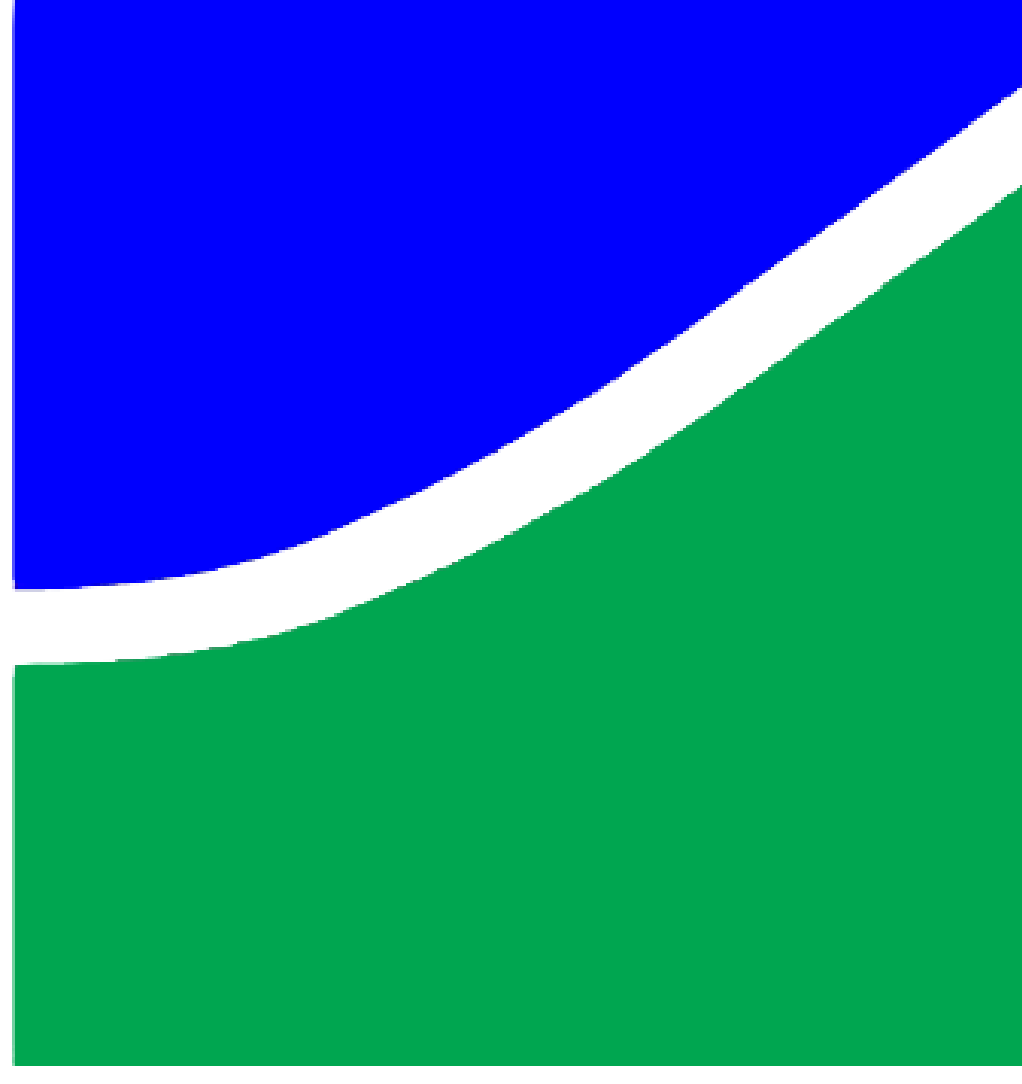

Masters Dissertation

OPTIMIZATION OF 4G CELLULAR NETWORKS FOR THE REDUCTION OF ENERGY CONSUMPTION

Samir Kolawolé Akanni Landou

Brasilia, August 2015 
UNIVERSITY OF BRASILIA

Faculty of Technology

MASTERS DISSERTATION

\section{OPTIMIZATION OF 4G CELLULAR NETWORKS FOR THE REDUCTION OF ENERGY CONSUMPTION}

\section{Samir Kolawolé Akanni Landou}

A thesis submitted to the University of Brasilia

in partial fulfillment of the requirements for the

degree of Master in Electrical Engineering

\section{Program of Study Committee:}

Prof. André Noll Barreto, ENE/UnB

Advisor

Prof. Vicente Angelo de Sousa Junior, UFRN

External examiner

Prof. Leonardo Aguayo, FGA/UnB

Internal examiner

Prof. Adoniran Judson de Barros Braga, UnB

Internal examiner 


\section{DATA CATALOG}

\section{SAMIR KOLAWOLÉ AKANNI LANDOU}

Optimization of 4G Cellular Networks for the Reduction of Energy Consumption [Distrito Federal] 2015.

xv, 54p., 210 x $297 \mathrm{~mm}$ (ENE/FT/UnB, Master, Electrical Engineering). A thesis submitted to the University of Brasilia in partial fulfillment of the requirements for the degree of Master in Electrical Engineering.

1. Cell zooming

3. Coordinated Multipoint

5. Green Cellular Networks

I. ENE/FT/UnB
2. CoMP

4. Energy efficiency

6. Sleep mode.

II. Title (Series)

\section{BIBLIOGRAPHIC REFERENCE}

S. K. A. LANDOU (2015). Optimization of 4G Cellular Networks for the Reduction of Energy Consumption. A thesis submitted in partial fulfillment of the requirements for the degree of Master in Electrical Engineering, Publication PPGEE.DM-606/2015, Department of Electrical Engineering, University of Brasilia, Brasilia, DF, 54p.

\section{ASSIGNMENT OF RIGHTS}

AUTHOR: Samir Kolawolé Akanni Landou TITLE: Optimization of 4G Cellular Networks for the Reduction of Energy Consumption. GRADE: Master degree

YEAR: 2015

It is granted to the University of Brasilia permission to reproduce copies of this work and to lend or sell such copies only for academic and scientific purposes. The author reserve other rights of publication and no part of this course conclusion work may be reproduced without written permission of the author.

Samir Kolawolé Akanni Landou

Campus Universitário Darcy Ribeiro, Asa Norte

CEP: 70.910-900 Brasília - DF - Brazil 


\section{ACKNOWLEDGEMENTS}

I would like to take this opportunity to appreciate my advisor Professor Dr. André Noll Barreto. Without whom, I would not have gotten the opportunity to study in the University of Brasilia and have new experience in this wonderful country. His tolerance and understanding helped me to endure the hard times and to overcome any possible difficulty to carry out this project.

I am thankful to CAPES for giving me the financial support without which I could not have kept myself in Brazil and complete this project.

I am thankful to my family and my girlfriend for their love, support and encouragement throughout this work.

Finally, I would like to thank my friends and colleagues for their help and motivations throughout this work.

Samir Kolawolé Akanni Landou 


\section{ABSTRACT}

With the growth of cellular networks and emergence of new technologies, the power consumption and energy efficiency of cellular networks have become more important. Recently, green communications have received much attention in order to reduce the energy consumption and minimize the carbon dioxide (CO2) emission. In this work, we are interested in power efficiency methods which optimize the energy saving of the cellular networks especially altering the transmitted power of base stations. We investigate some solutions found in the literature, namely sleep mode and cell zooming techniques. We also investigate the use of Coordinated Multi-Point (CoMP) transmission radio technology in order to improve the quality of the network.

Keywords: Cell zooming, CoMP, Coordinated Multipoint, Energy efficiency, Green Cellular Networks, Sleep mode. 


\section{RESUMO}

Com o crescimento das redes celulares e com o surgimento de novas tecnologias, o consumo de energia e a eficiência energética das redes celulares se tornaram mais importantes. Recentemente, as comunicações verdes têm recebido muita atenção, a fim de reduzir o consumo de energia e minimizar as emissões de dióxido de carbono (CO2). Neste trabalho, estamos interessados em métodos de eficiência energética que otimizam a redução do consumo de energia das redes celulares, especialmente alterando a potência transmitida de estações de base. Investigamos algumas soluções encontradas na literatura, a saber, o sleep mode e o cell zooming. Nós investigamos também o uso do Coordinated Multi-Point (CoMP), uma tecnologia de rádio de transmissão coordenada, a fim de melhorar a qualidade da rede.

Palavras-chave: Cell zooming, CoMP, Coordinated Multipoint, Energy efficiency, Green Cellular Networks, Sleep mode. 


\section{RESUMÉ}

Avec la croissance des réseaux cellulaires et l'émergence de nouvelles technologies, la consommation d'énergie et l'efficacité énergétique des réseaux cellulaires sont devenues plus importantes. Récemment, les communications vertes ont reçu beaucoup d'attention dans le but de réduire la consommation d'énergie et de réduire les émissions de dioxyde de carbone (CO2). Dans ce travail, nous nous intéressons à des méthodes d'efficacité de puissance qui optimisent l'économie d'énergie des réseaux cellulaires en altérant particulièrement la puissance transmise des stations de base. Nous avons étudié des solutions trouvées dans la littérature, à savoir le sleep mode et le cell zooming. Nous avons étudié également l'utilisation de Coordinated MultiPoint (COMP), une technologie de radio de transmission coordonnée, afin d'améliorer la qualité du réseau.

Mots-clés: Cell zooming, CoMP, Coordinated Multipoint, Energy efficiency, Green Cellular Networks, Sleep mode. 


\section{TABLE OF CONTENTS}

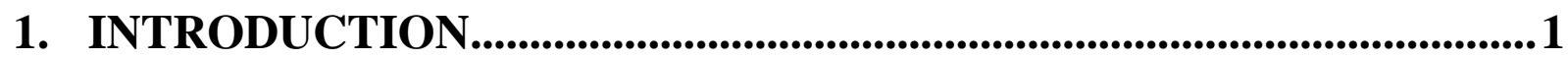

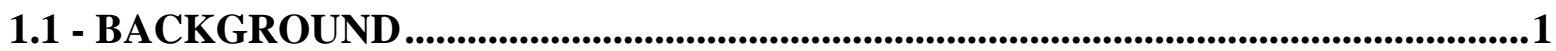

1.2 - OBJECTIVE

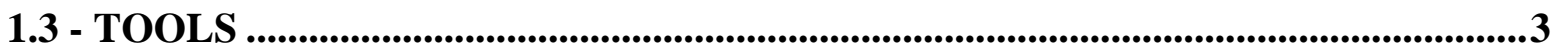

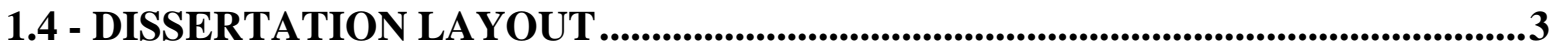

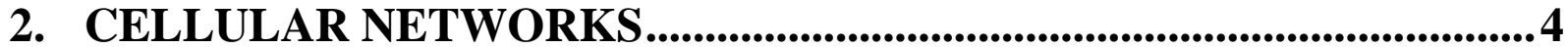

2.1 - EVOLUTION OF CELLULAR NETWORKS ............................................................4

2.2 - BASIC CONCEPTS OF A CELLULAR NETWORK …..............................................6

2.2.1 - Mobility of UE in cellular network .....................................................................

2.2.2 - The Radio Access Network ............................................................................

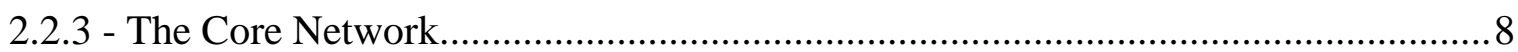

3. GREEN CELLULAR NETWORKS .....................................................9

3.1 - METRICS FOR CELLULAR NETWORKS .............................................................11

3.2 - BS ARCHITECTURAL CHANGES ..........................................................................12

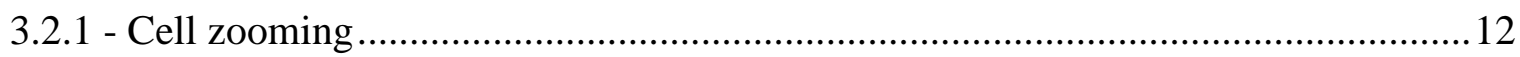

3.2.2 - Sleep mode

3.3 - COORDINATED MULTI-POINT (CoMP) .....................................................................14

4. SYSTEM MODELING (SIMULATOR) …..............................................17

4.1 - BASIC ENVIRONMENT .....................................................................................................18

4.1.1 - Cell grid ........................................................................................................... 19

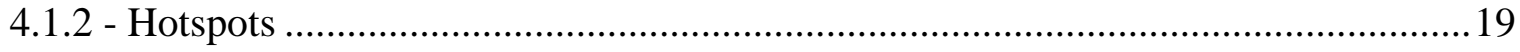

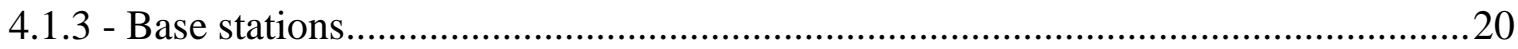

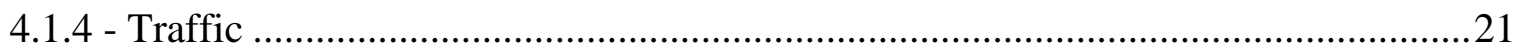

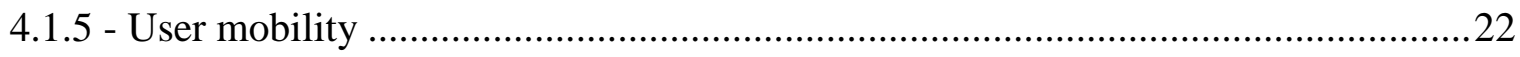

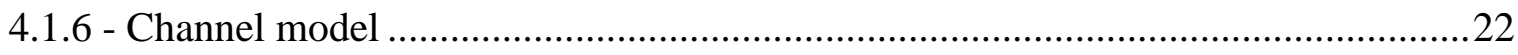

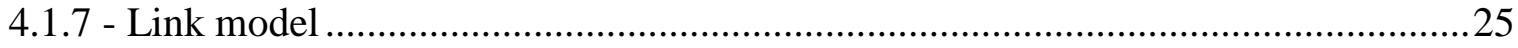

4.2 - CENTRALIZED SERVER.........................................................................................27

4.3 - PARAMETERS .......................................................................................................................27

4.4 - DATA COLLECTION.........................................................................................................29 


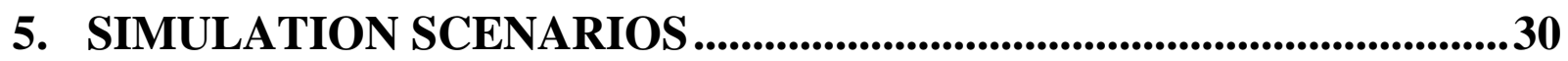

5.1 - PREVIOUS WORK ........................................................................................................30

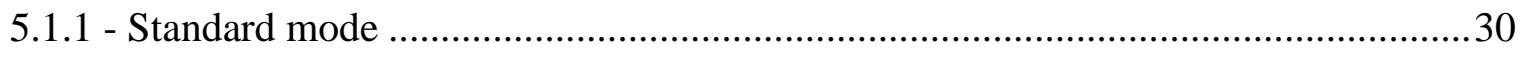

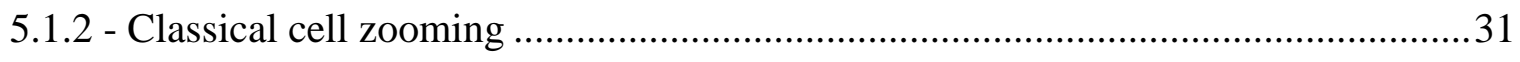

5.1 .3 - Sleep mode

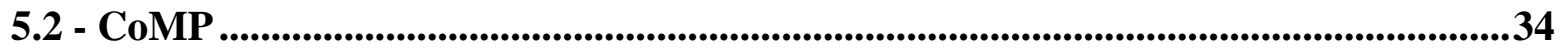

5.3 - SCENARIOS............................................................................................................................35

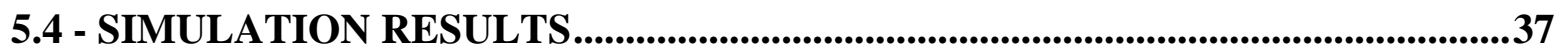

5.4.1 - Scenario 1: Standard mode ……………………................................................

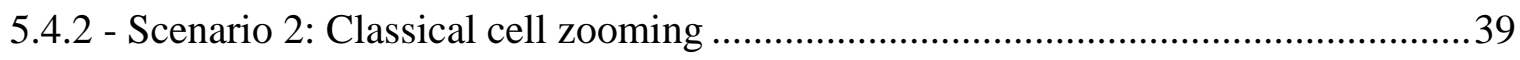

5.4.3 - Scenario 3: Sleep mode ................................................................................. 41

5.4.4 - Scenario 4: Classical cell zooming + CoMP ………………………………….....45

5.4.5 - Scenario 5: Sleep mode + CoMP …………………........................................47

5.5 - ANALYSES AND DISCUSSION...................................................................................50

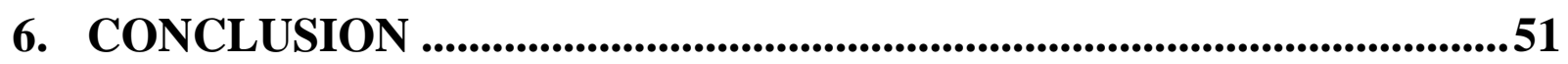

REFERENCES \& LITERATURE ..................................................................52 


\section{LIST OF FIGURES}

Figure 1.1 - Cellular network power consumption (from [2]).............................................. 1

Figure 1.2 - Mobile broadband coverage reach, 2009-2020 (from [5]) .................................3

Figure 2.1 - A summary of wireless technologies evolution since $2 \mathrm{G}$ (from [15]).................6

Figure 2.2 - Cellular network structure (adapted from [12]) ............................................. 6

Figure 2.3 - Frequency reuse pattern with factor $1: 7$ (from [16]). ......................................... 7

Figure 2.4 - Directive Antenna in a tri-sectored cell in a cell grid (from [11]).......................8

Figure 3.1 - Cell zooming concepts (adapted from [7])................................................. 12

Figure 3.2 - Sleep mode concepts (adapted from [7]).................................................... 13

Figure 3.3 - Coordinated Scheduling/Beamforming concept (adapted from [8])...................14

Figure 3.4 - Coordinated Dynamic Cell Selection concept (adapted from [4]). .....................15

Figure 3.5 - Coordinated Joint Transmission concept (adapted from [8]). ............................16

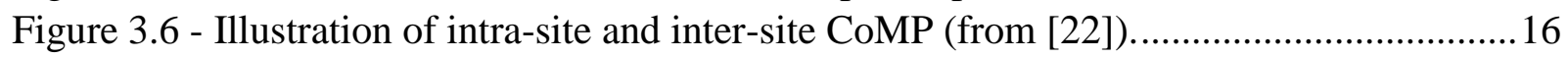

Figure 4.1 - Relation between each class of the simulator (From [11]) .............................. 18

Figure 4.2 - Hexagonal cells grid (from [11]) ............................................................ 19

Figure 4.3 - Power consumption distribution in a BS (Adapted from [3])...........................21

Figure 4.4 - Traffic model (adapted from [17]) ............................................................... 21

Figure 4.5 - Example of grid for the estimation of the SF (adapted from [25])....................24

Figure 4.6 - LTE downlink resources (from [26])........................................................26

Figure 5.1 - Rectangular grid of hexagonal cells and its configuration in the execution of the

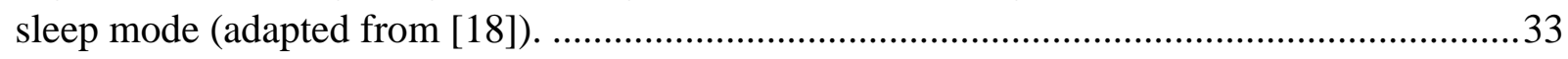

Figure 5.2 - Flowchart of the mains steps of the simulation scenarios ...................................36

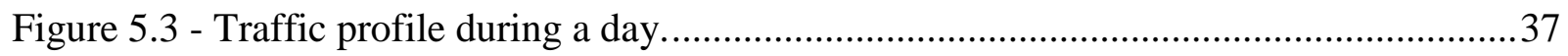

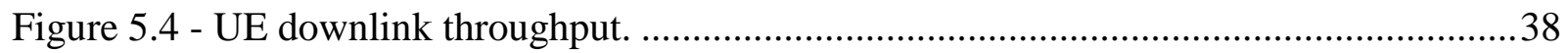

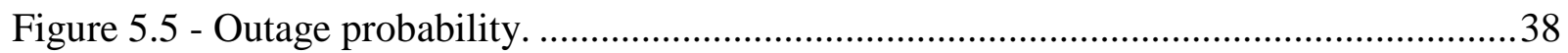

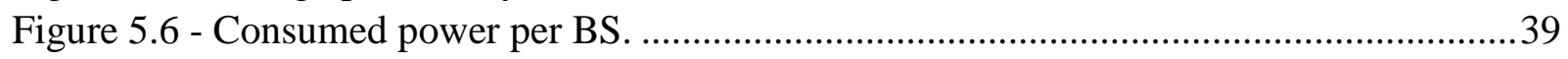

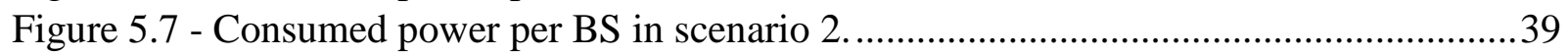

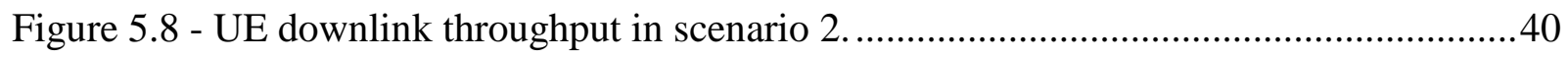

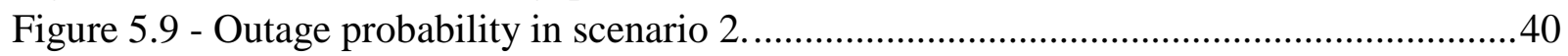

Figure 5.10 - Consumed power per BS in scenario 3 ..................................................41

Figure 5.11 - Consumed power: $75 \%$ sleep mode with different values of server granularity. 41

Figure 5.12 - Consumed power: $50 \%$ Sleep mode with different values of server granularity.42

Figure 5.13 - Consumed power: $25 \%$ Sleep mode with different values of server granularity.42

Figure 5.14 - Consumed power with different condition of sleep mode activation................43

Figure 5.15 - UE downlink throughput with different condition of sleep mode activation. .....43

Figure 5.16 - Outage Probability with different condition of sleep mode activation...............44

Figure 5.17 - UE downlink throughput in scenario 3 ....................................................44

Figure 5.18 - Outage probability (with different sleep mode schemes) in scenario 3.............45

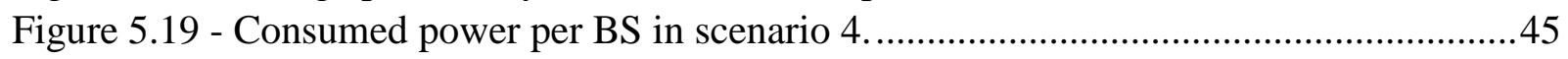

Figure 5.20 - UE downlink throughput in scenario 4 ......................................................46

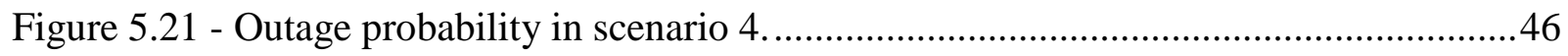




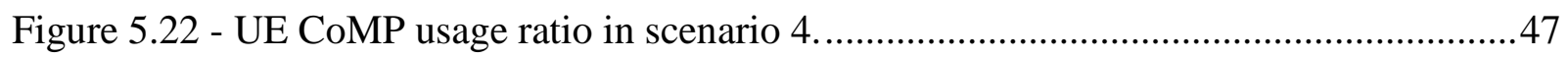

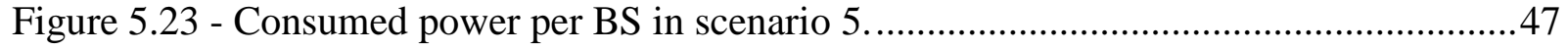

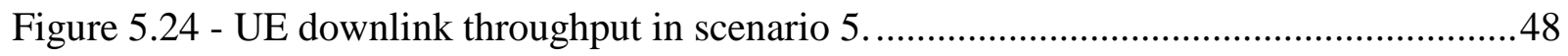

Figure 5.25 - Outage probability in scenario 5 ...........................................................48

Figure 5.26 - UE CoMP usage ratio in scenario 5...........................................................49 


\section{LIST OF TABLES}

Table 3.1 - Techniques used for a green cellular networks............................................ 10

Table 3.2 - Metrics for cellular networks. ........................................................................ 11

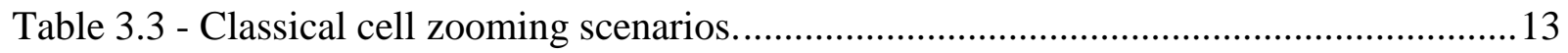

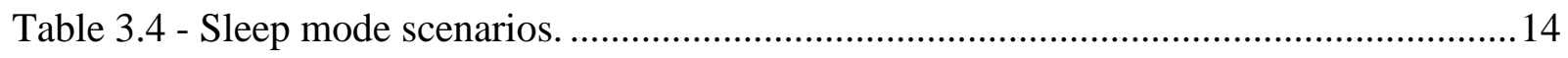

Table 4.1 - Hotspots specifications (adapted from [18]) ................................................... 19

Table 4.2 - UEs mobility specifications (adapted from [18]) .............................................22

Table 4.3 - Shadowing factor values (adapted from [25]) ................................................24

Table 4.4 - Parameters of the LTE downlink structure (Adapted from [26])........................26

Table 4.5 - Simulator parameters (adapted from [11])....................................................27

Table 5.1 - Classical cell zooming system parameters................................................... 31

Table 5.2 - Condition for Classical cell zooming execution. ................................................ 31

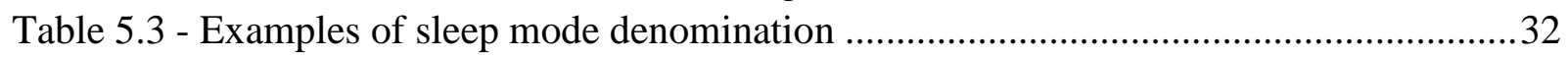

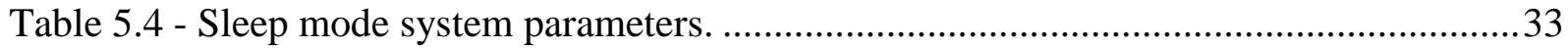

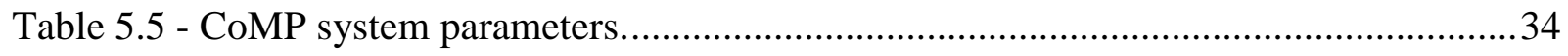

Table 5.6 - Comparative results of each simulation from $0-9 \mathrm{~h}$...........................................49 


\section{LIST OF ABBREVIATIONS}

$1 \mathrm{G} \quad 1$ st Generation of cellular networks

2G 2nd Generation of cellular networks

3G 3rd Generation of cellular networks

3GPP 3rd Generation Partnership Project

4G 4th Generation of cellular networks

1xEVDO 1x Evolution Data Optimized

AMPS Advanced Mobile Phone System

AU Antenna Unit

AUC Authentication Center

AWGN Additive White Gaussian Noise

BPSK Binary Phase Shift Keying

BS Base Station

CB Coordinated Beamforming

C-NETZ Funktelefonnetz-C

CDMA Code-Division Multiple Access

CN Core Network

CoMP Coordinated Multi-Point

CP Cyclic Prefix

CS Coordinated Scheduling

DCS Dynamic Cell Selection

DL Downlink

EDGE Enhanced Data rates for GSM Evolution

ETSI European Telecommunications Standards Institute

FDMA Frequency-Division Multiple Access

GPRS General Packet Radio Service

GSM Global System for Mobile Communications 


\begin{tabular}{|c|c|}
\hline HLR & home location register \\
\hline HSPA & High Speed Packet Access \\
\hline ICI & Inter-cell Interference \\
\hline IP & Internet Protocol \\
\hline IS-95 & Interim Standard 95 \\
\hline JP & Joint Processing \\
\hline JT & Joint Transmission \\
\hline LOS & Line-of-Sight \\
\hline LTE & Long Term Evolution \\
\hline LTE-A & LTE-Advanced \\
\hline MMS & Multimedia Message Service \\
\hline MU & Mobile User \\
\hline MSC & Mobile Switching Centers \\
\hline NLOS & Non Line-of-Sight \\
\hline NMT & Nordic Mobile Telephone \\
\hline OFDM & Orthogonal Frequency-Division Multiplexing \\
\hline OSS & Operation and Support Systems \\
\hline PDN & Packet Data Network \\
\hline PL & Path Loss \\
\hline PSTN & Public Switched Telephone Network \\
\hline PV & Photovoltaic \\
\hline QAM & Quadrature Amplitude Modulation \\
\hline QoE & Quality of Experience \\
\hline QoS & Quality of Service \\
\hline QPSK & Quadrature Phase Shift Keying \\
\hline RAN & Radio Access Network \\
\hline RB & Resource Block \\
\hline RBS & Radio Base Station \\
\hline
\end{tabular}




$\begin{array}{ll}\text { SF } & \text { Shadowing Factor } \\ \text { SIM } & \text { Subscriber Identity Module } \\ \text { SNIR } & \text { Signal-Interference-to-Noise-Ratio } \\ \text { SMS } & \text { Short Message Service } \\ \text { SMSC } & \text { Short Message Service Centers } \\ \text { TACS } & \text { Total Access Communication System } \\ \text { TDMA } & \text { Time-Division Multiple Access } \\ \text { UE } & \text { User Equipment } \\ \text { UL } & \text { Uplink } \\ \text { UMTS } & \text { Universal Mobile Telecommunication Service } \\ \text { VLR } & \text { Visitor Location Register } \\ \text { VoIP } & \text { Voice over Internet Protocol } \\ \text { WCDMA } & \text { Wideband Code-Division Multiple Access }\end{array}$




\section{INTRODUCTION}

\section{1 - BACKGROUND}

Within twenty years, the use of mobile communication services has grown considerably. The wireless network has become today a communication system essential for society. 3GPP-LTE (Long Term Evolution) is the latest standard technology of cellular networks that paved the way for a new generation of mobile radio, marketed by operators as the fourth generation $(4 \mathrm{G})$.

Standardized by 3GPP (3rd Generation Partnership Project), which is a mobile radio standardization forum, LTE enabled considerable improvement in the quality of service (QoS) of mobile systems, and the quality of experience (QoE) of users, when compared with the previous generations of cellular networks.

However, with the rapid evolution of cellular networks in the world, one should take into account the issue of energy efficiency, since telecommunication industries are responsible for about 2 percent of the total $\mathrm{CO}_{2}$ emissions in the world and this number is predicted to double by 2020 with the exponential growth of mobile traffic [1]. The increase in energy consumption is caused by the growing number of user equipments (UEs), the subscription to higher rates of mobile broadband data, as well as the higher contribution of information technology in the world [2].

This increase has an environmental impact in the world, not to mention economic. This fact has been gaining importance lately, especially with wireless networks [3]. In particular, solutions should be focused on the architecture and system design techniques of mobile cellular networks, particularly in the base stations (BS), which contribute 60 to $80 \%$ (Figure 1.1) of the total energy consumed in the network [4].

This concept of reducing energy consumption is known as "Green Cellular Networks".

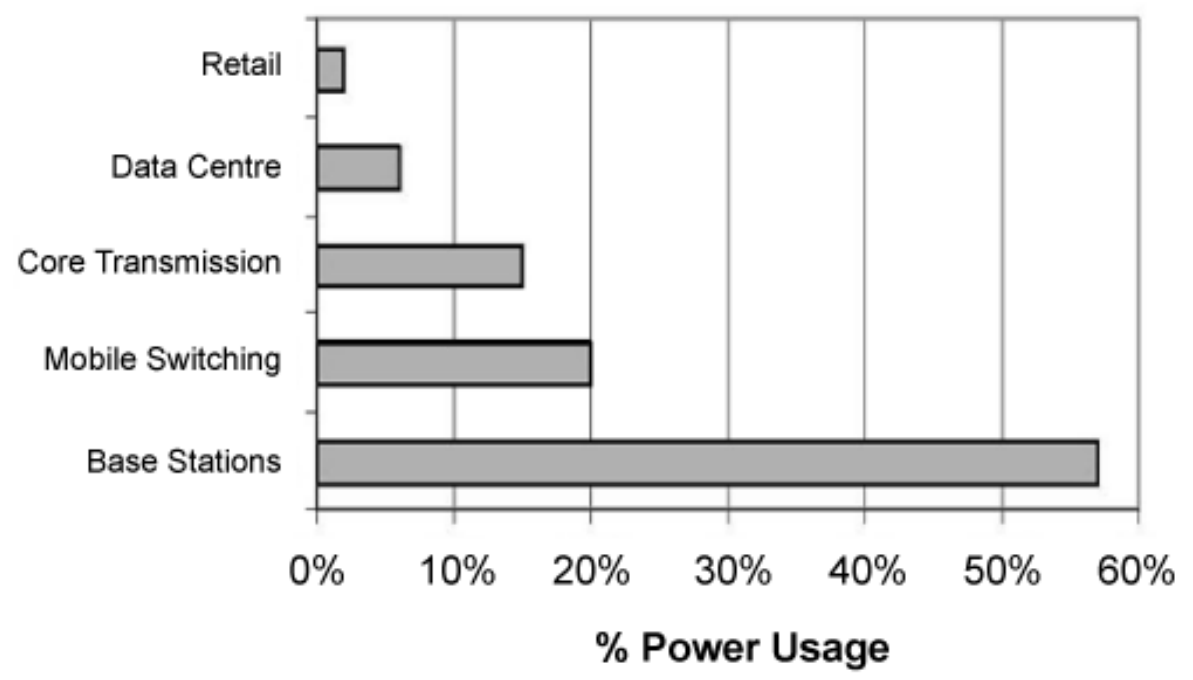

Figure 1.1 - Cellular network power consumption (from [2]). 


\section{2 - OBJECTIVE}

Nowadays, LTE 4th generation (4G) technology is implemented in most countries of the world and is still rapidly expanding in several countries which are still under 3rd generation (3G) technology (Figure 1.2); in other words, more than four out of five people worldwide will have access to 3G networks by 2020 (up from 70\% nowadays), while 4G networks will cover 60\% of the global population by this point (up from $25 \%$ nowadays) [5]. It is foreseeable that global population in a near future will be covered by $4 \mathrm{G}$ technology, which is becoming the worldwide dominant cellular networks technology in the world.

However, cellular networks essentially operate in 24 hours a day "always on", and base stations in particular consume significant power even when not carrying traffic [6]. Unfortunately, energy consumption has become one of the most important issues in the world, as the carbon emissions of energy sources have great negative impact on the environment, and the price of energy is also increasing [7].

Hence, it is of particular interest to investigate the green concept for LTE (4G) technology in order to reduce carbon footprint in the world.

Consequently, we investigate in this work some techniques suggested in the literatures. One of them is cell zooming, which consists in adjusting the cell size according to traffic condition [1] through antenna tilts and variable transmission power. Another one is the sleep mode approach, where some base stations (BS) can be switched off when their traffic loads are below a certain threshold for a certain period of time [8], thus reducing the number of active BSs. However, sleep mode and cell zooming techniques may result in coverage holes and higher outage probabilities while reducing the power consumption.

The goal of this work is to investigate solutions that not only reduce the energy consumption, but also maintain the quality of the network.

Thus, to overcome the problem of energy consumption growth and higher outage probabilities due to coverage holes, we extend in particular the concept of cell zooming and sleep mode by the use of Coordinated Multi-Point (CoMP), which is one of the techniques currently proposed in 3GPP-LTE Release 11 [9].

In CoMP radio technology, neighboring BSs cooperate to transmit or receive the same information to/from some individual UEs. This technique is especially beneficial to UEs located at the cell edge [8].

S. Landou and A. N. Barreto presented a short version of this work in [10]; where they proposed the use of Coordinated Multi-Point (CoMP) to mitigate the increase of the outage probability of the sleep mode and cell zooming. 


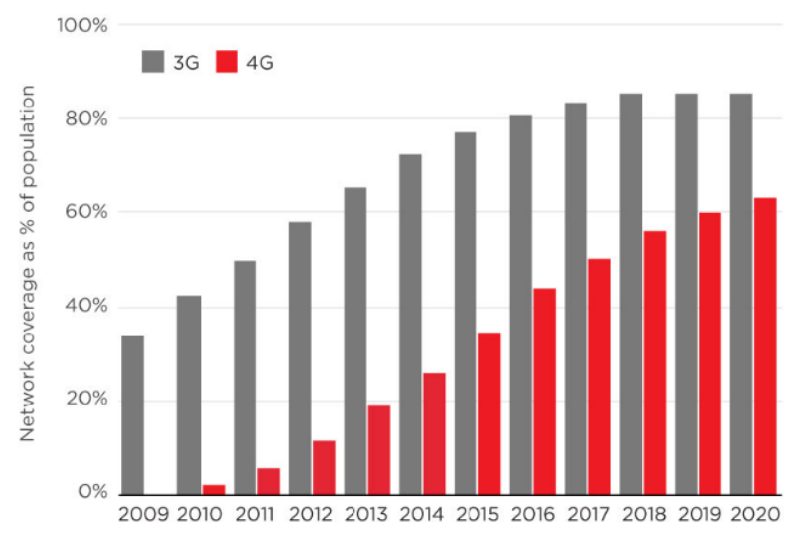

Figure 1.2 - Mobile broadband coverage reach, 2009-2020 (from [5])

\section{3 - TOOLS}

To get results and conclusions related to our proposed scheme for a green cellular network, we improved a simulator which models the downlink of an LTE standard cellular network. This simulator, written in $\mathrm{C}++$, has been built in a previous work (in [11]) to model long-term variation of UEs traffic, to measure the energy consumption and the downlink throughput of cellular networks.

In this work, we improve the simulator algorithm in order to reduce its execution time; to insert additional statistic data collection parameters; to modify the throughput calculation with Shannon's capacity, to model the impact of channel coding; to insert CoMP algorithm and to simulate CoMP with sleep mode or cell zooming techniques in order to improve the energy efficiency.

Then, to analyze the results, graphs are generated to analyze the impact of a green communication on the network performance and the energy consumption of a cellular network before its real implementation. The source code of the simulator is freely available from the address https://sourceforge.net/projects/green-cellular-network .

\section{4 - DISSERTATION LAYOUT}

This dissertation report consists of six chapters. The chapters are organized as follows:

Chapter 2 presents necessary background of historical and technical aspects of a cellular network. It explains briefly how the basic concept of a cellular network was since its beginning. Chapter 3 describes the goal of each investigated technique (i.e. sleep mode, cell zooming and CoMP) for energy efficiency used in this work. Chapter 4 presents functionalities of the simulator and explains how the standard cellular network simulator is built. Chapter 5 presents firstly the scenarios and algorithms considered for each simulation. Secondly, it explains the scenario of the previous work and the proposed scheme; and thirdly it presents the simulation results, analysis and discussions about it. Finally, Chapter 6 concludes the dissertation introducing some possibilities of future research. 


\section{CELLULAR NETWORKS}

A cellular network is a technology which is designed for mobile communication. It allows UEs to communicate via radio interface. Originally created to provide only analog speech service, mobile communications technology has grown considerably with advanced technology; now, it allows access to data services (SMS (Short Message Service), MMS (Multimedia Message Service), Internet access, VoIP (Voice over Internet Protocol), etc.) to its subscribers.

This chapter presents the major evolution and the basic concepts of cellular network.

\section{1 - EVOLUTION OF CELLULAR NETWORKS}

The $\mathbf{1}^{\text {st }}$ generation $(1 \mathrm{G})$ of cellular Network was launched and commercialized at the first time, in the 1980s. Several technologies of cellular networks have been created such as:

- $\quad$ AMPS (Advanced Mobile Phone System) in United State of America,

- TACS (Total Access Communication System) in Japan and United Kingdom,

- $\quad$ RadioCom2000 in France,

- $\quad$ NMT (Nordic Mobile Telephone) in Scandinavia,

- $\quad$ C-NETZ (Funktelefonnetz-C) in Germany.

In $1 \mathrm{G}$, only analog speech service was provided for UEs with a very limited system capacity of the system, and no compatibility among different systems. This capacity constraint as well as the high cost of mobile terminals and communication prices had restricted the use of $1 \mathrm{G}$ to limited number of UEs [12].

After $1 \mathrm{G}$ systems were deployed, much progress has been made, particularly in advanced radio mobile technologies, and new generations of cellular networks were born in order to improve the $1 \mathrm{G}$ 's drawbacks. In the $\mathbf{2}^{\text {nd }}$ Generation $(2 \mathrm{G})$, four cellular network technologies were created:

- $\quad$ GSM (Global System Mobile communications) in Europe,

- $\quad$ PDC (Personal Digital Communications) in Japan,

- $\quad$ IS-95 (Interim Standard 95) in USA.

- $\quad$ IS-136 (TDMA) in USA.

These systems, in their original versions, gave access to voice service with mobility, and also allowed low-speed data transfers, and short text messages, best known as SMS (Short Message Service) [12].

Arguably, the main technologies that have emerged in 2G are the IS-95 and GSM. However, GSM is the one that met the wider success, and was deployed in a large number of countries, allowing roaming between them. Both are based on digital modulation. 
IS-95 was based on CDMA (Code-Division Multiple Access), and provided access to multiple UEs on the same channel, each with a different spreading code, allowing great increase in network capacity.

GSM, which is still widely used, is based on FDMA (Frequency Division Multiple Access) and TDMA (Time Division Multiple Access). Two new standards were derived from GSM by ETSI (European Telecommunications Standards Institute) to incorporate the data packet switching to the already employed circuit switching: GPRS (General Packet Radio Service) and EDGE (Enhanced Data rates for GSM Evolution). The GSM / GPRS / EDGE family makes use of SIM (Subscriber Identity Module) cards and multiple access is based on time and frequency (TDMA / FDMA) [12], [13] for all versions.

However, at the end of the 1990 s, data rates provided by $2 \mathrm{G}$ networks were still too limited to access data services fluidly. This limitation has been the motivation for the definition of the $3^{\text {rd }}$ Generation (3G) technologies, which are initially characterized by the will of the telecommunication industries to define a global standard. The goals were to offer global roaming to UEs, but also to reduce the unit costs of mobile terminals and network equipment.

The main technologies that have emerged in 3G are UMTS (Universal Mobile Telecommunications System) from GSM, and CDMA2000 from IS-95. Companies, particularly those from the GSM world, have gathered in a consortium called 3GPP (3rd Generation Partnership Project) to develop the UMTS standard in late the 1990s. The first version of the standard is called Release 99 [11]. The main difference between 3G systems and its predecessors is the larger data rate in the former [13].

HSPA (High Speed Packet Access) and HSPA+ (High Speed Packet Access+) are two technologies standardized after UMTS by 3GPP (Release 7), in order to improve UMTS' performance bringing very significant benefits in terms of data rate, capacity and latency. UMTS met a greater commercial success than CDMA2000 and nowadays, it is widely deployed on every continent [12].

Since 1G, there was a great improvement in QoS, QoE and services provision (voice, data, multimedia, etc.). However, for a further improvement, a new technology was defined and standardized by 3GPP (Release 8) in December 2008 during the Future Evolution Workshop for the evolution in long term of UMTS. Thus, the name LTE (Long Term Evolution) has been defined by 3GPP for this technology considered as a fourth stage of the evolution of mobile access networks, also called commercially $4^{\text {th }}$ Generation (4G).

LTE has been standardized to achieve high peak rates in DL (Downlink) and UL (Uplink); to reduce latency; to improve spectral efficiency; to have a flexible bandwidth; to support mobility between different access networks $(2 \mathrm{G} / 3 \mathrm{G})$; to implement a new simplified network architecture; and to ensure compatibility with earlier 3GPP Releases [14].

The evolution of LTE is called LTE-A (LTE-Advanced). It has been introduced since Release 10 by 3 GPP in order to improve LTE technology.

Figure 2.1 shows a summary of wireless technologies evolution since $2 \mathrm{G}$. 


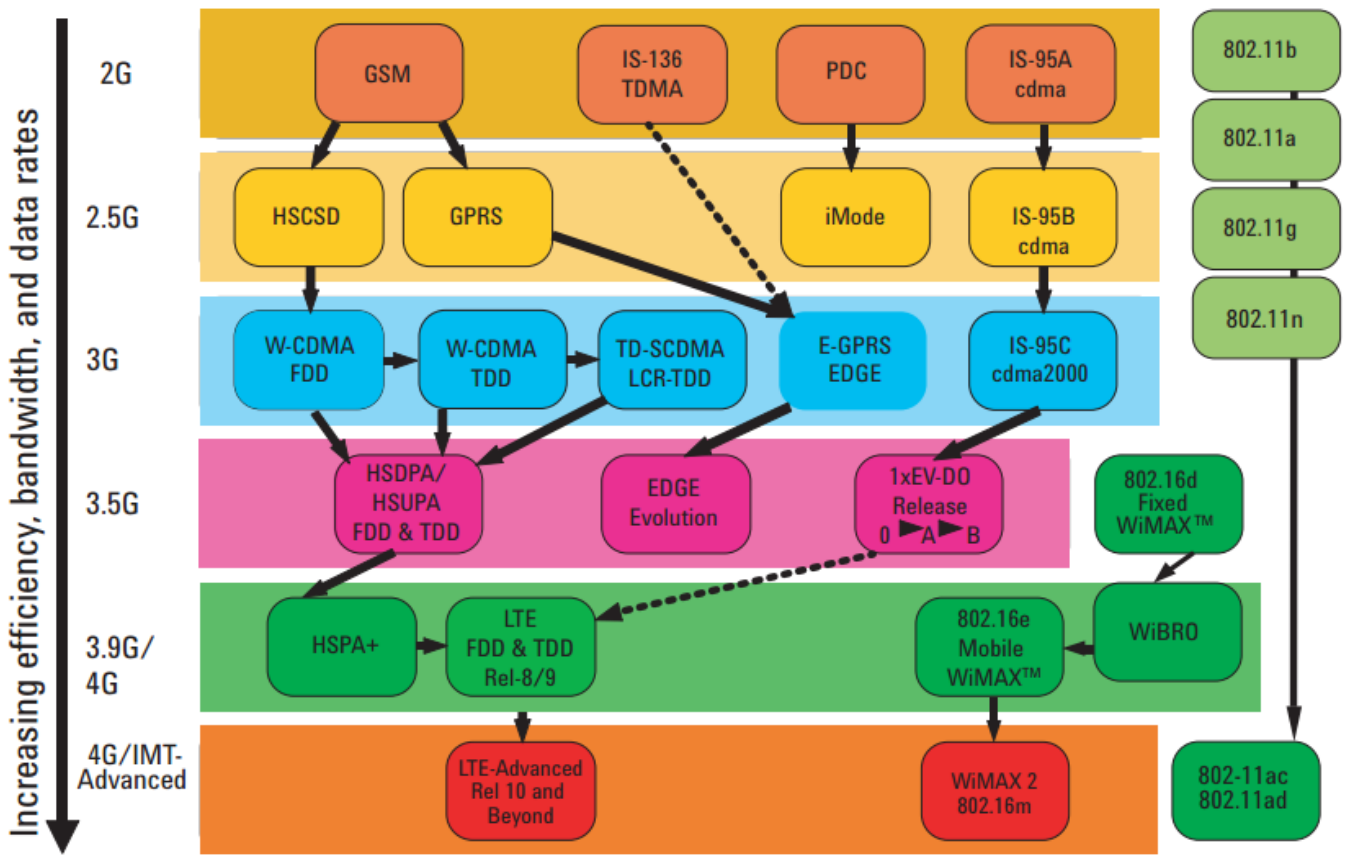

Figure 2.1 - A summary of wireless technologies evolution since $2 \mathrm{G}$ (from [15]).

\section{2 - BASIC CONCEPTS OF A CELLULAR NETWORK}

The architecture of a cellular network is based on three entities:

- $\quad$ the Mobile User (MU) or User Equipment (UE);

- $\quad$ the Radio Access Network (RAN);

- $\quad$ the Core Network (CN).

Figure 2.2 shows a simplified scheme of the cellular network structure.

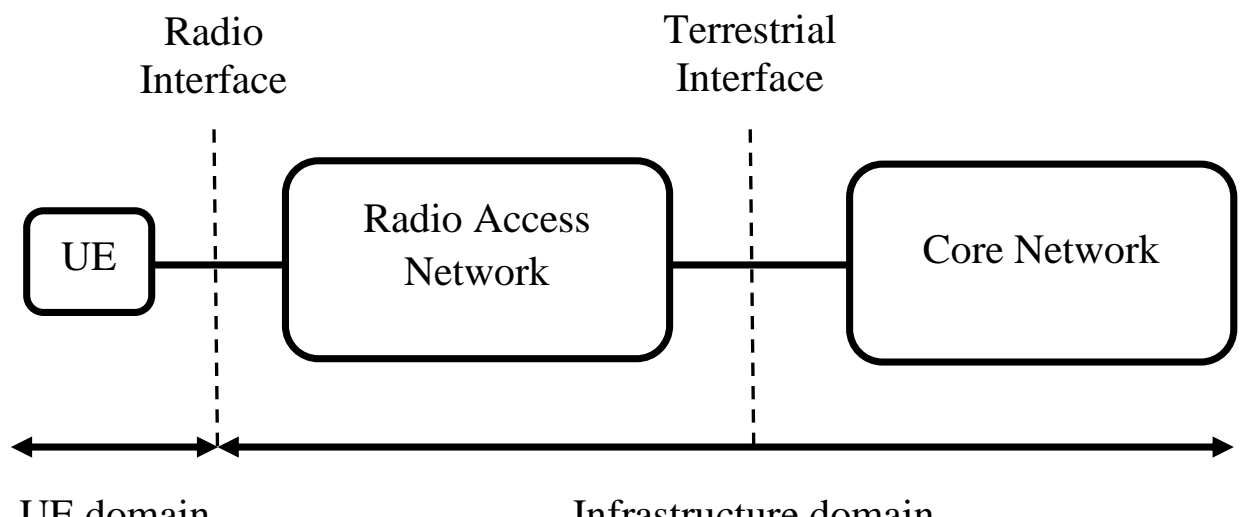

Figure 2.2 - Cellular network structure (adapted from [12]). 


\subsection{1 - Mobility of UE in cellular network}

Mobility is one of the key factors of wireless networks. It gives UEs freedom of movement. Depending on the radio technology, mobility can be either limited to pedestrian speeds only, or can support communication even at high speeds [16]. The two key concepts of mobility are roaming and handovers.

Roaming can be defined as the movement of a UE from one network to another while handover is the process of switching a call or session that is in progress from one physical channel to another [16].

\subsection{2 - The Radio Access Network}

The radio access network is the largest component of the mobile network, and a large number of base stations and cell sites are provisioned in order to provide coverage [16]. Mobile networks are based on the concept of cell; hence, the name Cellular Network. Cell size in an urban area is usually less than the one in a rural area. Cells are categorized in macrocell, microcell, picocell, and femtocell, depending on their radius and transmit power level. A cell is controlled by a transmitter/receiver called base station (BS) that provides the radio link with UEs in its coverage area. The coverage of a base station is limited by several factors including:

- $\quad$ the transmit power of UE and BS;

- $\quad$ the frequency used;

- $\quad$ the type of antennas used for BS and UE;

- $\quad$ the wave propagation in the environment (urban, rural, etc.);

- $\quad$ the radio technology used.

A cell is generally represented in the form of a hexagon which represents the geometric pattern of the coverage area that ensures a regular grid space. In reality, there are of course areas of overlap between adjacent cells that create inter-cell interference [12]. To minimize the inter-cell interference, a reuse frequency with a factor of reuse is commonly used. Figure 2.3 shows an example of frequency reuse with a factor 1:7.

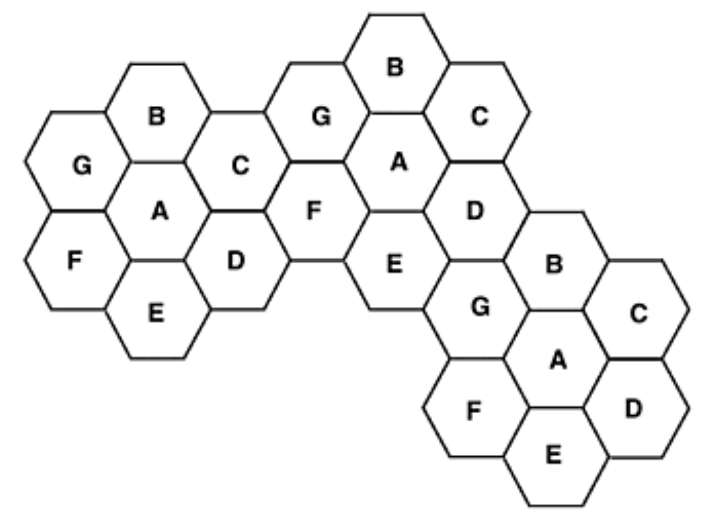

Figure 2.3 - Frequency reuse pattern with factor 1:7 (from [16]). 
Also, directive antennas are usually used to minimize the interference between neighboring BSs. They can be configured in sectors.

Figure 2.4 shows an example of directive antennas in a tri-sectored cell.

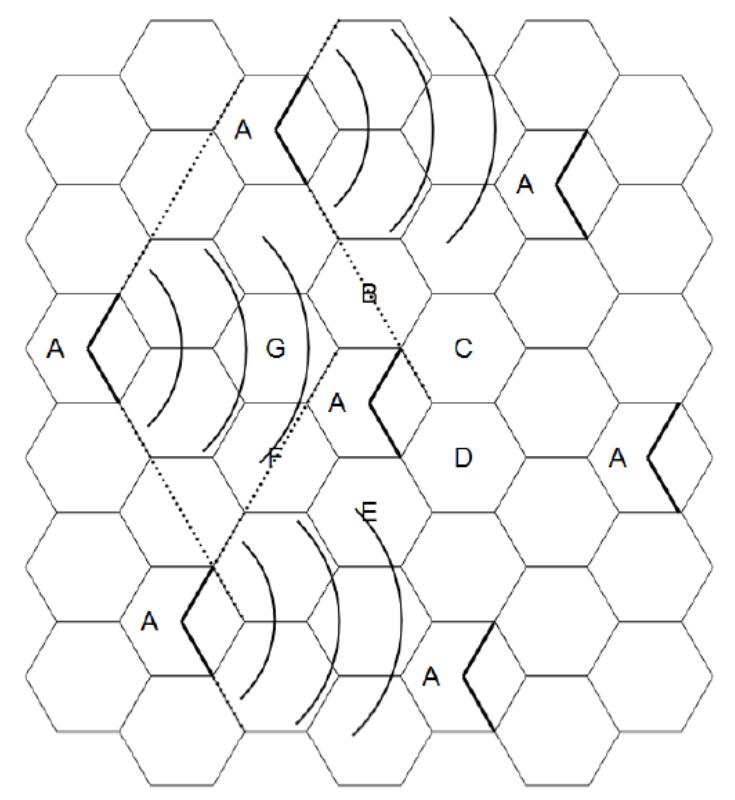

Figure 2.4 - Directive Antenna in a tri-sectored cell in a cell grid (from [11]).

\subsection{3 - The Core Network}

The core network, consists of the mobile switching centers (MSCs), the home location register (HLR), visitor location register (VLR), authentication center (AUC), billing servers, operation and support systems (OSS), short message service centers (SMSC), and many other elements. The interface to the public switched telephone network (PSTN) and the packet data network (PDN) are from the MSC in the core network [16]. 


\section{GREEN CELLULAR NETWORKS}

The notion of "green" technology in wireless systems can be made meaningful with a comprehensive evaluation of energy savings and performance in a practical system [3]. The concept of green cellular network is becoming a necessity to support social, environmental, and economic sustainability [8].

In some papers in the literature, several methods for energy saving in access networks are proposed by authors, implementing mostly cell size adjustment according to the traffic load fluctuations.

- N. Zhisheng, W. Yiqun, G. Jie and Y. Zexi [7] proposed a scheme where cells with low traffic zoom to zero and its neighboring cells zoom out with BS physical adjustments in order to compensate the coverage hole.

- X. Wang, P. Krishnamurthy and D. Tipper [6] studied the feasibility and benefits of "BS sleeping" for energy conservation.

- E. Oh et al [17] proposed an estimate of the potential base station energy saving based on real cellular traffic traces.

- T. Han and N. Ansari [8] proposed multicell cooperation solutions for improving the energy efficiency of cellular networks. The authors categorized it into three solutions i.e. sleep mode, renewable energy, and CoMP.

- B. S. Carminati, M. F. Costa and A. N. Barreto [18] focused the study of energy efficiency through power management using sleep mode and virtual cell zooming. Our work is a continuation of the system modeling presented by B. S. Carminiti et al.

- S. Tombaz, A. Västberg and J. Zander [19] proposed a framework for a total cost analysis and surveyed some strategies to minimize the overall system cost.

- G. Cili, H. Yanikomeroglu and F. R. Yu proposed in [20] to use the cell switch off scheme without increasing the transmit power of the active cells and combined it with the coordinated multipoint to enable receive sufficient power level.

- Z. Hasan, H. Boostanimehr and V. K. Bhargava [3] detailed a survey on motivations for green cellular networks and different methods for energy savings. 
Various optimization methods for energy savings have been listed by Z. Hasan et al in [3] and categorized as follow:

- $\quad$ energy savings via cooperative networks,

- renewable energy resources,

- heterogonous networks,

- cognitive radio.

They also identified four important aspects of green networking such as:

- defining metrics,

- bringing architectural changes in base stations,

- network planning,

- $\quad$ efficient system design.

Here, we focused our research considering only the two first important approaches of Hasan et al i.e. metrics definitions and BSs architectural changes for sleep mode and cell zooming. We add to the two approaches, the signal processing for CoMP.

BSs architectural changes (cell zooming and sleep mode) and signal processing (CoMP) aim to improve respectively the energy efficiency and the network performance.

A summary of techniques used in this work for a green cellular network is listed in Table 3.1.

Table 3.1 - Techniques used for a green cellular networks.

\begin{tabular}{|c|c|c|}
\hline Techniques & Applications & Observations \\
\hline \hline $\begin{array}{c}\text { Cell zooming } \\
\text { Sleep mode }\end{array}$ & BSs architectural changes & $\begin{array}{c}\text { Minimize BS energy } \\
\text { consumption altering } \\
\text { transmission power }\end{array}$ \\
\hline CoMP & Signal Processing & Cooperative BSs with CoMP \\
\hline
\end{tabular}

We detail in the next subsections, the green metrics that we used in this work, and techniques for a green cellular network mentioned above. 


\section{1 - METRICS FOR CELLULAR NETWORKS}

A green metric is necessary in order to directly compare and assess the energy consumption and performance of various components, and the overall network.

Thereby, for a green cellular network, a set of practical metrics should provide necessary information about system operation, energy savings and performance [3].

According to [3] and [19], green metrics can be evaluated by economical and/or energy efficiency aspects. Here, we mainly focused our research on the energy efficiency aspect.

This work is a continuity of the system modeling presented in [11] and [18] where, some metrics are used such as:

- the number of UEs per cell,

- the average consumed power per base station,

- the average and $10 \%$ worst case UEs downlink throughput,

- the outage probability.

Then, to evaluate the whole system of the cellular network in CoMP, we add to these metrics, the "CoMP usage ratio", which evaluates the ratio of UEs using CoMP.

The outage or throughput metrics are needed to assure that user experience is not degraded because of energy saving [18].

A summary of metrics used in this work is listed in Table 3.2.

Table 3.2 - Metrics for cellular networks.

\begin{tabular}{|c|c|c|}
\hline $\begin{array}{c}\text { Practical } \\
\text { metrics }\end{array}$ & Metrics & Functions \\
\hline $\begin{array}{c}\text { System } \\
\text { operation }\end{array}$ & Number of UE per cell & $\begin{array}{c}\text { It is a control metric used as a basis parameter } \\
\text { to evaluate the others metrics. }\end{array}$ \\
\hline $\begin{array}{c}\text { Energy } \\
\text { consumption }\end{array}$ & $\begin{array}{c}\text { Average consumed } \\
\text { power per base station }\end{array}$ & $\begin{array}{c}\text { Evaluates the average consumed power of the } \\
\text { cellular network. }\end{array}$ \\
\hline $\begin{array}{c}\text { Performance } \\
\text { for the QoS }\end{array}$ & $\begin{array}{c}\text { UEs downlink } \\
\text { throughput }\end{array}$ & $\begin{array}{c}\text { Evaluates the downlink throughput of the } \\
\text { cellular network. }\end{array}$ \\
\cline { 2 - 3 } & Outage probability & $\begin{array}{c}\text { Evaluates the ratio of UEs which received a } \\
\text { low signal and cannot be connected to a base } \\
\text { station. }\end{array}$ \\
\hline Use of CoMP & CoMP usage ratio & Evaluates the ratio of UEs using CoMP. \\
\hline
\end{tabular}




\section{2 - BS ARCHITECTURAL CHANGES}

Sleep mode and cell zooming depend essentially on the traffic load, which can have significant spatial and temporal fluctuations [8]. The traffic load varies generally in each cell as a function of time, space, weather and other societal factors [6].

However, CoMP is an alternative solution which, implementing with cell zooming or sleep mode, can enhance the quality of the network.

\subsection{1 - Cell zooming}

Cell zooming has the potential to balance the traffic load and reduce the energy consumption [7]. According to the scenarios 1 and 2 of Figure 3.1, the central cell can respectively "zoom in" or "zoom out" depending on the traffic loads.

Cell size can be adjusted by:

Option 1: Increasing or decreasing the transmit power when traffic load is respectively low or high in the cell.

Option 2: Physically adjusting the cell size by the mean of the antenna height and tilts adjustment [7].

Here, we called cell zooming using such cell adjusting technique describe in "option 1" and/or "option 2" as classical cell zooming.

Classical cell zooming aims mainly at energy efficiency, while in virtual cell zooming, also known as "load balancing", which was presented in [18], EUs can reselect another neighboring best serving cell that is more lightly loaded. Virtual cell zooming is focused only in system performance and better resource distribution without physical adjustment.

In this work, only classical cell zooming has been considered with cell size adjusting technique presented in "option 1", because the mechanism to adjust physically antenna's height and tilts is not readily available in existing BSs for the "option 2". Classical cell zooming scenarios are listed in Table 3.3.

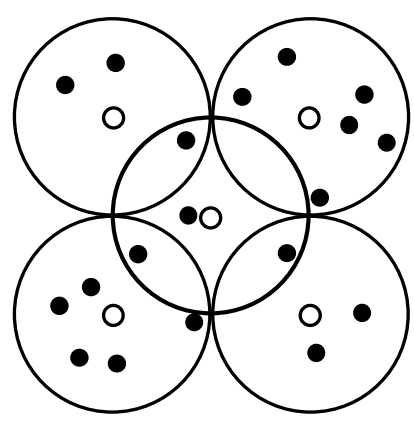

Standard cell size

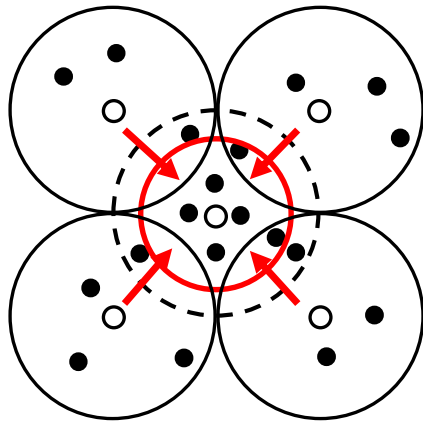

Cell zooming scenario 1

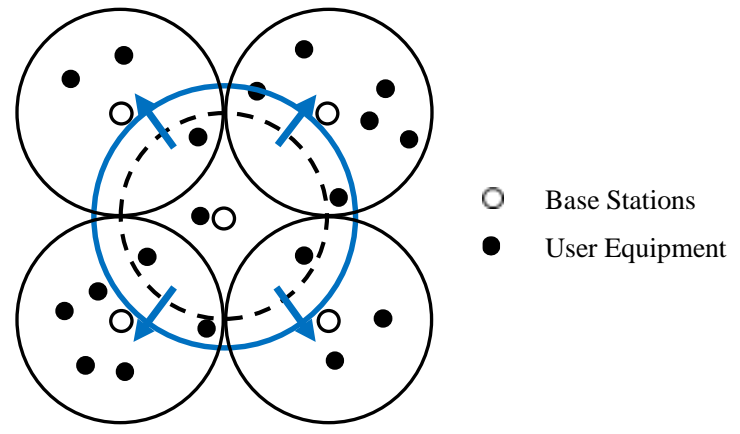

Cell zooming scenario 2

Figure 3.1 - Cell zooming concepts (adapted from [7]). 
Table 3.3 - Classical cell zooming scenarios.

\begin{tabular}{|c|c|c|c|}
\hline Scenarios & $\begin{array}{c}\text { Central cells } \\
\text { functions }\end{array}$ & $\begin{array}{c}\text { Traffic load } \\
\text { condition }\end{array}$ & Cells adjusting \\
\hline \hline Scenario 1 & $\begin{array}{c}\text { "Zoom in" when } \\
\text { some UEs move in } \\
\text { and make it } \\
\text { congested. }\end{array}$ & High & $\begin{array}{c}\text { Transmit power } \\
\text { adjustment } \\
\text { and/or }\end{array}$ \\
\hline Scenario 2 & $\begin{array}{c}\text { "Zoom out" when } \\
\text { UEs move out and } \\
\text { make neighboring } \\
\text { cells congested. }\end{array}$ & Low & $\begin{array}{c}\text { Physical cell size } \\
\text { adjustment. }\end{array}$ \\
\hline
\end{tabular}

\subsection{2 - Sleep mode}

The sleep mode concept is a variant of the classical cell zooming concept, where the central cell can be switched off (i.e. zoomed to zero) depending on the traffic load conditions. At the stage of network planning, cell size and capacity are usually fixed based on the estimation of peak traffic load [7]. During low traffic load, some BSs can be switched off, particularly at the idle hours during the night with relatively little impact on the network quality.

In scenarios 1 and 2 of Figure 3.2, central cells are switched off. However, in scenario 1, neighboring cells zoom out to compensate the coverage whilst, in scenario 2 , neighboring cells remain in standard mode and use the CoMP to transmit or receive the signal.

The more cells we turn off, the more energy consumption we will save. On the other hand, there will be some coverage holes, which will imply in the increase of the outage probabilities.

A summary of sleep mode scenarios is listed in Table 3.4.

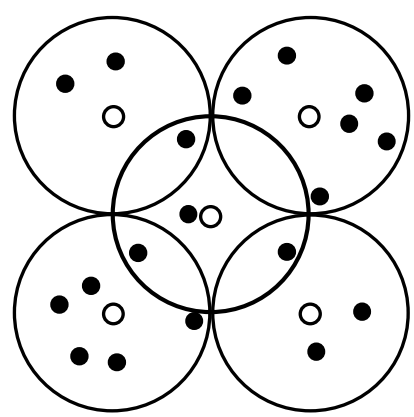

Standard cell size

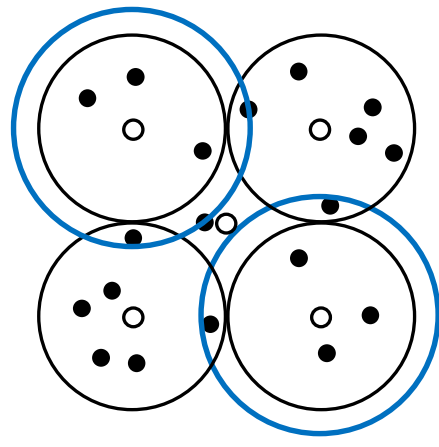

Sleep mode scenario 1

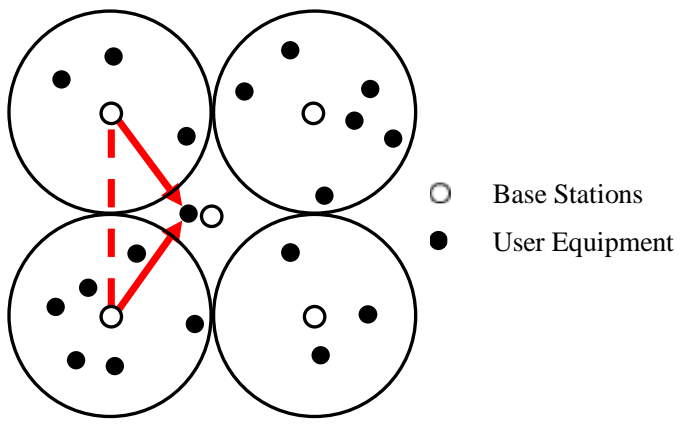

Sleep mode scenario 2

Figure 3.2 - Sleep mode concepts (adapted from [7]). 
Table 3.4 - Sleep mode scenarios.

\begin{tabular}{|c|c|c|}
\hline $\begin{array}{l}\text { Sleep mode } \\
\text { scenarios }\end{array}$ & $\begin{array}{l}\text { Central cells } \\
\text { functions }\end{array}$ & Active cells functions \\
\hline Scenario 1 & Switch off & $\begin{array}{l}\text { "Zoom out" to compensate coverage holes due to the } \\
\text { central cell. }\end{array}$ \\
\hline Scenario 2 & Switch off & $\begin{array}{l}\text { They cooperate each other the transmission (or } \\
\text { reception) signals using CoMP (Cooperative BSs). }\end{array}$ \\
\hline
\end{tabular}

\section{3 - COORDINATED MULTI-POINT (CoMP)}

One possible solution to maintain the cellular network quality is CoMP. The main idea of CoMP is to allow geographically separated base stations to cooperate in serving the UEs [21], which may or may not belong to the same physical cell; thus minimizing the inter-cell interference (ICI) which is typically the primary source of interference [6].

In a downlink scenario, two main transmissions schemes are considered for CoMP namely Coordinated Scheduling/Beamforming (CS/CB) and Joint Processing (JP-CoMP).

\section{$>$ Coordinated Scheduling/Beamforming $(\mathrm{CS} / \mathrm{CB})$}

For CS/CB [4], data for UE is only available at the serving cell where, radio beams signal processing are formed to enhance the signal strength of its serving UEs while focusing on eliminating the ICI with null steering towards UEs from neighboring [8]. As depicted in Figure 3.3, $\mathrm{BS}_{1}$ forms the radio beam toward $\mathrm{UE}_{1}$ then, in order to reduce the interference to $\mathrm{UE}_{2}$ served by $\mathrm{BS}_{2}, \mathrm{BS}_{1}$ forms the null steering toward $\mathrm{UE}_{2}$.

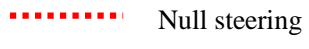

Beamforming

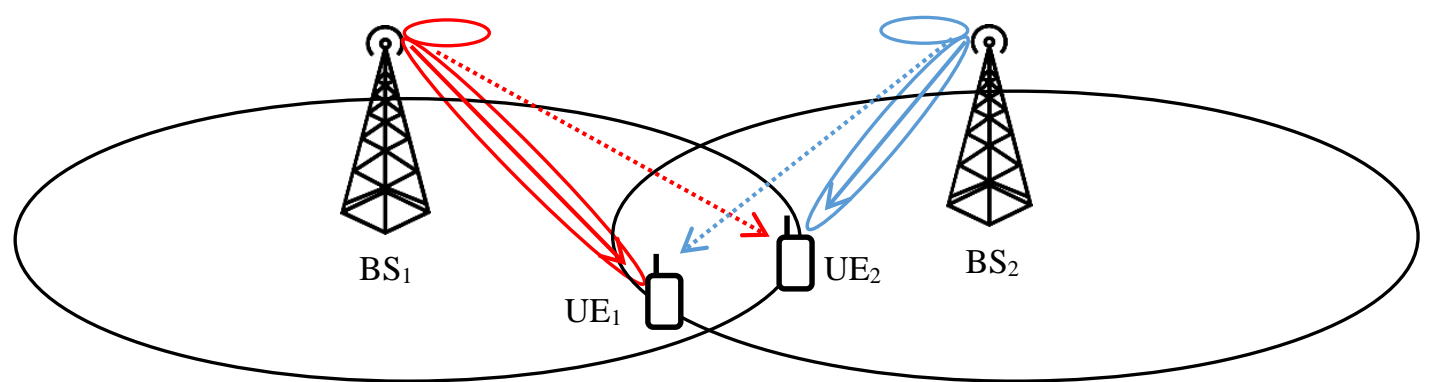

Figure 3.3 - Coordinated Scheduling/Beamforming concept (adapted from [8]). 


\section{$>$ Joint Processing (JP-CoMP)}

Joint processing is categorized into Coordinated Dynamic Cell Selection (DCS-CoMP) and Joint Transmission (JT-CoMP) [4], [8]. In JP-CoMP, data for UE is available at more than one cooperating BS [21].

\section{- Dynamic Cell Selection (DCS-CoMP)}

For DSC-CoMP, the coordination of the scheduling decisions is made among all cooperating BSs set. A UE can reselect dynamically another serving cell based on the highest received Signal-to-Interference-plus-Noise-Ratio (SINR) and minimum path loss. When a UE reselect a cell, its resource is transmitted from the first serving cell to one cell among the coordinated cells. The first serving cell resource is muted in order to transmit UE Resource Block (RB) to the second serving cell. In this process, data transmit occurs only by one BS at the time [21].

As depicted in Figure 3.4, $\mathrm{UE}_{1}$ initially served by $\mathrm{BS}_{1}$ at the resource block $\mathrm{RB}_{1}$ (i.e. the minimum resource in an LTE network that can be assigned to a UE), can balance its resource from $\mathrm{BS}_{1}$ to $\mathrm{BS}_{2}$ (i.e. from $\mathrm{RB}_{1}$ to $\mathrm{RB}_{2}$ ) according to the conditions of decision of DSC-CoMP mentioned above.

RB 1

RB 2 Cell selection

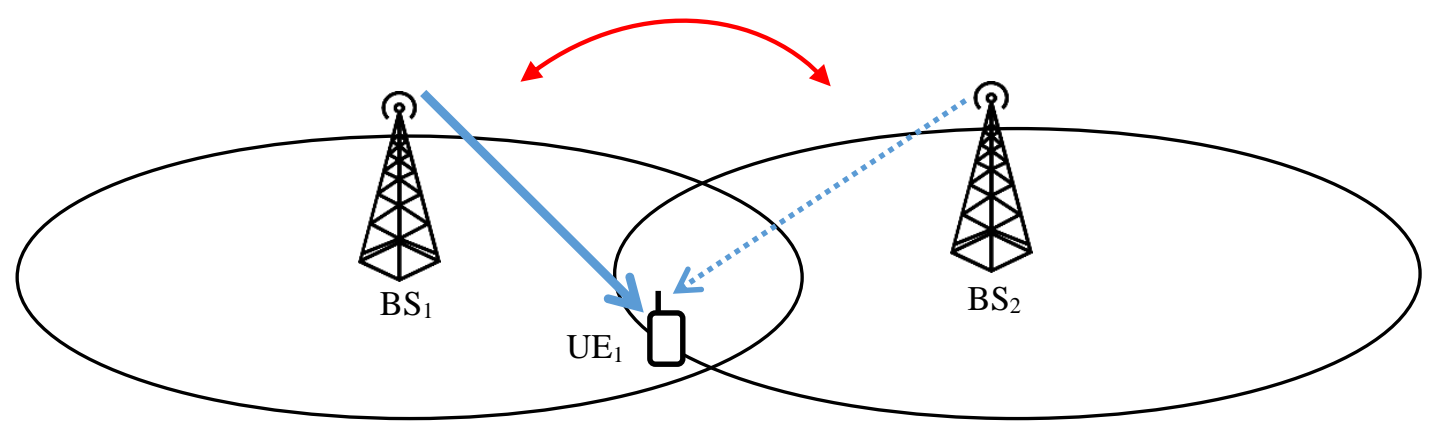

Figure 3.4 - Coordinated Dynamic Cell Selection concept (adapted from [4]).

\section{- Joint Transmission (JT-CoMP)}

For JT-CoMP, a UE data is simultaneously processed and transmitted from multiple cooperating BSs. JT-CoMP can be used as a MIMO (Multiple Input Multiple Output) approach to turn the inter-cell interference into a useful signal to transmit the same information to individual UEs located at the cell edge [8], where the received power can be very low. It can improve the spectrum efficiency, enhance effective coverage area by exploiting the co-channel interferences and increase the overall throughput [21]. According to Figure 3.5, base stations $\left(\mathrm{BS}_{1}\right.$ and $\left.\mathrm{BS}_{2}\right)$ coordinate the transmission to user equipments $\left(\mathrm{UE}_{1}\right.$ and $\left.\mathrm{UE}_{2}\right)$, i.e., $\mathrm{UE}_{1}$ receives a signal from $\mathrm{BS}_{1}$ and $\mathrm{BS}_{2}$ at the same resource block $1\left(\mathrm{RB}_{1}\right)$; and $\mathrm{UE}_{2}$ at the same resource block $2\left(\mathrm{RB}_{2}\right)$. 
In sleep mode, when some BSs are switched off, users who were previously served with these BSs, will now be on the cell edge of the active BSs. Then, combining the JT-CoMP mechanism in the sleep mode, we can improve the SINR and enhance the reception power at the cell edge area; consequently, we can improve the cell-edge throughput and reduce the outage probability in order to maintain the required QoS.

H...... RB 1
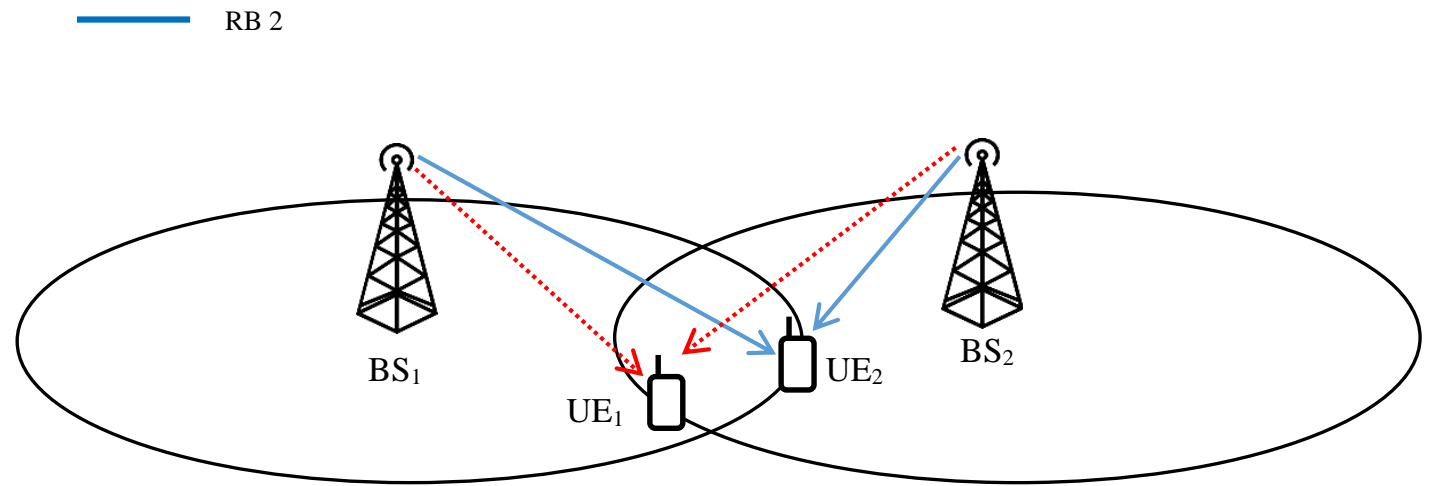

Figure 3.5 - Coordinated Joint Transmission concept (adapted from [8]).

CoMP can be operated in two main concepts namely inter-site and intra-site CoMP [22].

As described in Figure 3.6, in inter-site CoMP, the coordination is performed between BSs located at separated geographical areas; whilst, intra-site CoMP enables the coordination between sectors of the same BS, where the coordination is performed through multiple Antenna Units (AUs) that allow the coordination between the sectors [21].

However, these techniques require more network-level power management where multiple BSs coordinate together [3].

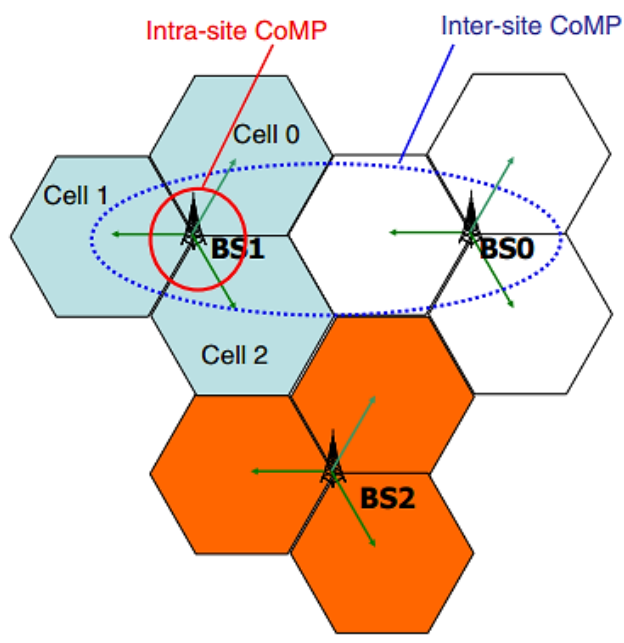

Figure 3.6 - Illustration of intra-site and inter-site CoMP (from [22]). 


\section{SYSTEM MODELING (SIMULATOR)}

In order to evaluate the viability of green cellular networks, we have developed in C++ a systemlevel simulator for a standard cellular network (i.e. cellular network without techniques to improve the energy efficiency) which models the radio environment of a $4 \mathrm{G}$ cellular network.

The simulator is written in $\mathrm{C}++$ because, comparing with other programming languages, $\mathrm{C}++$ has the performance of $\mathrm{C}$ programming language, the usability of oriented-object languages and the portability of the source file.

As mentioned in Subsection 1.3, the simulator has been built in [11] to model long-term variation of UEs traffic, and to measure the energy consumption and downlink throughput of a cellular network.

In this work, we call a standard network one that doesn't employ any of the energy-saving techniques proposed in Chapter 3.2. In the previous work [11], the green cellular network simulator has been developed on top of a standard cellular network simulator to investigate the BS architectural changes techniques mentioned in Table 3.1.

In this work, we built upon the aforementioned green cellular network simulator by improving the algorithm of BSs architectural changes techniques, adapting them to the signal processing technique (CoMP).

To build the simulator, some classes has been created in [11], in order to implement some components of the simulator such as:

- a basic regular cellular network environment,

- $\quad$ a distributed server to manage the BS architectural change techniques, namely cell zooming and sleep mode,

- some parameters to configure the simulator,

- $\quad$ and a system of data collection for each metric.

Each component has been created and organized as a class with its own attributes and methods.

Figure 4.1 shows the organization [11] and the relationship between some of the main classes of the simulator:

- the class "BaseStation" is used by the class "Grid" to generate the base station of the grid.

- the class "MobileUser" is used together with the class "Scheduler" to manage UEs events (i.e. appearance, scheduling, call, deletion to the grid) and, to form the traffic profile of class "Traffic". 
- the class "Channel" uses classes "Grid" and "Traffic" to establish the connection and the throughput between UEs and BSs.

- the class "Stats" collects periodically some network statistics (metrics), according to events triggered by class "Scheduler".

- Finally, class "Server" manages through the class "Scheduler", the BSs architectural changes of the grid.

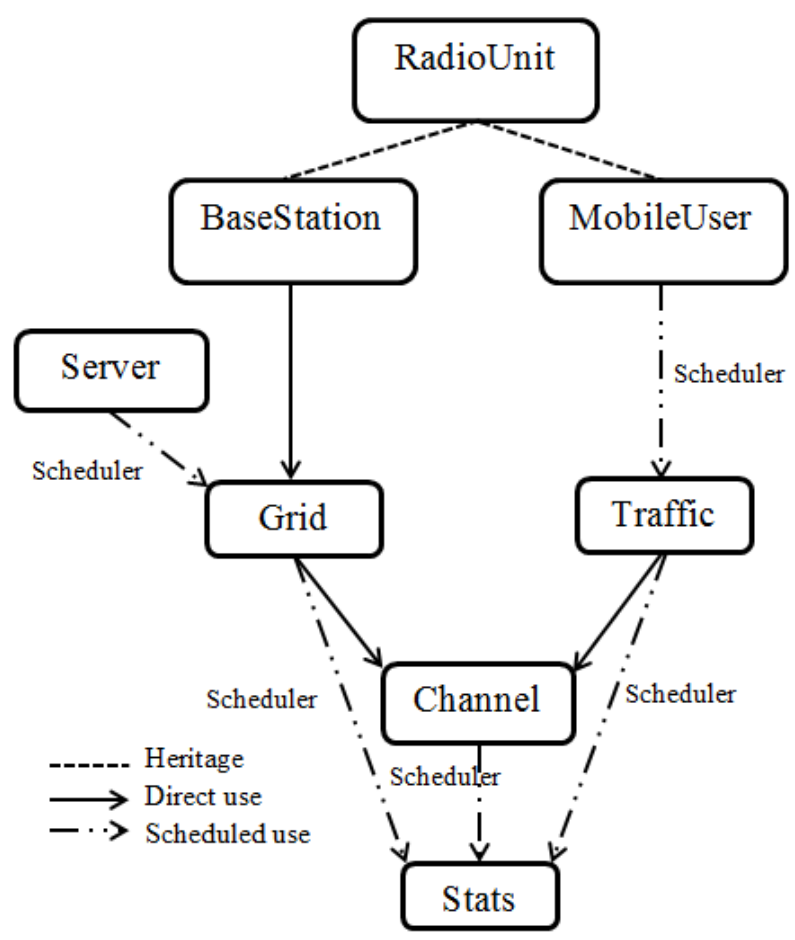

Figure 4.1 - Relation between each class of the simulator (From [11]).

\section{1 - BASIC ENVIRONMENT}

The basic environment that we simulate is composed of some characteristic elements of cellular network such as:

- the cell grid;

- the base stations;

- the traffic;

- the user's mobility;

- the hotspots;

- the channel model;

- the link model.

They are explained in the following subsections with additional detail. 


\subsection{1 - Cell grid}

The whole grid is built with regular hexagonal cells. For instance, it can be configured with a given number of columns as shown in Figure 4.2, where 6 columns and 5 rows were considered. In the grid, BSs and UEs are positioned randomly.

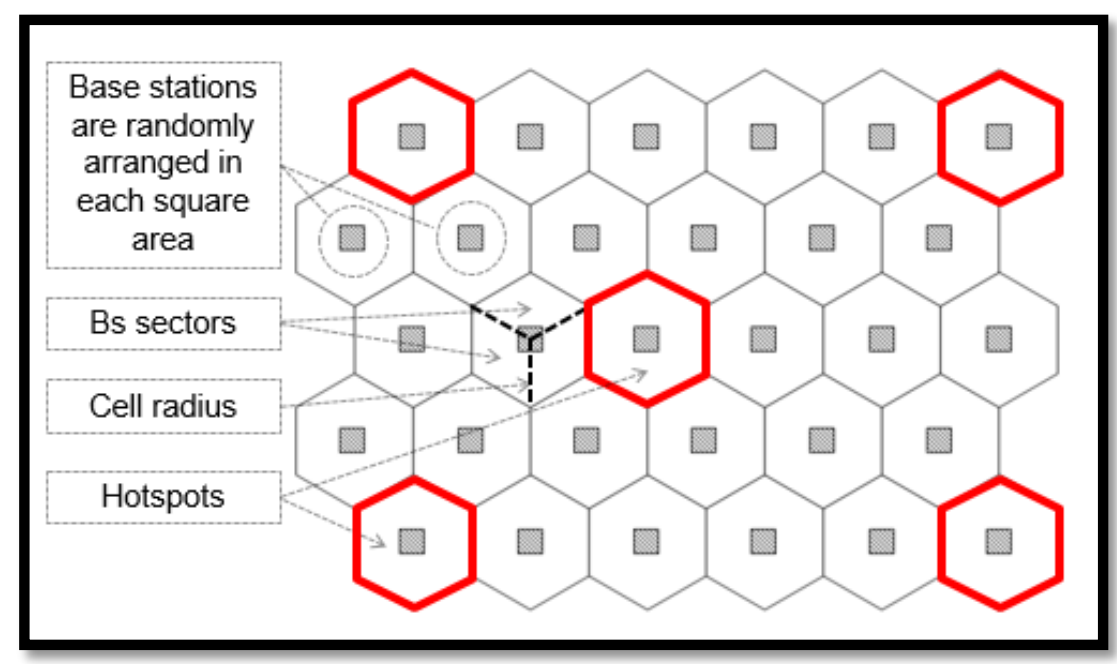

Figure 4.2 - Hexagonal cells grid (from [11]).

\subsection{2 - Hotspots}

Some cells of the grid are considered as hotspots, such that they have a very high probability of active UEs.

As we can see in Figure 4.2, five (05) hotspots are considered: one (01) in the centre of the grid, and four (04) in the corners of the grid according to the specifications of Table 4.1.

Table 4.1 - Hotspots specifications (adapted from [18]).

\begin{tabular}{|c|c|c|}
\hline Hotspots & Localization & \multicolumn{1}{c|}{ Observation } \\
\hline \hline $\mathrm{N}^{\mathrm{o}} 1$ & Center & $\begin{array}{l}\text { Located in the center of the city (the grid) where } \\
\text { concentration of UEs is higher at the regular time (work } \\
\text { hours). }\end{array}$ \\
\hline $\mathrm{N}^{\mathrm{o}} 2,3,4$ and 5 & Corners & $\begin{array}{l}\text { Hotspots 2, 3 and 4 are located at the vicinity of the } \\
\text { city, for instance in shopping centers where most UEs } \\
\text { are located during non-regular work period. }\end{array}$ \\
- $\begin{array}{l}\text { Hotspot 5 may be located in a part of the city where } \\
\text { the UE concentration is motivational (e.g. football } \\
\text { stadium). }\end{array}$ \\
\hline
\end{tabular}




\subsection{3 - Base stations}

Tri-sector BSs are placed randomly with a uniform distribution around each cell centre in the hashed squared region set here to $150 \mathrm{~m}^{2}$ (Figure 4.2) because of the irregularity of the grid in the real life. The basic characteristics of the BSs used in the simulator are mentioned below, and can be configured with parameters:

- BS heights,

- BS radius,

- BS transmit carrier frequency,

- Directive antennas have been arranged as shown in Figure 2.4.

- $\quad$ BS power consumption ( $\left.\mathrm{P}_{\mathrm{CONS}}\right)$.

According to Figure 4.3 and the specifications of Z. Hasan et al in [3], BS power consumption is distributed into:

* Transmit power $\left(\mathrm{P}_{\mathrm{Tx}, \mathrm{dBm}}\right)$;

* Power amplifier ( $\left.\mathrm{P}_{\mathrm{AMP}}\right)$ i.e. the power consumed to convert the low-power electronic signal to an amplified signal;

* Signal processing $\left(\mathrm{P}_{\mathrm{PROC}}\right)$ i.e. the power consumed to digitally process the signal for the UEs;

* Air conditioning ( $\left.\mathrm{P}_{\mathrm{AIR}}\right)$ i.e. power consumed with air conditioner to cool the equipment;

* The total consumed power per BS is given by Equation (4.1) and its value is between 800 and $1,500 \mathrm{~W}[3]$.

$$
\mathrm{P}_{\mathrm{CONS}}=\mathrm{P}_{\mathrm{Tx}, \mathrm{dBm}}+\mathrm{P}_{\mathrm{AMP}}+\mathrm{P}_{\mathrm{AIR}}+\left(\mathrm{P}_{\mathrm{PROC}}\right) \times N_{U E s},
$$

where, $N_{U E s}$ is the number of UEs per cell.

As we can see, only processing power is a function of the number of UEs because it is the one which process the information to UEs. Then, the more UEs we have, the higher will the signal processing power be, but most of the consumed power is independent of the number of UEs, which shows that in order to save a significant amount of energy we must switch off the equipment.

Figure 4.3 shows the distribution of the power consumption for each BS. 


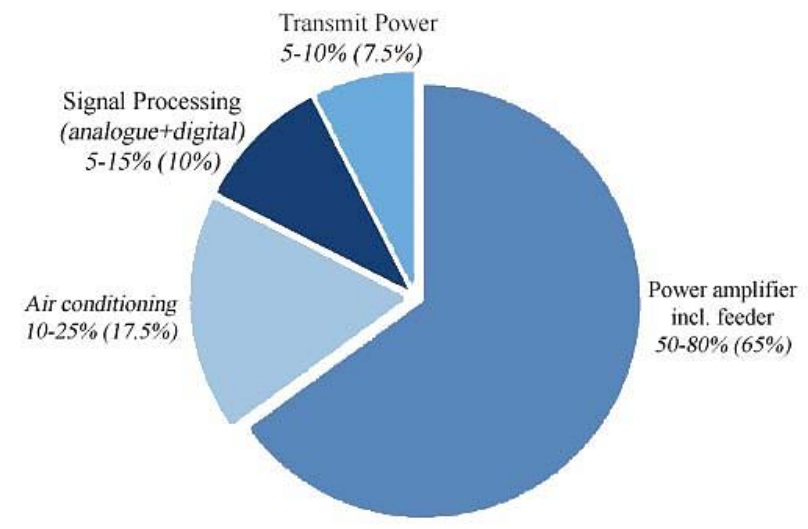

Figure 4.3 - Power consumption distribution in a BS (Adapted from [3]).

\subsection{4 - Traffic}

The traffic model is computed similarly to the one described in [3]. UEs arrival is modeled as a Poisson process with mean arrival rate ups $(t)$, which changes with time $t$ in a sinusoidal profile [18]:

$$
u p s(t)=u_{\max }\left(1-\cos \left(\frac{2 \pi t}{T}+\tau\right)\right)^{\alpha},
$$

where, ups $_{\text {max }}$ is defined as the maximum number of UEs arriving per second, $T$ is the time period in $24 \mathrm{~h}$ format, $\tau$ is a shift to adjust peak time, and $\alpha$ is an adjustment factor on the curve.

Figure 4.4 is an adaptation of the traffic model presented in [17] in which the yellow curve represents the traffic model proposed by Equation (4.2) and the other colored curves represent a set of real traffic samples in different cells. Parameters $\tau$ and $\alpha$ are chosen to make the traffic pattern look like a real traffic curve. Here, for instance we set $\alpha$ to 1.6 and $\tau$ to $17 \mathrm{~h}$, which represents the peak hour.

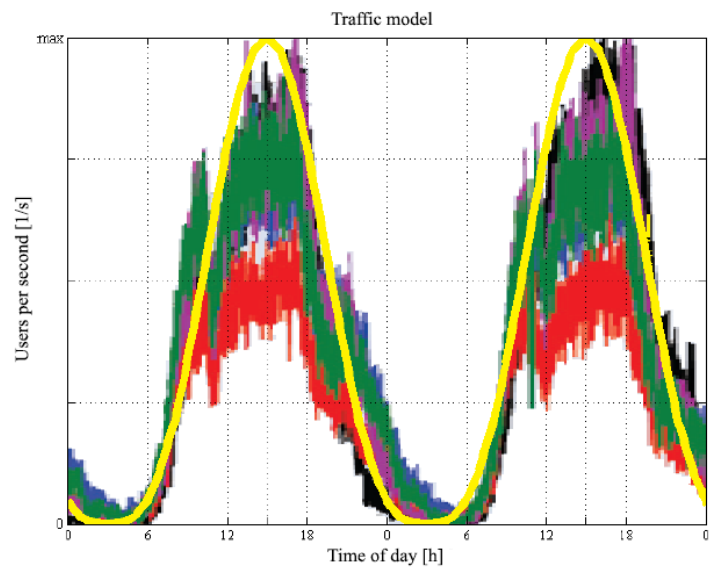

Figure 4.4 - Traffic model (adapted from [17]). 


\subsection{5 - User mobility}

In the grid, UEs appear, move, set up voice calls or data sessions and are deleted randomly. They are connected to the BS which provides best signal strength.

The UE mobility is computed according to one of three movement patterns, namely Brownian, pedestrian, and vehicular. UE direction and speed are computed according to the specifications listed in Table 4.2 for each model.

In mobility:

- UE position is computed and updated in the grid.

- The handover is computed to transfer the mobile connection from one resource to another without disconnecting the voice or data call, while UE is moving from one cell to another.

Table 4.2 - UEs mobility specifications (adapted from [18]).

\begin{tabular}{|c|c|c|}
\hline $\begin{array}{c}\text { Pattern } \\
\text { movement }\end{array}$ & Speed & Observation \\
\hline Brownian & $1.2 \mathrm{~m} / \mathrm{s}$ & UEs assume random movement each second. \\
\hline Pedestrian & $6 \mathrm{~m} / \mathrm{s}$ & May or may not orthogonally change their direction each second. \\
\hline Vehicular & $16 \mathrm{~m} / \mathrm{s}$ & Do not change directions each second during connection period. \\
\hline
\end{tabular}

\subsection{6 - Channel model}

Regarding channel and propagation models, UE received power $\mathrm{P}_{\mathrm{RX}, \mathrm{dBm}}$ is given by Equation (4.3).

$$
\mathrm{P}_{\mathrm{RX}, \mathrm{dBm}}=\mathrm{P}_{\mathrm{TX}, \mathrm{dBm}}+\mathrm{G}_{\mathrm{TX}, \mathrm{dB}}-\mathrm{PL}_{\mathrm{dB}}-S F_{d B},
$$

where, $\mathrm{P}_{\mathrm{TX}, \mathrm{dBm}}$ is the $\mathrm{BS}$ transmit power, $\mathrm{G}_{\mathrm{TX}, \mathrm{dB}}$ is the transmit antenna gain, $\mathrm{PL}_{\mathrm{dB}}$ is the path loss, and $\mathrm{SF}_{\mathrm{dB}}$ is the shadowing factor.

Here, we consider that the received antenna gain $\mathrm{G}_{\mathrm{RX}, \mathrm{dB}}$ for $\mathrm{UE}$ has a value of $0 \mathrm{~dB}$.

Then, to obtain the value of the received power, we compute: 
* The transmit antenna gain: proposed by Gunnarsson et al [23] whose formula is given by Equation (4.4). The antenna proposed in [23] can be used in hexagonal cell grid in order to have authentic conditions in system simulation.

$$
G_{T X, d B}(\varphi, \theta)=G_{h}(\varphi)+G_{v}(\theta)
$$

- The horizontal BS antenna gain $G_{h}(\varphi)$, whose formula is given by Equation (4.5).

$$
G_{h}(\varphi)=-\min \left(12\left(\frac{\varphi}{H P B W_{h}}\right)^{2}, F B R\right)+G_{\max },
$$

where $\varphi,-180 \leq \varphi \leq 180$, is the vertical angle relative to the main beam pointing direction, $G_{\max }$ is the maximum gain, $H P B W_{h}$ is the half-power beamwidth and FBR is the front-to-back ratio.

- $\quad$ The vertical BS antenna gain $G_{v}(\theta)$, whose formula is given by Equation (4.6).

$$
G_{v}(\theta)=\max \left(-12\left(\frac{\theta-\theta_{\text {tilt }}}{H P B W_{h}}\right)^{2}, S L L\right),
$$

where $\theta,-90 \leq \varphi \leq 90$, is the vertical angle relative to the horizontal plane, $H P B W_{v}$ is the half-power beamwidth, $S L L$ is the side-lobe-level and $\theta_{\text {tilt }}$ is the down tilt angle.

* The path loss $\left(\boldsymbol{P} \boldsymbol{L}_{\boldsymbol{d}}\right)$ : proposed by Okumura-Hata considering the Extended Cost-231 model for frequencies between 1500 and $2000 \mathrm{MHz}$ for large cities environment [24]. The path loss of the COST-231 Hata's model in $d B$ is mathematically given by Equation (4.7).

$$
P L_{d B}=46.3+33.9 \log f_{M H z}-13.82 \log h_{T X}-a\left(h_{R X}\right)+\left(44.9-6.55 \log h_{T X}\right) \log d_{K m}+C_{M},
$$

where, $f_{M H z}$ is the transmit frequency, $h_{T X}$ is the BS's height, $d_{k m}$ is the distance between the $\mathrm{UE}$ and the BS, $a\left(h_{R X}\right)$ is the correction factor given by Equation (4.8), and $C_{M}$ is set to 0 or 3 for suburban or dense urban area, respectively.

$$
a\left(h_{R X}\right)=3.2\left(\log 11.75 h_{R X}\right)^{2}-4.97,
$$

where, $h_{R X}$ is the UE's height.

* The shadowing factor $\left(\boldsymbol{S} \boldsymbol{F}_{\boldsymbol{d} \boldsymbol{B}}\right)$ : proposed by J. Zhuang et al [25] as an additional loss. Shadowing factor is computed as a log-normal distribution with zero mean and standard deviation depending on the scenario, according to Table 4.3.

In the simulated system, when UEs are close, their SFs are similar or correlated. Therefore, they cannot assume any random value of SF because this would trigger discontinuities in 
the fading within the small region where they are positioned [25]. However, we can obtain the SF via the following interpolation model:

- For each BS: a uniformly spaced grid is generated, where each node represents a corresponding SF to a geographical location separated to its adjacent by a predetermined decorrelation distance (e.g. 50 meters) (Figure 4.5). Nodes for each BS represent a corresponding SF to a geographical location.

- For each UE: the $S F$ is determined by calculating the interpolation linear of the closest four nodes (square region) located at the position $\left(X_{p o s}, Y_{p o s}\right)$ of UE in the cell grid (Figure 4.5). The value of $S F$ due to obstacle between UE and the serving BS is obtained after the calculation of $S F_{d B}$ given by Equation (4.9).

Table 4.3 - Shadowing factor values (adapted from [25]).

\begin{tabular}{|c|c|}
\hline Propagation scenario & Standard deviation of shadowing factor \\
\hline \hline Urban macro-cell & $8 \mathrm{~dB}$ \\
\hline Sub-urban macro-cell & $8 \mathrm{~dB}$ \\
\hline Urban micro-cell & NLOS: 4dB; LOS: 3dB \\
\hline Rural macro-cell & NLOS: 8dB; LOS: 6dB \\
\hline
\end{tabular}

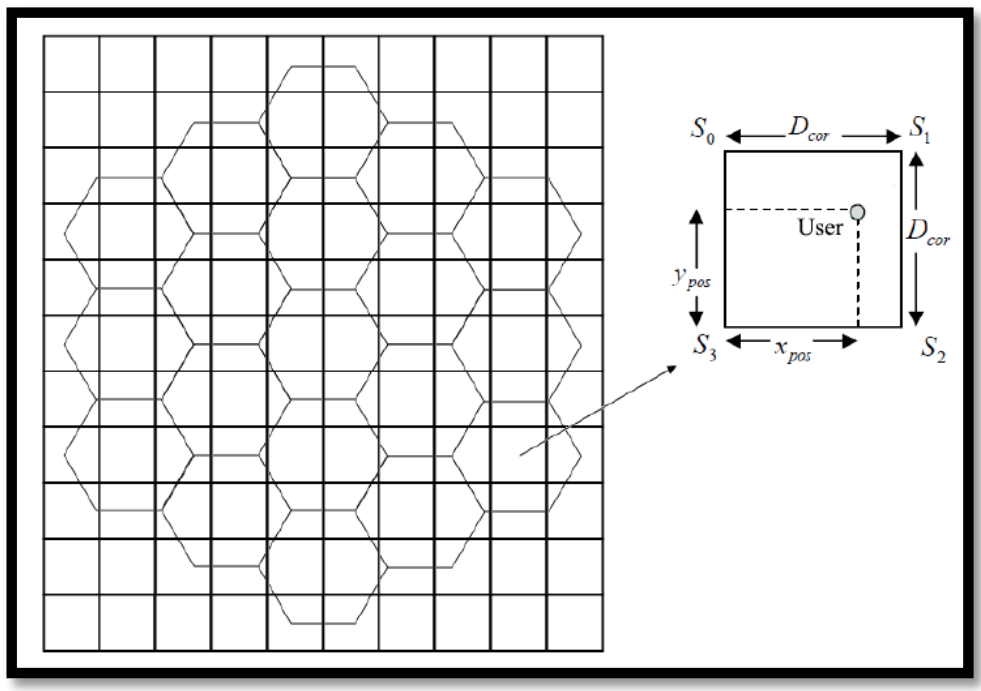

Figure 4.5 - Example of grid for the estimation of the SF (adapted from [25]).

$$
S F_{d B}=\sqrt{1-\frac{x_{p o s}}{D_{c o r}}}\left(S_{0} \sqrt{\frac{y_{p o s}}{D_{c o r}}}+S_{3} \sqrt{1-\frac{y_{p o s}}{D_{c o r}}}\right)+\sqrt{\frac{x_{p o s}}{D_{c o r}}}\left(S_{1} \sqrt{\frac{y_{p o s}}{D_{c o r}}}+S_{2} \sqrt{1-\frac{y_{p o s}}{D_{c o r}}}\right),
$$

As show in Figure 4.5, nodes are represented as $S_{i}(i=0$ to 3 ), and assume random values according to Table 4.3. This guarantees smooth of $S F$ changes around the nodes on the grid [25]. 


\subsection{7 - Link model}

Differently to the previous work (in [11]), where the transmission rate is calculated without channel coding, here we consider the number of bits per symbol based on the Shannon capacity for the throughput calculation.

* Capacity: the received downlink capacity C for each UE proposed in [20] is computed through the Equation (4.10).

$$
C=\log _{2}(1+\operatorname{SINR}),
$$

where, SINR is the Signal-to-Interference-plus-Noise-Ratio given by Equation (4.11).

$$
\operatorname{SINR}=\frac{P_{R X, i}}{B N_{o}+\sum_{j \neq i} P_{R X, j}},
$$

where, $\mathrm{P}_{R X, i}$ is the received power from the serving cells, $\mathrm{P}_{R X, j}$ is the interference power from cell $j$ and $B N_{o}$ is the noise power, with $B$ the signal bandwidth and $N_{0} / 2$ the noise power spectral density.

* Throughput: the throughput is calculated according to the number of frame resources assigned to each UE. As show Figure 4.6, in the frequency and time domain, a frame is grouped into slots; a slot is grouped into $N$ resource blocks, and a resource block is grouped into 12 adjacent subcarriers and 7 or 6 resource elements ( 7 consecutive OFDM symbols when a short cyclic prefix (CP) is employed, or 6 symbols with an extended cyclic prefix). However, some resource elements are reserved for signaling channel.

In this work, we consider that all the resource blocks are evenly distributed among the UEs in a cell; and they are all used for the data transmission, i.e. no resource blocks are considered for signaling channel.

Table 4.4 lists the parameters used in a frame structure of a direct LTE downlink.

The calculation of the throughput is given by Equation (4.12).

$$
\frac{\text { bits } / \text { second }}{\# \text { users }}=\frac{\text { bits }}{\text { symbol }} \times \frac{\text { Useful_symbols }}{\text { frame }} \times \frac{\text { frames }}{\text { second }} \times \frac{1}{\# \text { users }},
$$

where,

$\frac{\text { Useful_symbols }}{\text { frame }}=\left(\frac{\text { subcarriers }}{\text { resource_block }} \times \frac{\text { symbols }}{\text { subcarrier }}-\frac{\text { control_symbols }}{\text { resource_block }}\right) \times \frac{\text { resource_blocks }}{\text { slot }} \times \frac{\text { slots }}{\text { quadro }}$, 


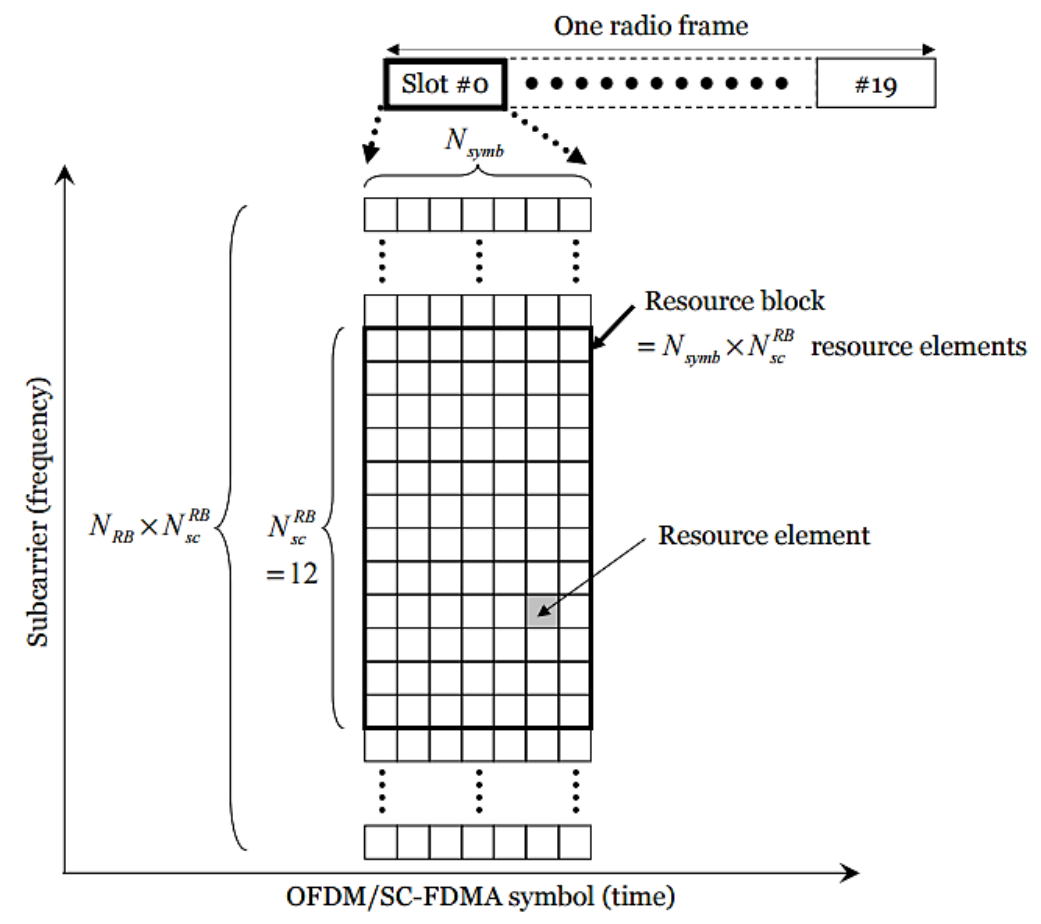

Figure 4.6 - LTE downlink resources (from [26]).

Table 4.4 - Parameters of the LTE downlink structure (Adapted from [26]).

\begin{tabular}{|c|c|c|c|c|c|c|}
\hline Channel bandwidth (MHz) & $\mathbf{1 . 4}$ & $\mathbf{3}$ & $\mathbf{5}$ & $\mathbf{1 0}$ & $\mathbf{1 5}$ & $\mathbf{2 0}$ \\
\hline \hline Frame duration (ms) & \multicolumn{7}{|c|}{10} \\
\hline Spacing between subcarriers (KHz) & \multicolumn{7}{|c|}{15} \\
\hline Subcarriers per resource block & \multicolumn{7}{|c|}{12} & \\
\hline FFT size & 128 & 256 & 512 & 1024 & 1536 & 2048 \\
\hline Occupied subcarriers & 76 & 151 & 301 & 601 & 901 & 1201 \\
\hline Resource blocks per slot & 6 & 15 & 25 & 50 & 75 & 100 \\
\hline OFDM symbols per subcarrier (short/long CP) & \multicolumn{7}{|c|}{4} \\
\hline Control symbols per resource block & \multicolumn{7}{|c|}{} \\
\hline
\end{tabular}

In this work, we consider that:

- the channel is AWGN (Additive White Gaussian Noise);

- the OFDM resource blocks are evenly distributed among the UEs in a cell;

- the LTE bandwidth is considered with single antenna;

- the maximum downlink throughput permitted per UE is 5Mbps.

However, we do not take into account:

$>$ the bit error rate (BER) for the modulation;

$>$ and signaling channel. 


\section{2 - CENTRALIZED SERVER}

We consider the server as a centralized entity which knows the whole network and can decide which cells will be switched off or will active the zooming. In other words, the goal of the server is to manage BSs architecture changes techniques, deciding which cells can be switched off or not in sleep mode and which ones can be activated or not for the zooming in cell zooming mode. Each BSs architecture changes technique is implemented into the class "SERVER" through specific algorithms.

Then, a parameter specifies the time interval at which the server decides about the execution of each mode. We called this time interval as server granularity.

\section{3 - PARAMETERS}

Some parameters are created which can be defined in a file for each simulation run.

The choice of each simulation scheme is available in the simulator as well as parameters values.

Table 4.5 lists the parameters used in the simulator, as well as their values in the standard simulation.

Table 4.5 - Simulator parameters (adapted from [11]).

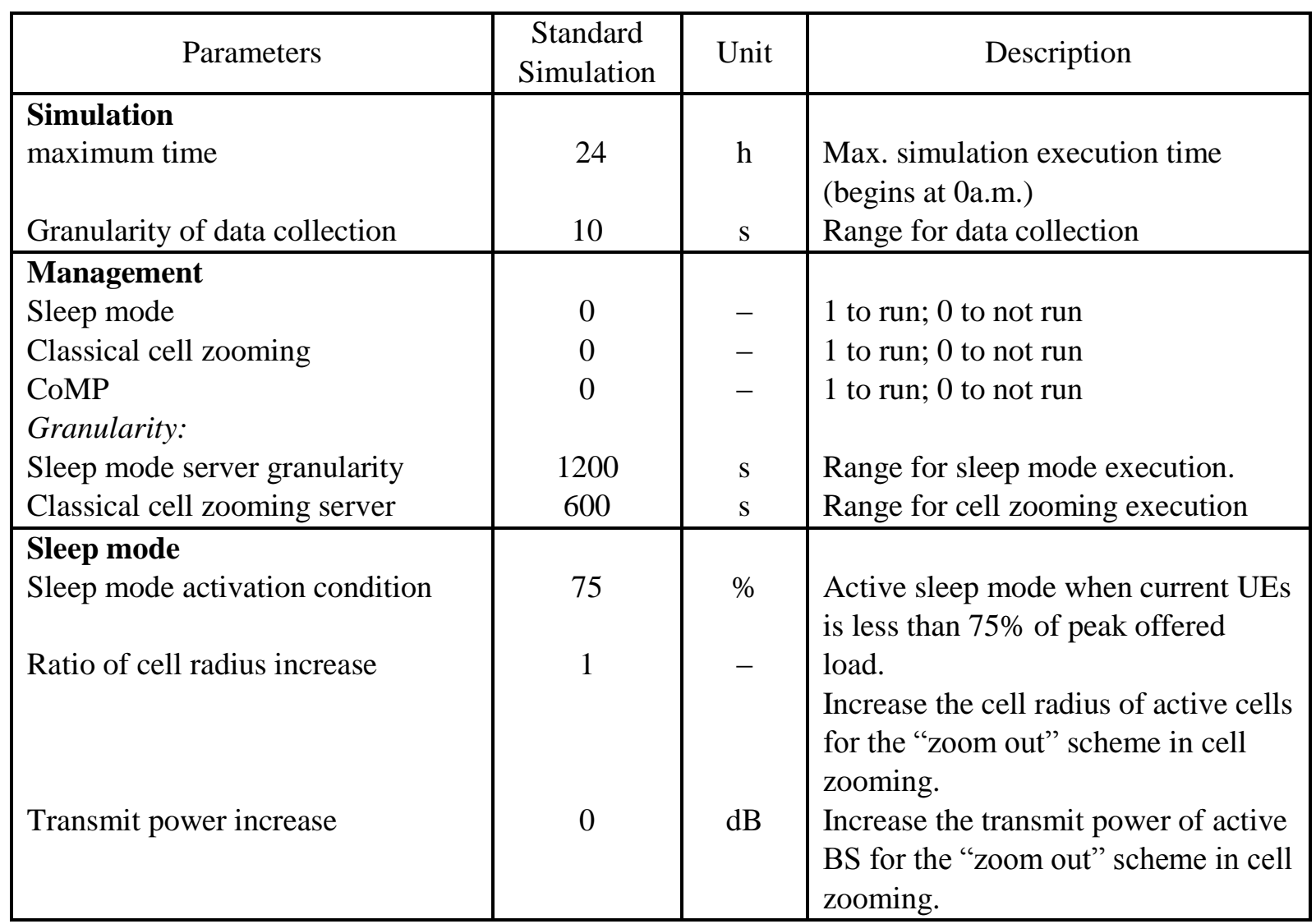




\begin{tabular}{|c|c|c|c|}
\hline $\begin{array}{l}\text { Grid } \\
\text { Columns } \\
\text { Rows } \\
\text { Cell radius } \\
\text { Cell radius variation }\end{array}$ & $\begin{array}{c}6 \\
5 \\
250 \\
5\end{array}$ & $\begin{array}{l}- \\
- \\
\mathrm{m} \\
\%\end{array}$ & $\begin{array}{l}\text { Number of cells in horizontal axis } \\
\text { Number of cells in vertical axis } \\
\text { Average cell radius } \\
\text { Variation in cell size radius }\end{array}$ \\
\hline $\begin{array}{l}\text { Base Station } \\
\text { Transmit power } \\
\text { Amplification power } \\
\text { Air conditioner power } \\
\text { Processing power per UE } \\
\text { Height }\end{array}$ & $\begin{array}{c}43 \\
58.92 \\
53.22 \\
40.85 \\
35\end{array}$ & $\begin{array}{l}\mathrm{dBm} \\
\mathrm{dBm} \\
\mathrm{dBm} \\
\mathrm{dBm} \\
\mathrm{m}\end{array}$ & $\begin{array}{l}\text { Initial transmit power } \\
\text { Signal amplification power } \\
\text { Power spent on cooling system } \\
\text { Power processing spent per UE } \\
\text { Average height of the BS }\end{array}$ \\
\hline $\begin{array}{l}\text { Antenna } \\
\text { Horizontal half-power beamwidth } \\
\text { Horizontal front-to-back ratio } \\
\text { Vertical half-power beamwidth } \\
\text { Side-lobe level } \\
\text { Maximum gain }\end{array}$ & $\begin{array}{r}70 \\
20 \\
6.2 \\
-18 \\
14\end{array}$ & $\begin{array}{c}\circ \\
\mathrm{dB} \\
\circ \\
\mathrm{dB} \\
\mathrm{dB}\end{array}$ & \\
\hline $\begin{array}{l}\text { Modem } \\
\text { Transmit frequency } \\
\text { Bandwidth }\end{array}$ & $\begin{array}{c}1700 \\
10\end{array}$ & $\begin{array}{l}\mathrm{MHz} \\
\mathrm{MHz}\end{array}$ & \\
\hline $\begin{array}{l}\text { Mobile User } \\
\text { Sensitivity } \\
\text { Height }\end{array}$ & $\begin{array}{l}-95 \\
1.7\end{array}$ & $\begin{array}{c}\mathrm{dBm} \\
\mathrm{m}\end{array}$ & $\begin{array}{l}\text { Min. power to receive the signal [27] } \\
\text { Average UE height }\end{array}$ \\
\hline $\begin{array}{l}\text { Channel } \\
\text { Noise power spectral density } \\
\text { Max. throughput per UE } \\
\text { Shadowing factor }\left(S F_{d B}\right) \\
\text { Correlation distance }\end{array}$ & $\begin{array}{c}-180 \\
5 \\
8 \\
50\end{array}$ & $\begin{array}{c}\mathrm{dBm} / \mathrm{Hz} \\
\mathrm{Mbps} \\
\mathrm{dBm} \\
\mathrm{m}\end{array}$ & $\begin{array}{l}\text { Max. throughput permitted per UE. } \\
\text { Standard deviation of } S F_{d B} \text {. } \\
\text { Correlation distance for shadowing. }\end{array}$ \\
\hline $\begin{array}{l}\text { Traffic } \\
\text { Max. number of UEs per second } \\
\text { Peak time } \\
\text { Typical call duration } \\
\text { Log }\end{array}$ & $\begin{array}{c}10 \\
17 \\
60 \\
0\end{array}$ & $\begin{array}{l}1 / \mathrm{s} \\
\mathrm{h} \\
\mathrm{s} \\
-\end{array}$ & $\begin{array}{l}\text { Peak time in the format } 24 \text {-hours } \\
1 \text { to save simulation history }\end{array}$ \\
\hline $\begin{array}{l}\text { OFDMA } \\
\text { Subcarriers per resource block } \\
\text { Symbols per subcarrier } \\
\text { control symbols per resource block } \\
\text { Resource blocks per slot } \\
\text { Slots per frame } \\
\text { Frames per Second } \\
\text { Number of occupied subcarriers }\end{array}$ & $\begin{array}{c}12 \\
7 \\
4 \\
50 \\
20 \\
100 \\
601\end{array}$ & $\begin{array}{c}- \\
- \\
- \\
- \\
- \\
1 / \mathrm{s} \\
-\end{array}$ & Considering a Bandwidth of $10 \mathrm{Mhz}$ \\
\hline
\end{tabular}




\begin{tabular}{|l|c|l|l|}
\hline CoMP & -70 & $\mathrm{dBm}$ & $\begin{array}{l}\text { Max. received power for CoMP } \\
\text { Prx }_{\max } \text { to activate the CoMP }\end{array}$ \\
Prx $_{\min }$ to activate the CoMP & -110 & $\mathrm{dBm}$ & $\begin{array}{l}\text { Min. received power for CoMP } \\
\text { Prx }\end{array}$ \\
& 10 & $\mathrm{dBm}$ & $\begin{array}{l}\text { Difference between } \mathrm{P}_{\mathrm{RX}, 1} \& \mathrm{P}_{\mathrm{RX}, 2} ; \\
\left.\text { (with } \mathrm{P}_{\mathrm{RX}, 1} \geq \mathrm{P}_{\mathrm{RX}, 2}\right)\end{array}$ \\
\hline
\end{tabular}

\section{4 - DATA COLLECTION}

In the simulator, the class "STAT" has been created to collect periodically metrics' information about each UE and each BS.

During a simulation, average results are created and saved in a statistics file at each data granularity time of the whole system. Simulator's granularity time is set to 10 seconds to avoid more computer processing power. However, the data granularity cannot take a great value because the data would suffer very marked changes between each collection interval [11].

A log file can be created for all events (e.g. UE deletion, UE position, etc.) in order to have a supplement information.

Through MATLAB software, results are generated in graphs to allow a better comprehension and analyses. 


\section{SIMULATION SCENARIOS}

The standard cellular network system modeling is the reference for the simulator of the green cellular network. The same metrics are used in both cases (i.e. in "standard" and "green" cellular network) to make comparisons between them. Simulations usually run on a 24-hour period, to model the typical variations in the traffic load over a typical work day [18].

Green cellular network simulations have been performed with the objective of assessing the energy efficiency as mentioned in Chapter 3.

In this chapter, we explain the scenarios of the previous work from [11] and [18]; and the scenario of the proposed scheme.

\section{1 - PREVIOUS WORK}

Standard mode, sleep mode and classical cell zooming have been studied in a previous work [11], [18]. Here, we simulated these scenarios again taking into consideration the system modeling mentioned in Chapter 4 and the scenarios presented in this Chapter.

\subsection{1 - Standard mode}

Standard mode is performed without any BSs architectural changes and signal processing techniques.

Basically, in the standard simulation scenario the following steps are taken:

Step 1: At regular intervals, defined by the simulator time granularity, UEs move throughout the grid according to the user mobility condition. In this process, UEs can receive or make a call and/or be deleted from the grid according to random processes (Exponential process for call duration time, and Poisson process to create new users).

Step 2: Each UE is automatically connected to the BS which provides the best signal strength. However, UE cannot connect when the level of the received signal is below the sensitivity level. If this level is not reached for any BS, then, we consider that these UEs are in outage.

Step 3: The downlink throughput is calculated for each UE according to its SINR level and the channel capacity.

Step 4: when UE moves, step 2 and 3 are updated.

Step 5: BSs power consumption is calculated according to Equation (4.1).

Step 6: Values of each metric are collected and their average results are saved into a specific statistics file at each simulator granularity time. 


\subsection{2 - Classical cell zooming}

In classical cell zooming, the cell radius can be decreased or increased according to the traffic load. As mentioned in subsection 3.2.1, this can be achieved by decreasing or boosting the transmit power in order to reduce or increase the cell radius (scenario 1 of

Figure 3.1). Classical cell zooming can act during the whole day.

The server verifies at every multiple of the server granularity the number of active UEs in each cell, and decides according to the condition of execution of classical cell zooming listed in Table 5.2 , which cell radius can be decreased or not by adjusting the transmit power of the cell.

A summary of classical cell zooming system parameters used in our simulations is listed in Table 5.1.

Table 5.1 - Classical cell zooming system parameters.

\section{CLASSICAL CELL ZOOMING SYSTEM PARAMETERS}

\begin{tabular}{|c|c|}
\hline Classical cell zooming server granularity & 600 s (10min) \\
\hline Initial transmit power & $43 \mathrm{dBm}$ \\
\hline Condition for execution & Table 5.2 \\
\hline
\end{tabular}

Table 5.2 - Condition for Classical cell zooming execution.

\section{CLASSICAL CELL ZOOMING EXECUTION CONDITION}

\begin{tabular}{|c|c|}
\hline Number $x$ of UEs connected to a BS & Reduction of the transmit power \\
\hline 0.8 average $\leq x<1.0$ average & $\mathrm{P}_{\mathrm{TX}, \mathrm{dB}}-1.0 \mathrm{~dB}$ \\
1.0 average $\leq x<1.1$ average & $\mathrm{P}_{\mathrm{TX}, \mathrm{dB}}-2.0 \mathrm{~dB}$ \\
1.1 average $\leq x<1.2$ average & $\mathrm{P}_{\mathrm{TX}, \mathrm{dB}}-2.5 \mathrm{~dB}$ \\
1.2 average $\leq x<1.4$ average & $\mathrm{P}_{\mathrm{TX}, \mathrm{dB}}-3.0 \mathrm{~dB}$ \\
$x \leq 1.4$ average & $\mathrm{P}_{\mathrm{TX}, \mathrm{dB}}-3.5 \mathrm{~dB}$ \\
\hline
\end{tabular}




\subsection{3 - Sleep mode}

In sleep mode, BS energy consumption can be saved by switching off some cells as a function of the traffic loads. In this work, low traffic period is considered during 0a.m. to 9a.m. In this interval of time, sleep mode can be activated.

When sleep mode acts, 3 out of 4 cells can be switched off progressively when the number of the current UEs becomes less than a certain percentage of the maximum number of active UEs offered by the simulator (according to the condition of sleep mode activation listed in Table 5.4).

In this sleep mode scheme, 1 out of 4 cells remain permanently active in order to guarantee the minimum coverage as depicted in Figure 5.1.

After 9a.m., cells switch on progressively to turn the cellular network into normal mode.

During the simulation, the server updates the sleep mode status at every multiple of the server granularity.

Then, in the sleep mode updating process, the server firstly verifies the number of active UEs in each activated cell, and then it decides whether some cells could be switched on.

According to Scenario 1 of Figure 3.2, active cells may zoom out to compensate the coverage holes by increasing the transmit power and/or the cell radius (i.e. adjusting the tilt of the antennas and by pointing them to a more distance border where it has the greater gain).

However in Scenario 2 of Figure 3.2, there are no increases in the transmit power and/or the cell radius.

We denominate these models of sleep mode as: "Sleep mode (increase of the transmission power/cell radius increase ratio)".

Some examples of sleep mode denominations are listed in Table 5.3

Table 5.3 - Examples of sleep mode denomination

\begin{tabular}{|l|c|c|c|}
\hline $\begin{array}{c}\text { Sleep mode } \\
\text { denomination }\end{array}$ & $\begin{array}{c}\text { Increase of the } \\
\text { transmit power }\end{array}$ & $\begin{array}{c}\text { Cell radius } \\
\text { increase ratio }\end{array}$ & Observations \\
\hline \hline Sleep mode $(+0 \mathrm{~dB} / 1 \mathrm{x})$ & $+0 \mathrm{~dB}$ & $1 \mathrm{x}$ & $\begin{array}{c}\text { Does not increase the transmit } \\
\text { power and the cell radius }\end{array}$ \\
\hline Sleep mode $(+0 \mathrm{~dB} / 2 \mathrm{x})$ & $+0 \mathrm{~dB}$ & $2 \mathrm{x}$ & Doubles only the cell radius \\
\hline Sleep mode $(+3 \mathrm{~dB} / 1 \mathrm{x})$ & $+3 \mathrm{~dB}$ & $1 \mathrm{x}$ & $\begin{array}{c}\text { Increases only the transmit } \\
\text { power of } 3 \mathrm{~dB}\end{array}$ \\
\hline Sleep mode $(+3 \mathrm{~dB} / 2 \mathrm{x})$ & $+3 \mathrm{~dB}$ & $2 \mathrm{x}$ & $\begin{array}{c}\text { Increases the transmit power } \\
\text { of } 3 \mathrm{~dB} \text { and doubles the cell } \\
\text { radius }\end{array}$ \\
\hline
\end{tabular}

Here, we consider the sleep mode $(+\mathbf{0 d B} / \mathbf{1} \mathbf{x})$ represented in Scenario 2 of Figure 3.2, in order to assess the real efficiency of CoMP, as we discard cell zooming effects. 
However, we simulate the outage probability of sleep mode $(+0 \mathrm{~dB} / 2 \mathrm{x})$, sleep mode $(+3 \mathrm{~dB} / 1 \mathrm{x})$ and sleep mode $(+3 \mathrm{~dB} / 2 \mathrm{x})$ in the case of Scenario 1 of Figure 3.2, in order to compare them to the outage probability of sleep mode $(+0 \mathrm{~dB} / 1 \mathrm{x})$; here, we suppose that the increase of the transmit power and the physical antenna tilt adjustment are available for active cells.

A summary of sleep mode $(+0 \mathrm{~dB} / 1 \mathrm{x})$ system parameters is listed in Table 5.4.

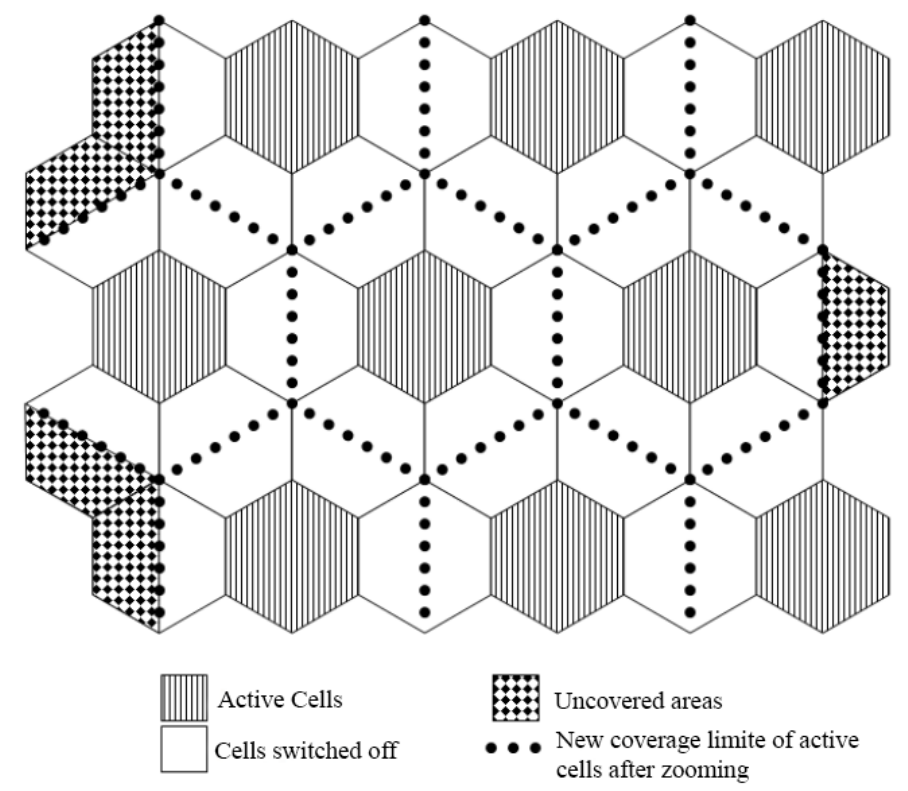

Figure 5.1 - Rectangular grid of hexagonal cells and its configuration in the execution of the sleep mode (adapted from [18]).

Table 5.4 - Sleep mode system parameters.

\begin{tabular}{|c|c|}
\hline \multicolumn{2}{|c|}{ SLEEP MODE SYSTEM PARAMETERS } \\
\hline Sleep mode server granularity & 1200s (20min) \\
\hline Peak offered load & 4000 UEs \\
\hline Condition to activate the Sleep mode & Load $<0.75$ peak offered load \\
\hline Increasing the transmit power of the active cells & $+0 \mathrm{~dB}$ \\
\hline Increasing the cell radius of the active cells & $1 \mathrm{x}$ \\
\hline
\end{tabular}




\section{2 - CoMP}

Generally, CoMP is employed when UE is at the cell-edge, where the received signal can be very low. Here, we propose to use the signal processing technique especially the Joint Transmission (JT-CoMP), which can operate jointly with the previous schemes i.e. standard simulation, sleep mode and cell zooming; in order to reduce the outage probability and to increase the received SINR level of the UEs in the cellular network.

In JT-CoMP, cells cooperate to jointly serve UEs. Here, we consider the cooperation of at most two cells simultaneously; and the activation of CoMP for UEs according to the conditions listed in Table 5.5.

Table 5.5 - CoMP system parameters.

\begin{tabular}{|c|c|}
\hline \multicolumn{2}{|c|}{ COMP SYSTEM PARAMETERS } \\
\hline Maximum number of cooperating BS & 02 \\
\hline CoMP type & Intra-site / Inter-site \\
\hline CoMP technique & Joint Processing (JT-CoMP) \\
\hline Condition to activate CoMP & $\begin{array}{c}1^{\text {st }} \text { Condition } \\
-70 \mathrm{dBm} \leq P_{R X, i} \leq-110 \mathrm{dBm} \\
\text { where } P_{R X, i} \text { is the received power from the } \\
i \text {-th cell; with } i=1,2,3, \ldots, n . \\
\mathbf{2}^{\text {nd }} \text { Condition } \\
P_{R X, 1}-P_{R X, 2} \leq 10 \mathrm{dBm} \\
P_{R X, 1} \geq P_{R X, 2} \geq P_{R X, 3} \geq \ldots \geq P_{R X, n} \\
\text { Received power model: } \\
P_{R X, d B m}=P_{R X, 1}+P_{R X, 2} \\
P_{R X, d B m} \geq \text { Sensitivity }\end{array}$ \\
\hline
\end{tabular}


* In the $\mathbf{1}^{\text {st }}$ condition, we define an interval of a pre-activation of CoMP according to the level of the UE received power from the first serving cell in order to ensure that UE is close to the cell-edge and can be served by a second BS.

* In the $2^{\text {nd }}$ condition, a calculation of the difference in UE received power between the first serving cell and a second serving cell is made to ensure that the difference is lower than $3 \mathrm{~dB}$ (as mentioned in [20]) because CoMP benefit will be negligible if the second strongest received power is much lower than the first one. Then, concerning the received power model, as we cannot model exactly the CoMP benefits at the physical layer level, we suppose that the UE received power is the sum of the UE received powers from the two serving cells. For instance, in Figure 3.5, when CoMP is activated for $\mathrm{UE}_{1}$, we suppose that the received power of $\mathrm{UE}_{1}$ is the sum of the received power of its serving cells i.e. $\mathrm{P}_{\mathrm{RX}, 1}$ from $\mathrm{BS}_{1}$ and $\mathrm{P}_{\mathrm{RX}, 2}$ form $\mathrm{BS}_{2}$.

* Finally, in the $3^{\text {rd }}$ condition, we suppose that CoMP can be activated if the sum of the received power from the two serving cells is greater than the sensitivity. This condition will avoid the unnecessary use of CoMP due to the excess signaling process, which can cause high energy inefficiency in the system [20].

The calculation of the UE received powers in the $2^{\text {nd }}$ condition is an optimist use of CoMP, because the real CoMP scheme is more complex.

However, the use of CoMP is independent from the use of the investigated energy-saving schemes, i.e., it can be employed irrespectively of the use of sleep mode or cell zooming.

\section{3 - SCENARIOS}

In the previous work ([11]), sleep mode and classical cell zooming were the solutions considered to improve the energy efficiency. In this work, we combine CoMP with the sleep mode and the cell zooming.

We also simulate different scenarios for the execution of sleep mode, namely:

different server granularity values;

$>$ different sleep mode activation condition as described in Table 5.4;

$>$ the outage probability of the sleep mode;

A summary of the mains steps of the simulation scenarios is listed in Figure 5.2 


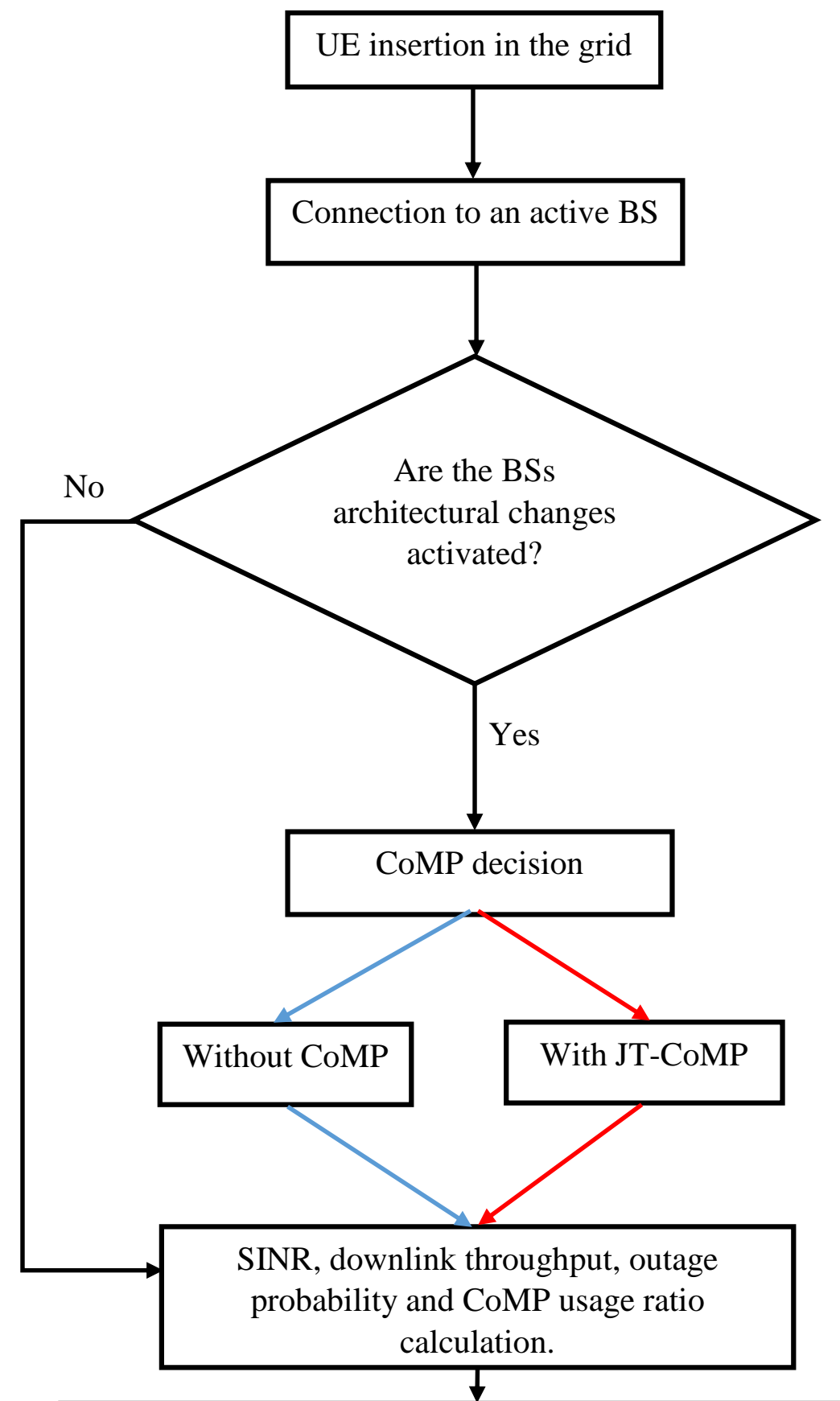

Calculation of the consumed power for each active BS.

Figure 5.2 - Flowchart of the mains steps of the simulation scenarios 


\section{4 - SIMULATION RESULTS}

This subsection presents simulation results of the metrics defined in Chapter 3. Figure 5.3 to Figure 5.6 show the results for a standard cellular network on a 24-hour simulation.

According to the parameters used in the simulator to compute the traffic model, traffic load is low in sleep mode simulations, only during $0-9 \mathrm{~h}$.

As classical cell zooming and CoMP can be activated during the entire day, and sleep mode between $0-9 \mathrm{~h}$, we perform each scenario in the interval $0-12 \mathrm{~h}$ in order to compare the results.

Then, to get reliable results, each scenario is simulated five times with random traffic sources. Then, for each metric, we determine the average results obtained after five simulations of each scenario. They are presented in Figure 5.7 to Figure 5.26.

Comparative results of each metric in all scenarios are presented in Table 5.6.

\subsection{1 - Scenario 1: Standard mode}

As mentioned in subsection 4.1.4, the traffic model computed for each simulation, looks like the one presented in Figure 4.4. Figure 5.3 presents a sinusoidal model of the traffic profile repeated in each simulation scenario. As we can see, traffic load is low between $0-9 \mathrm{~h}$ and increases after $9 \mathrm{~h}$ to reach it peak time at $17 \mathrm{~h}$. Then, between $17-24 \mathrm{~h}$, traffic load decreases.

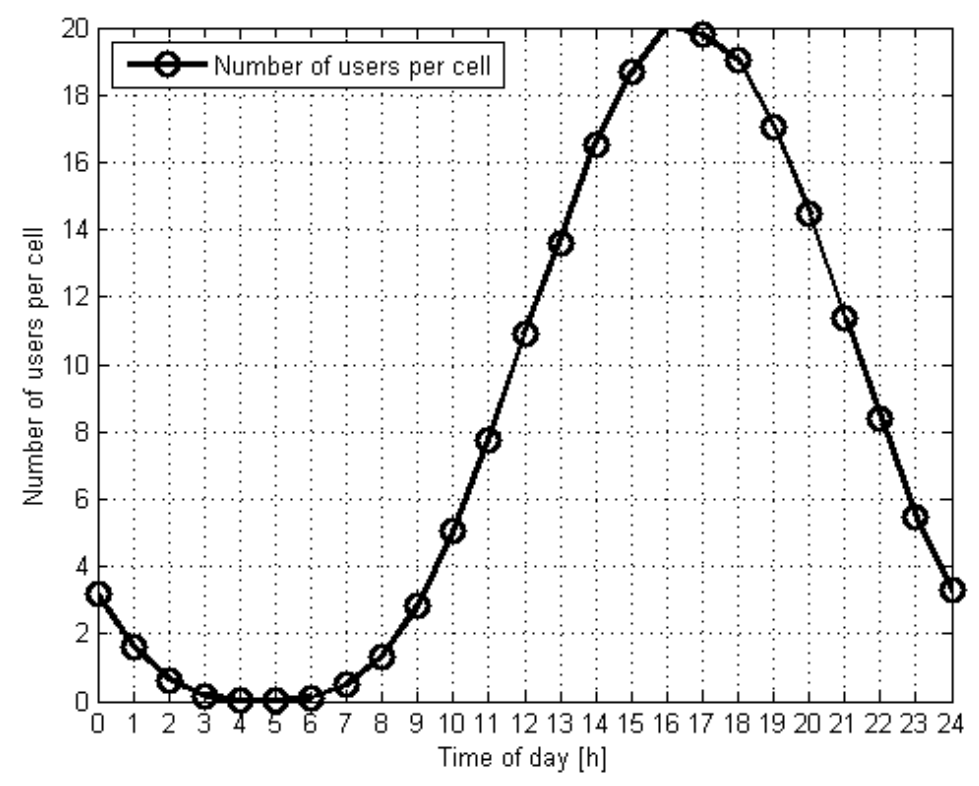

Figure 5.3 - Traffic profile during a day. 
As mentioned in Table 3.2, the network quality is evaluated by the UE downlink throughput and the outage probability. We can note in Figure 5.4 that the throughput is inversely proportional to the traffic load. On the other hand, the more UEs appear in the grid to make a call, the more resources will be divided, worsening the network quality.

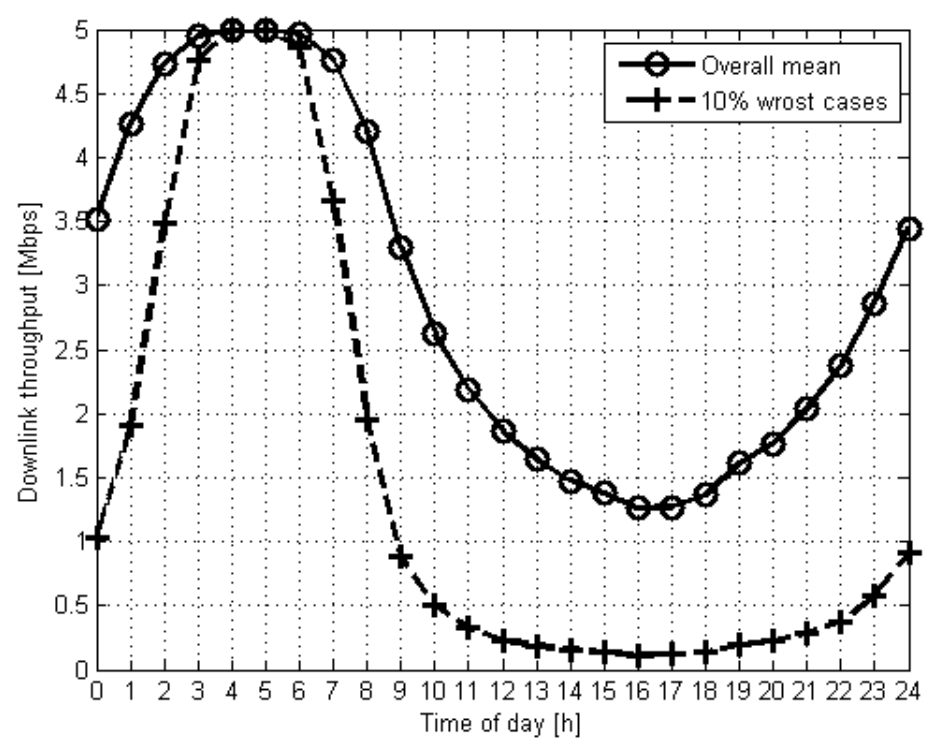

Figure 5.4 - UE downlink throughput.

The outage probability increases when UEs cannot be connected to a BS. This outage varies during a day, as we can see in Figure 5.5, on account of the random traffic characteristics.

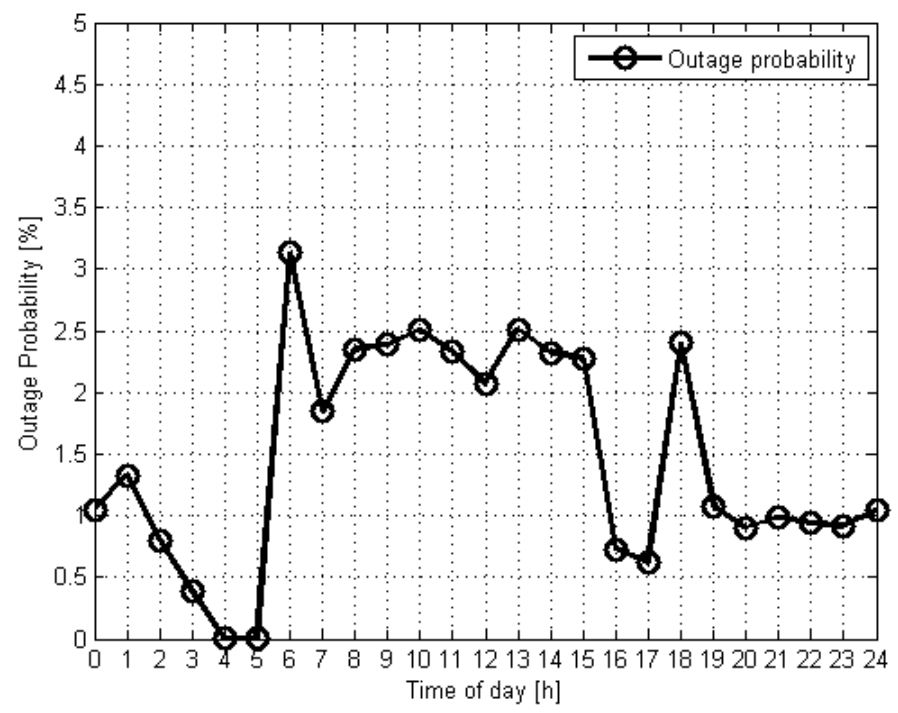

Figure 5.5 - Outage probability. 
The average consumed power per BS varies according to the traffic load, as we can see in Figure 5.6. As the signal processing power is a function of the number of UEs connected to a cell, the more UEs we have in a cell, the more will the energy consumption increase in a BS. However, despite the traffic load condition, we can see that in 24 hours, the power varies relatively a little, and the consumption is almost constant while the BSs are connected.

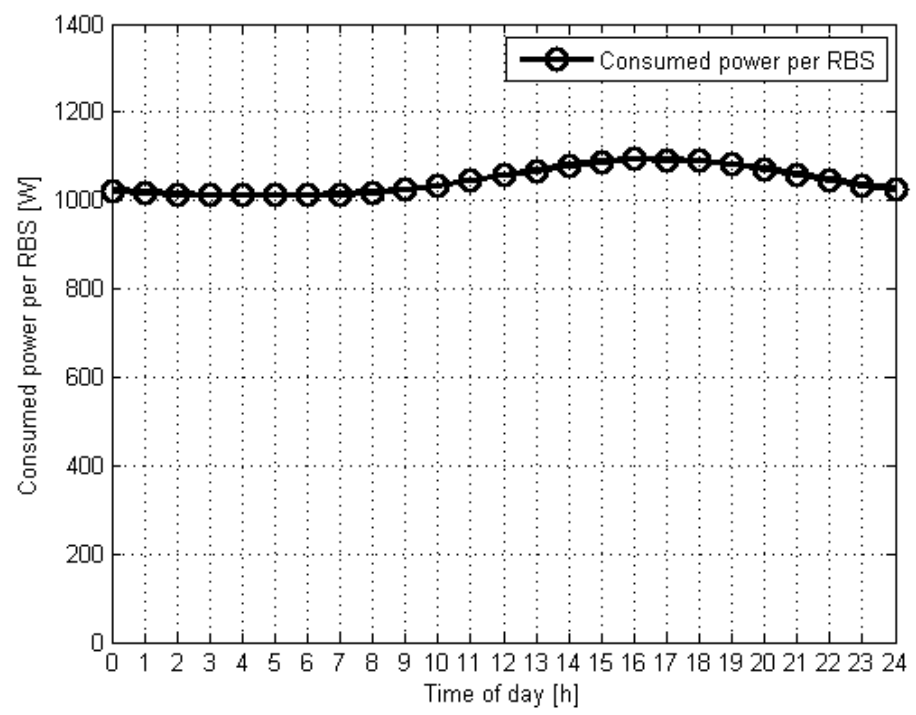

Figure 5.6 - Consumed power per BS.

\subsection{2 - Scenario 2: Classical cell zooming}

When we apply a "zoom in" according to the Scenario 1 of Figure 3.1, we can note a very small decrease in the power consumption per base station (Figure 5.7) and in the throughput (Figure 5.8). However, there is an increase in the outage probability (Figure 5.9) due to the coverage holes while cells zoom in.

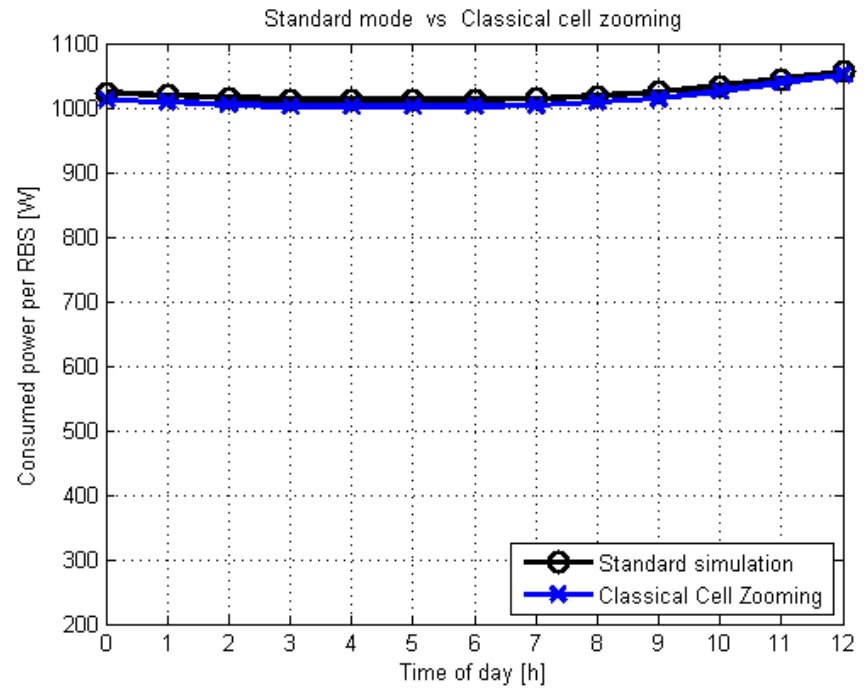

Figure 5.7 - Consumed power per BS in scenario 2. 


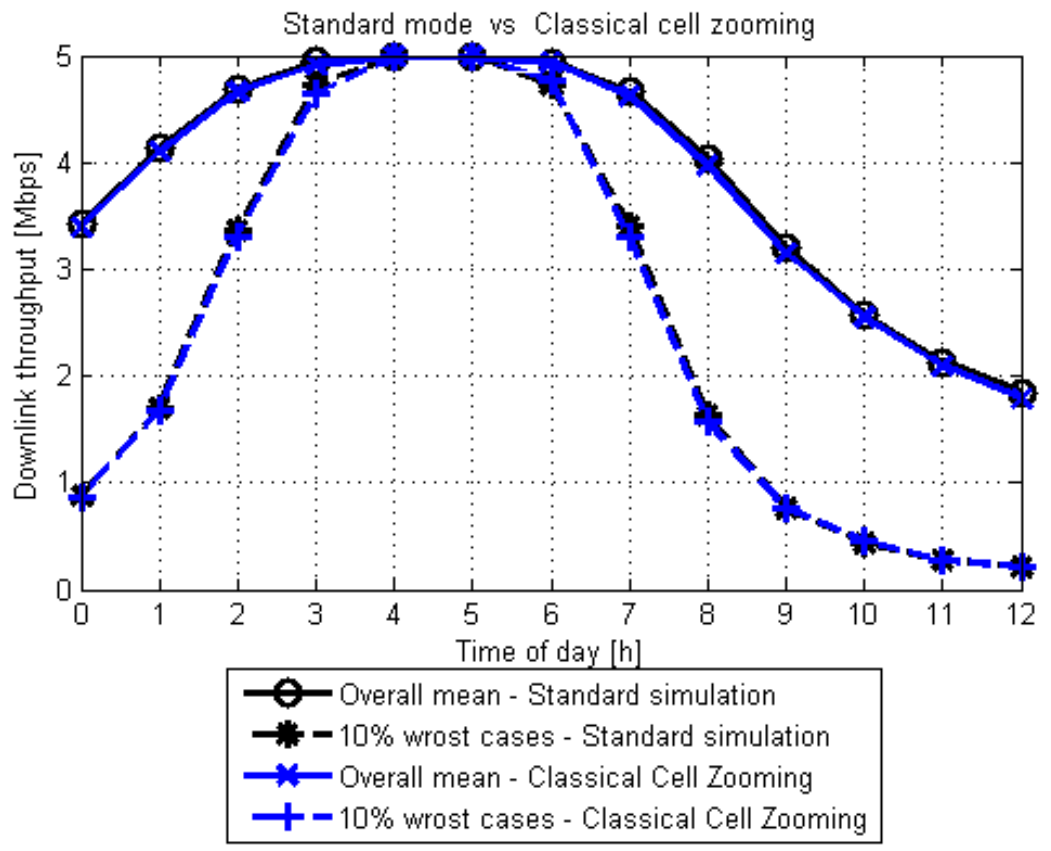

Figure 5.8 - UE downlink throughput in scenario 2.

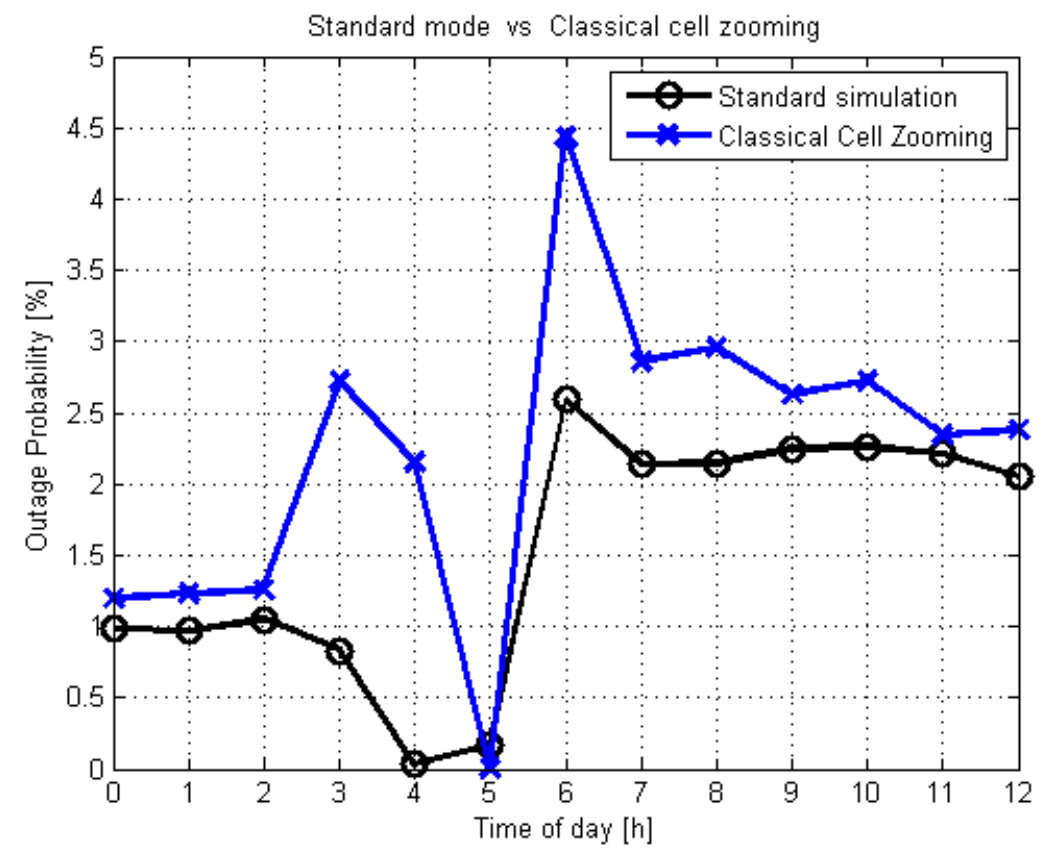

Figure 5.9 - Outage probability in scenario 2. 


\subsection{3 - Scenario 3: Sleep mode}

The sleep mode considered here is the one presented in Scenario 2 of Figure 3.2; whose parameters are listed in Table 5.4, i.e., sleep mode $(+0 \mathrm{~dB} / 1 \mathrm{x})$ with a server granularity of $1200 \mathrm{~s}$ and $75 \%$ of the peak offered traffic load for sleep mode activation. Figure 5.11, Figure 5.14, Figure 5.13, Figure 5.14, we compare the consumed power of sleep mode $(+0 \mathrm{~dB} / 1 \mathrm{x})$ with different values of server granularity and condition of sleep mode activation.

In sleep mode $(+0 \mathrm{~dB} / 1 \mathrm{x})$, some cells are switched off during low traffic load $(0-9 \mathrm{~h})$. As we can see in Figure 5.10, we can notice that between 0-9h, there is a considerable decrease of energy consumption per BS. Between 9-11h the energy consumption increases progressively. In this interval of time, traffic load increases, and, then, cells which were previously switched off can be switched on. However, after $11 \mathrm{~h}$, all the cell are loaded and the network returns to the standard mode.

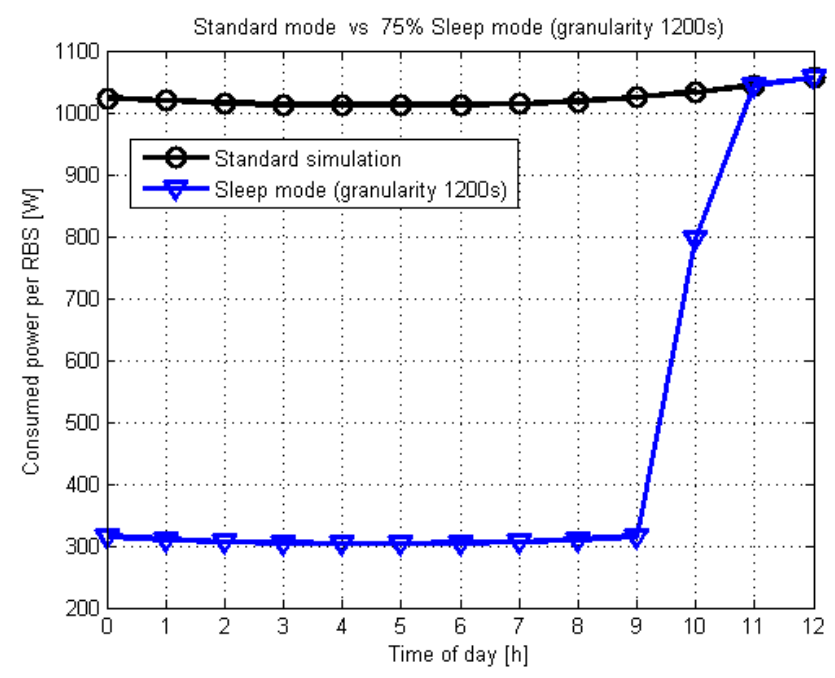

Figure 5.10 - Consumed power per BS in scenario 3.

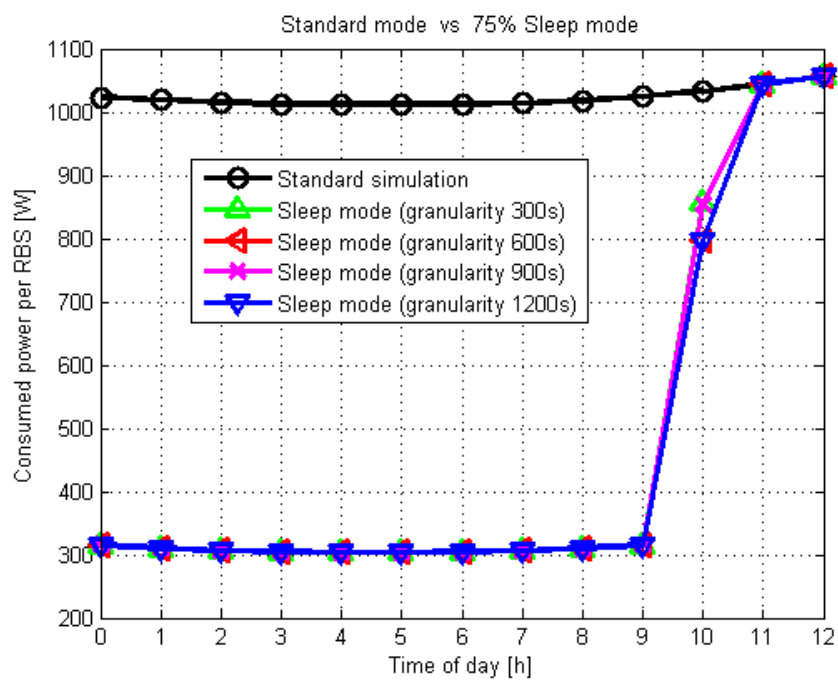

Figure 5.11 - Consumed power: $75 \%$ sleep mode with different values of server granularity. 


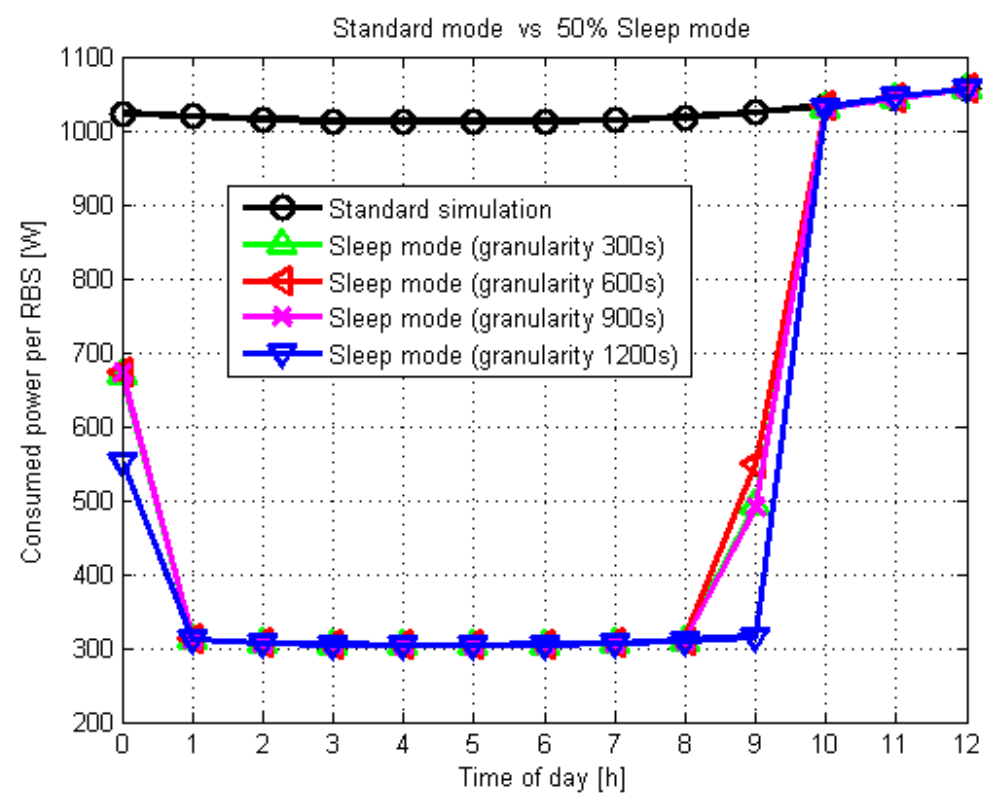

Figure 5.12 - Consumed power: 50\% Sleep mode with different values of server granularity.

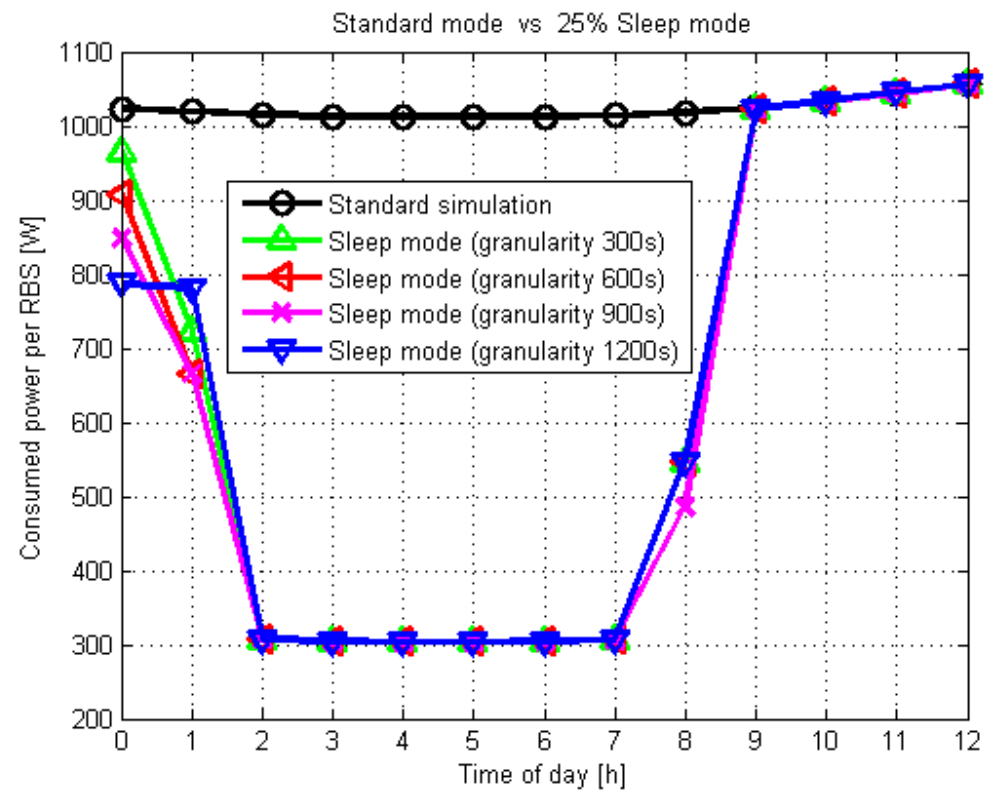

Figure 5.13 - Consumed power: $25 \%$ Sleep mode with different values of server granularity.

According to Figure 5.11, Figure 5.14, Figure 5.13, we can notice that when we reduce the server granularity value which corresponds to the sleep mode update time, the system reacts more quickly.

In Figure 5.11, the consumed power of sleep mode with the granularity 300, 600 and 900s, increases between 9-11h comparing with sleep mode (granularity 1200s). The increase is also observed in Figure 5.12 between 0-1h and 8-10h; and in Figure 5.13, between 0-2h and a small decrease between 7-9h. 


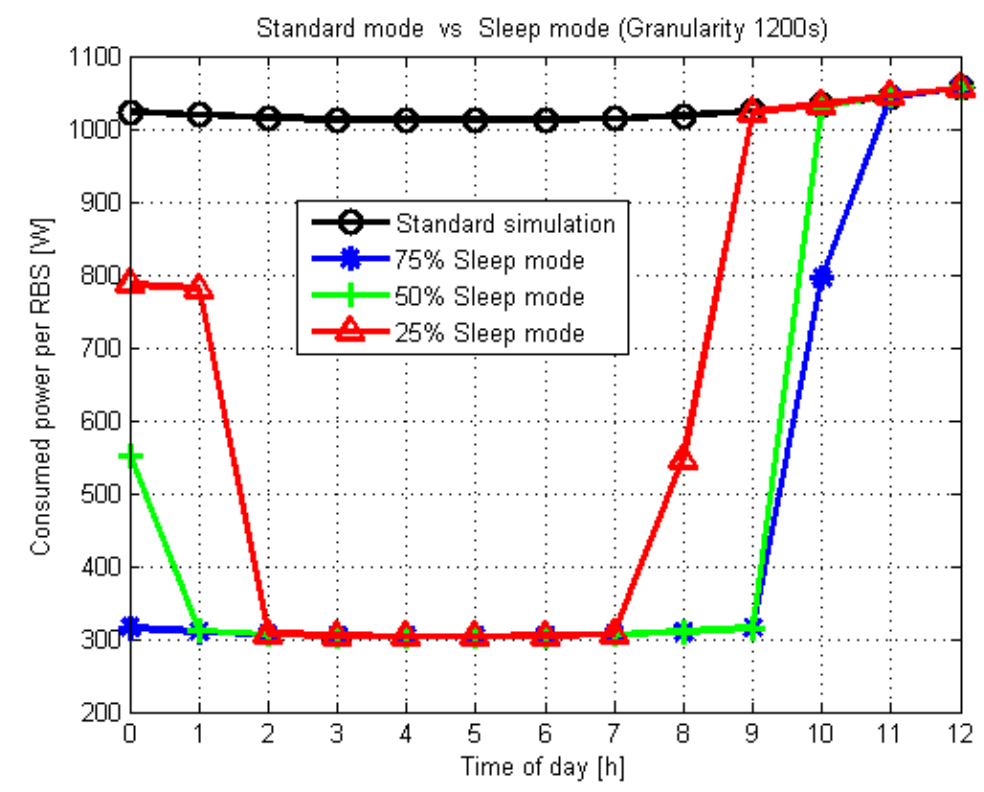

Figure 5.14 - Consumed power with different condition of sleep mode activation.

According to Figure 5.14, we can notice that the consumed power increases when we decrease the maximum traffic load for sleep mode activation. In other words, the higher the percentage of the peak offered load, for sleep mode activation, the more energy consumption we will save.

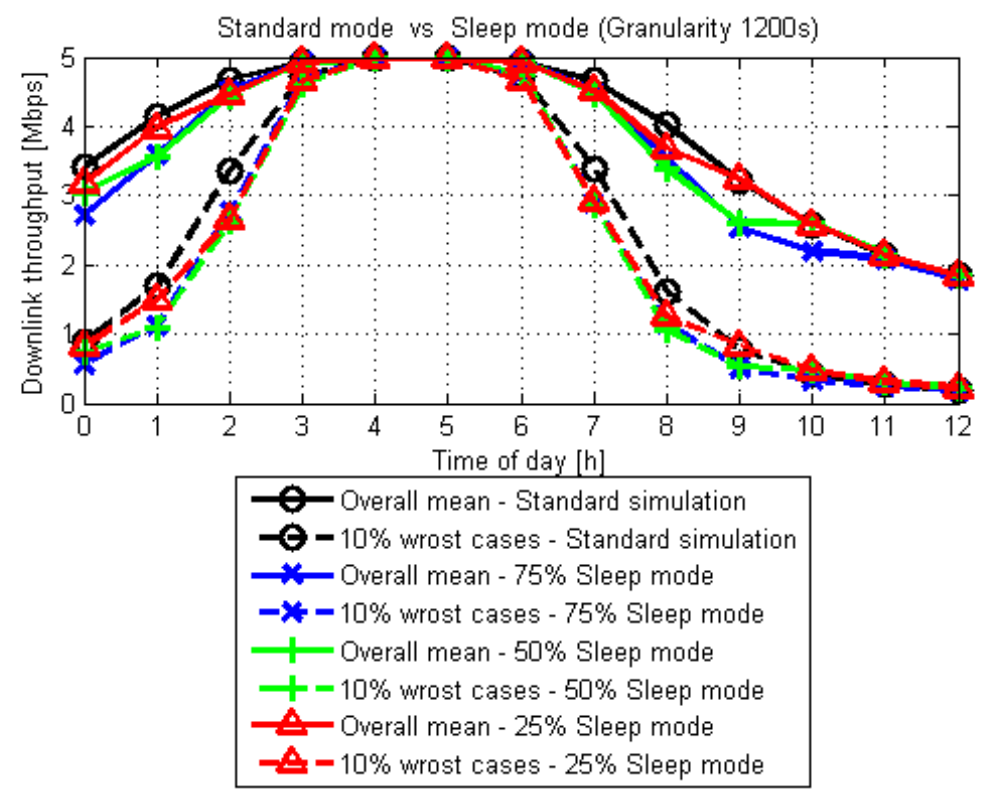

Figure 5.15 - UE downlink throughput with different condition of sleep mode activation.

As we can see in Figure 5.15, we can notice that UE downlink throughput increases when we decrease the maximum traffic load for sleep mode activation. In other words, the lower the percentage of the peak offered load, for sleep mode activation, the more UE downlink throughput we will have. 


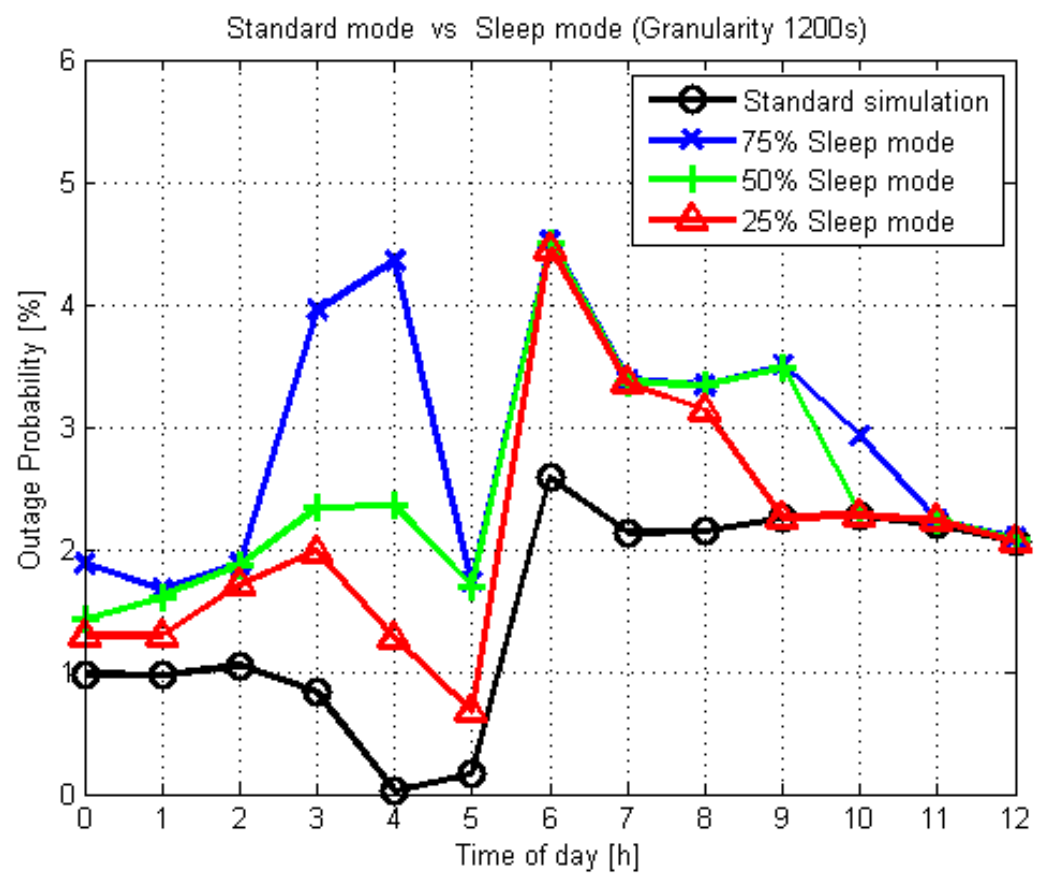

Figure 5.16 - Outage Probability with different condition of sleep mode activation.

In Figure 5.16, we can see that the outage probability decreases when we decrease the maximum traffic load for sleep mode activation. In other words, the lower the percentage of the peak offered load, for sleep mode activation, the less outage probability we will have.

In Figure 5.17, comparing with the standard mode, we can see that between 0-11h, the throughput and the cell-edge throughput (corresponding to the $10 \%$ worst cases) decrease considerably, because more cells are switched off, then, reducing the available resources.

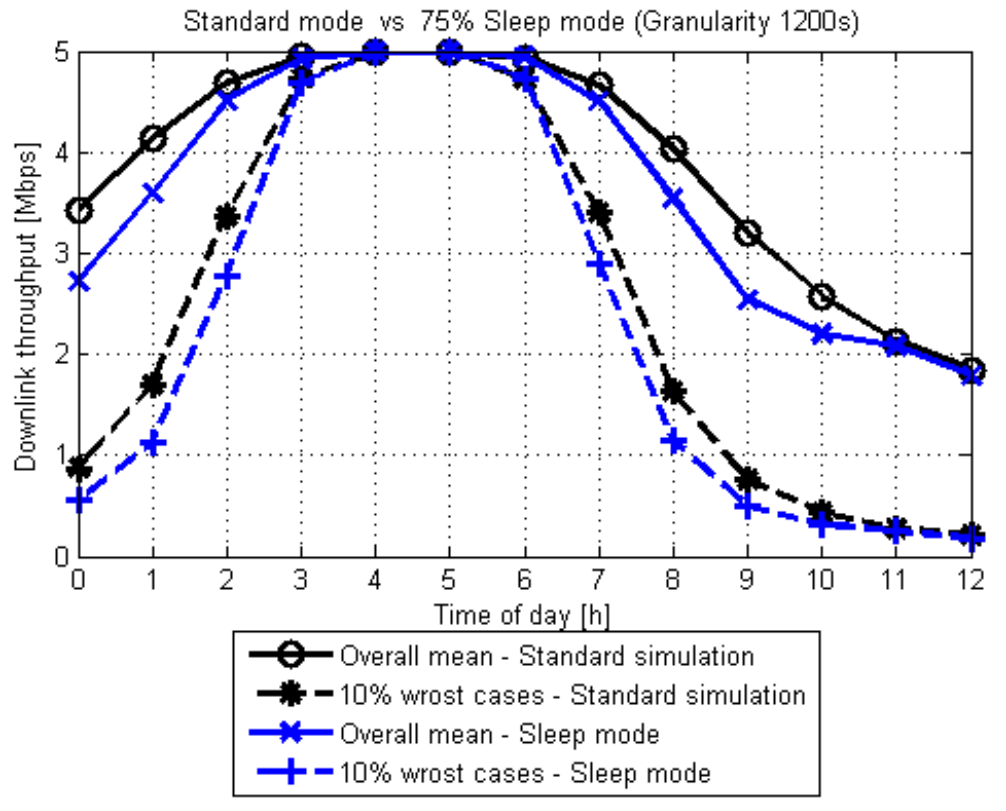

Figure 5.17 - UE downlink throughput in scenario 3. 
In Figure 5.18, we compare the outage probability of sleep mode $(+0 \mathrm{~dB} / 1 \mathrm{x})$ with different schemes i.e. when zoom out is applied to the active cells (Scenario 1 of Figure 3.2) or not (Scenario 2 of Figure 3.2).

In Figure 5.18, we can notice that when we increase the cell radius or the transmit power, the outage probability decreases considerably. However, increasing the cell radius is more beneficial than increasing the transmit power. Then, combining these two techniques for the sleep mode scheme, we can have a considerable reduction of the outage probability.

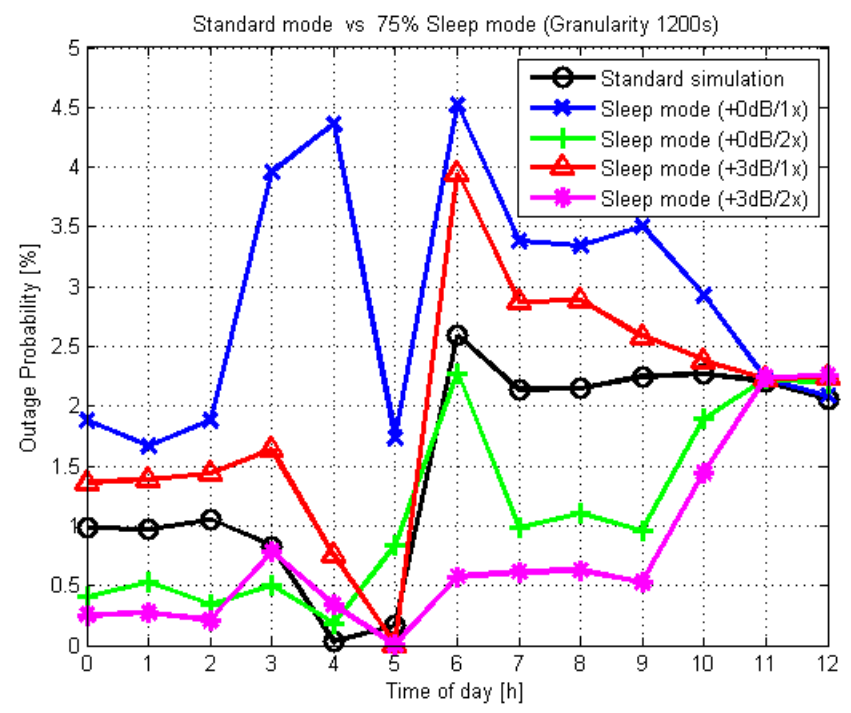

Figure 5.18 - Outage probability (with different sleep mode schemes) in scenario 3.

\subsection{4 - Scenario 4: Classical cell zooming + CoMP}

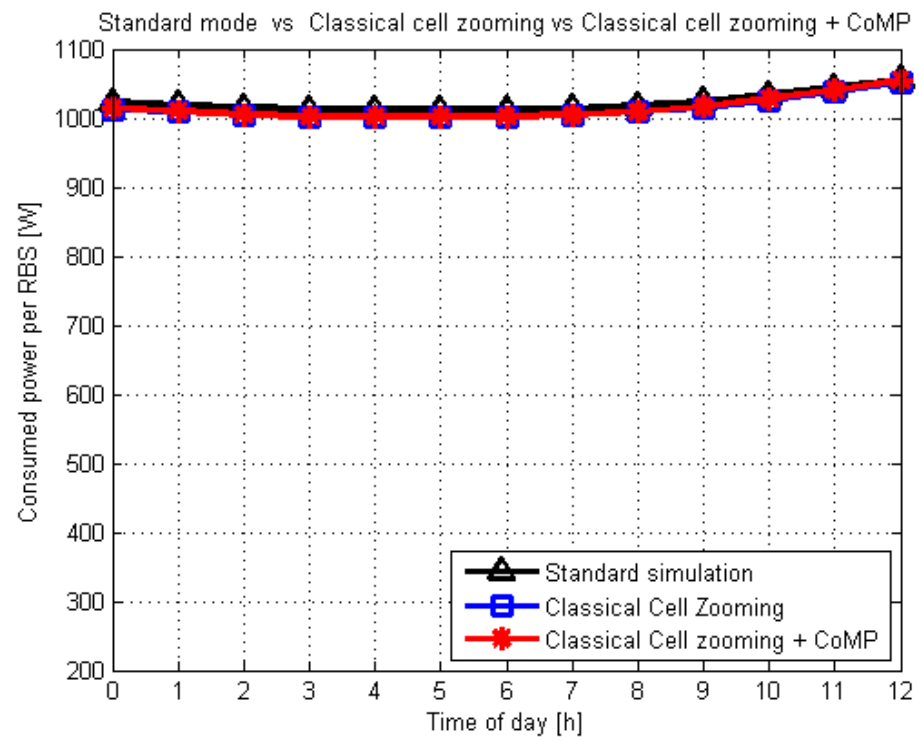

Figure 5.19 - Consumed power per BS in scenario 4. 
In Figure 5.19, we can notice that there is a small increase in the BS power consumption of the classical cell zooming when we apply CoMP. This is due to the supplement of signal processing when UE is jointly served by two BSs.

In Figure 5.20, we can see that there is a little increase in throughput and cell-edge throughput due to the increase of the UE received SINR.

In Figure 5.21, we see that CoMP helps us to decrease the outage probability especially between $2-5 h$.

Figure 5.22, presents the UE CoMP usage ratio. We can notice that the CoMP usage ratio decreases considerably between 3-6h due to the low traffic load at this period.

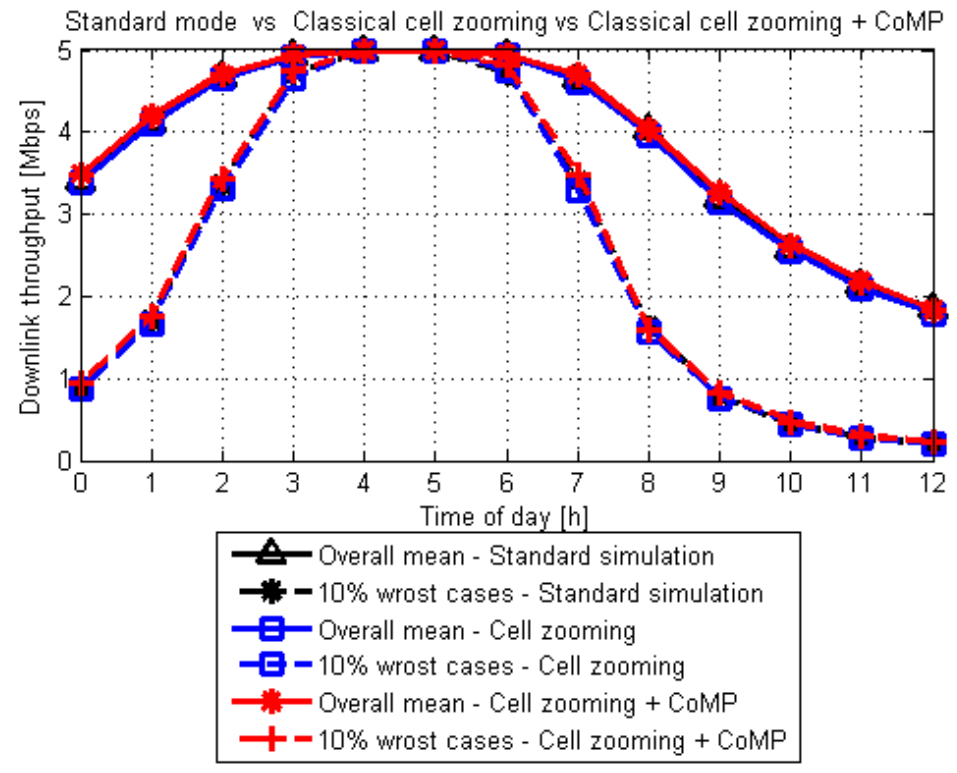

Figure 5.20 - UE downlink throughput in scenario 4.

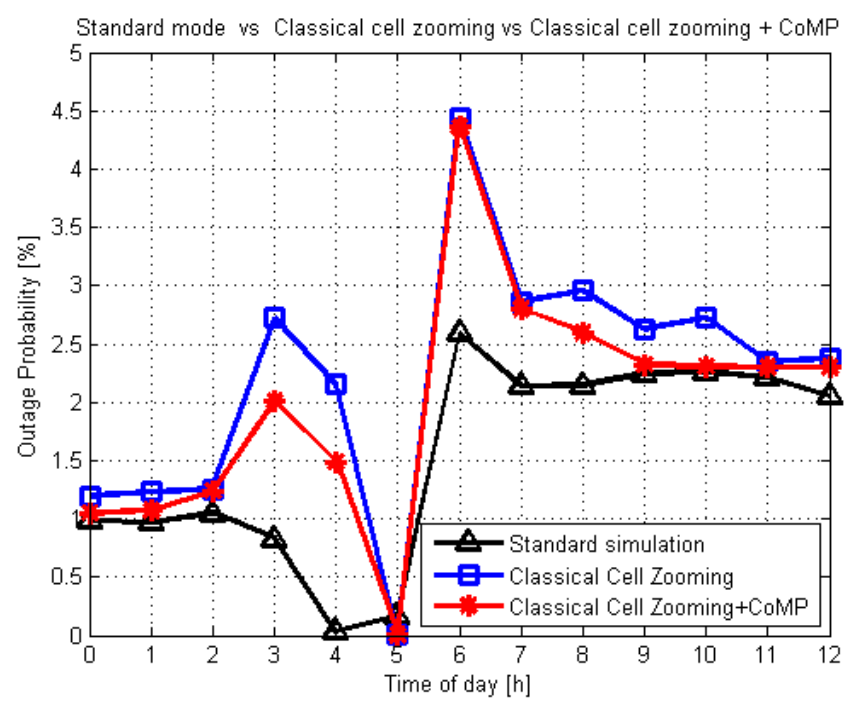

Figure 5.21 - Outage probability in scenario 4. 


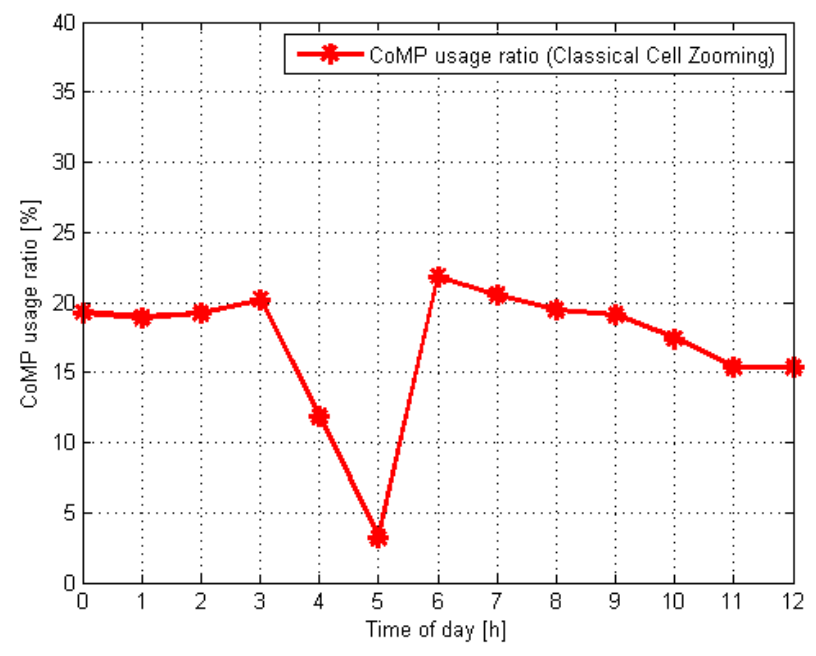

Figure 5.22 - UE CoMP usage ratio in scenario 4.

\subsection{5 - Scenario 5: Sleep mode + CoMP}

As mentioned in Section - CoMP5.2, UEs can use JT-CoMP technique; then, as we can see in Figure 5.23, CoMP brings a small increase in the BS power consumption of the sleep mode.

In Figure 5.24, we can see that there is a little increase in throughput. Comparing with the classical cell zooming, CoMP improves the cell-edge throughput of the sleep mode due to the need of the UEs localized at the cell-edge to be served by a second BS.

In Figure 5.25, CoMP decreases considerably the outage probability especially between 2-6h.

In Figure 5.26, we can notice that the CoMP usage ratio decreases considerably between 3-5h due to the low traffic load at this period. However, between 9-12h, sleep mode and CoMP are deactivating at the same time.

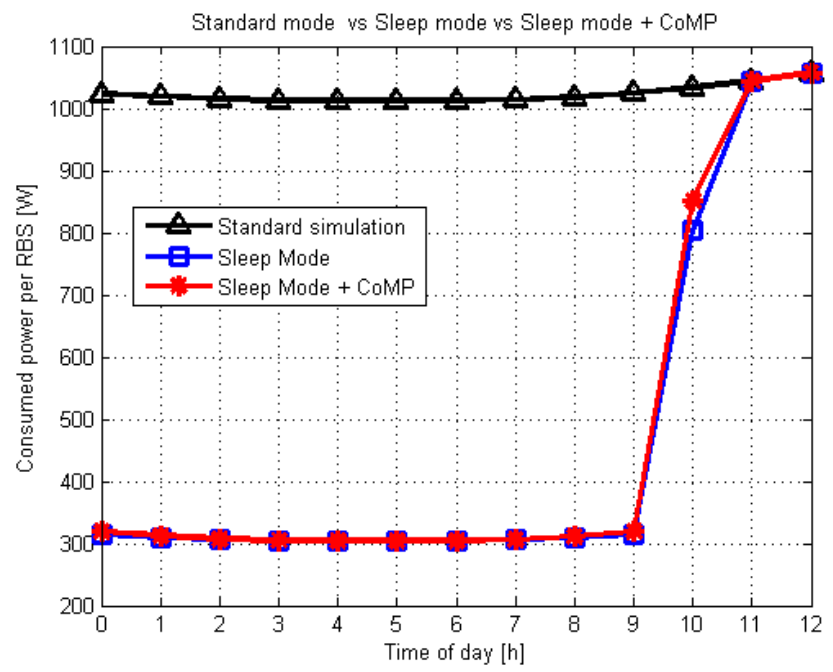

Figure 5.23 - Consumed power per BS in scenario 5. 


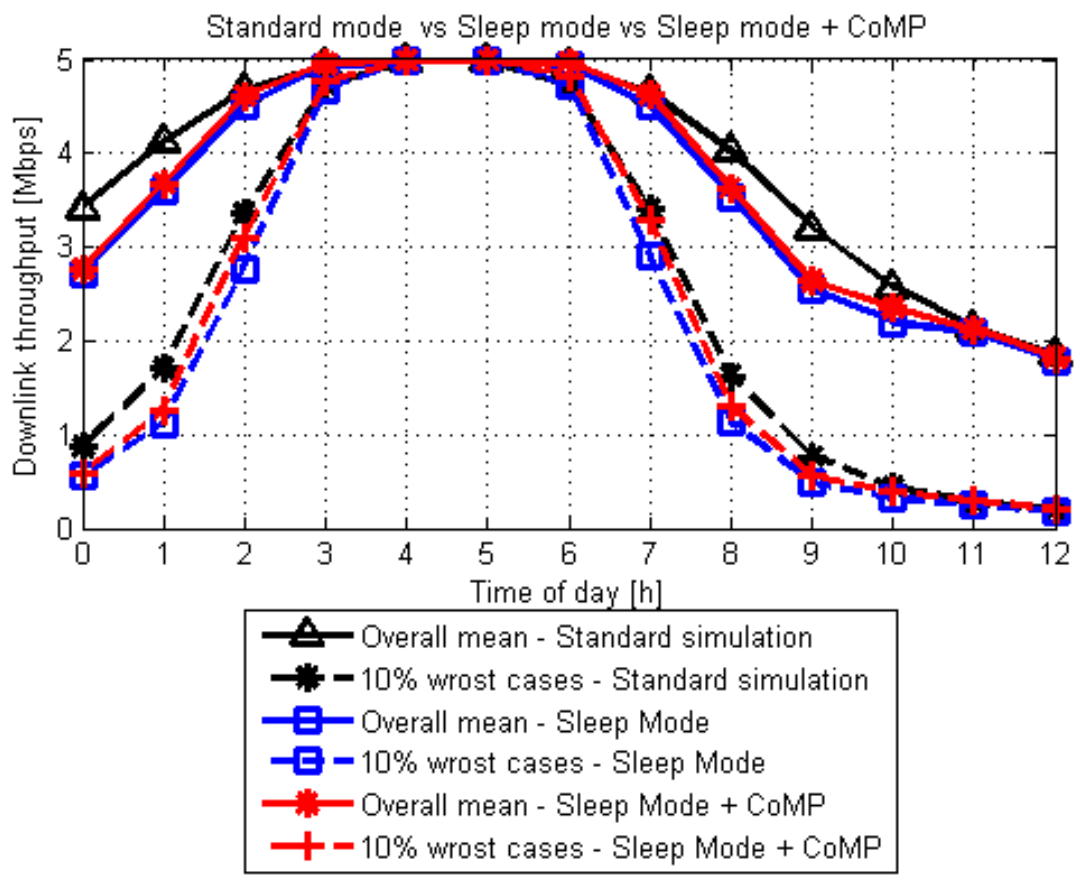

Figure 5.24 - UE downlink throughput in scenario 5.

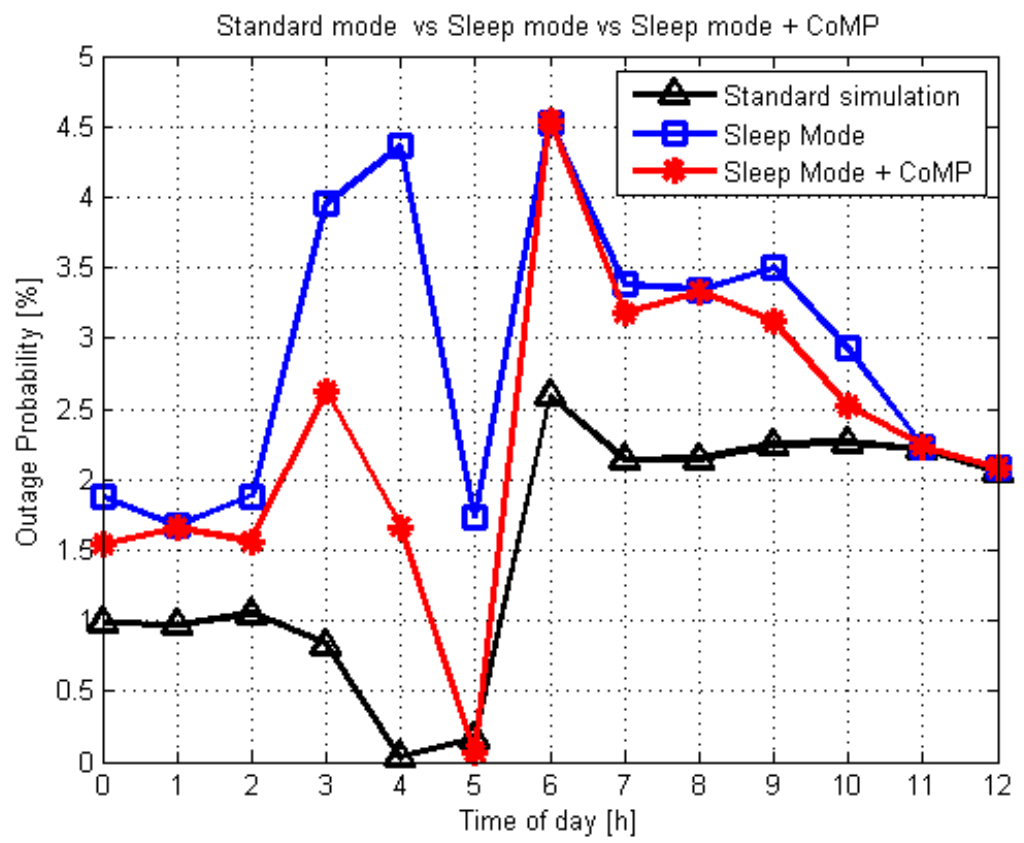

Figure 5.25 - Outage probability in scenario 5. 


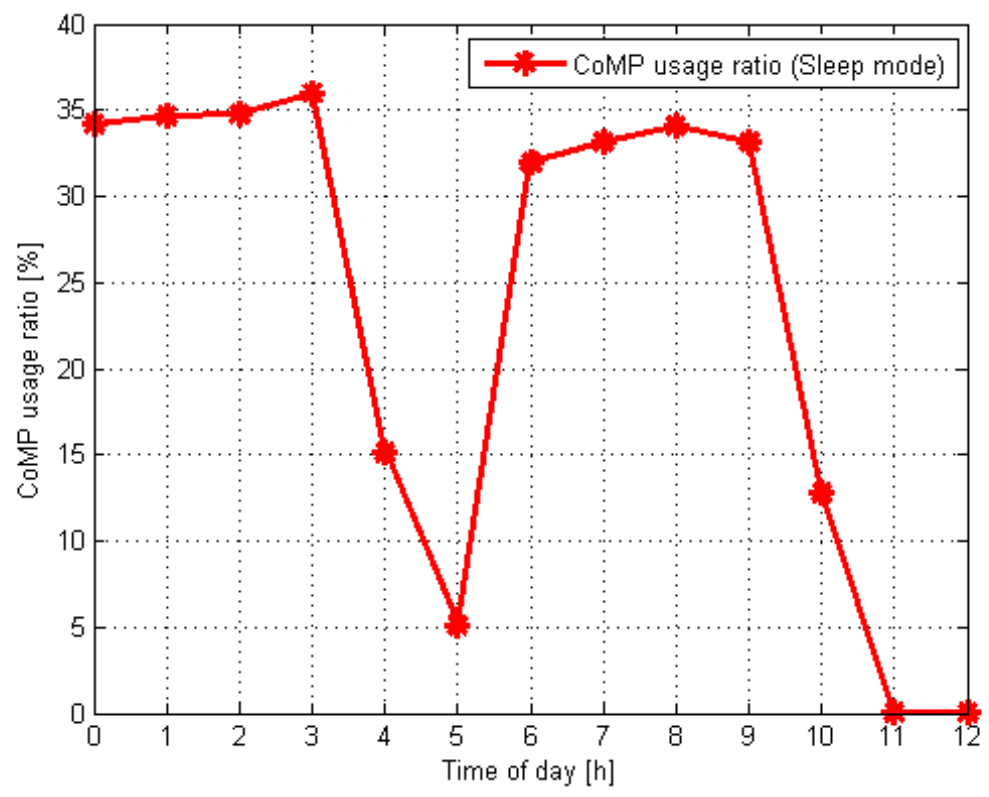

Figure 5.26 - UE CoMP usage ratio in scenario 5.

Table 5.6 - Comparative results of each simulation from 0-9h

\begin{tabular}{|c|c|c|c|c|c|}
\hline \multirow{2}{*}{$\begin{array}{c}\text { METRICS } \\
\text { (Overall means between 0-9h) }\end{array}$} & $\begin{array}{c}\text { Standard } \\
\text { mode }\end{array}$ & \multicolumn{2}{c|}{$\begin{array}{c}\text { Sleep mode } \\
(+0 \mathrm{~dB} / 1 \mathrm{x})\end{array}$} & \multicolumn{2}{c|}{$\begin{array}{c}\text { Classical cell } \\
\text { zooming }\end{array}$} \\
\cline { 2 - 6 } & Standard & Normal & + CoMP & Normal & + +CoMP \\
\hline Consumed Power (W) & $1,015.6$ & 307.16 & 308.00 & $1,005.1$ & $1,005.6$ \\
\hline Energy Saving (\%) & - & 69.75 & 69.67 & 1.03 & 0.98 \\
\hline CoMP usage ratio (\%) & - & - & 28.78 & - & 17.16 \\
\hline $\begin{array}{c}\text { Average throughput (Mbps) } \\
\text { Average cell-edge throughput } \\
\text { (10\% worst cases) } \\
\text { (Mbps) }\end{array}$ & 4.53 & 4.30 & 4.35 & 4.50 & 4.55 \\
\hline Outage Probability (\%) & 1.21 & 2.96 & 2.26 & 2.09 & 1.84 \\
\hline Average UEs per cell & 0.8357 & 0.8303 & 0.8391 & 0.8385 & 0.8426 \\
\hline
\end{tabular}




\section{5 - ANALYSES AND DISCUSSION}

According to the comparative results listed in Table 5.6 we can say that:

* The average throughput in the standard mode presents results as it was defined in the simulator, i.e., with limit of $5 \mathrm{Mbps}$. However, we can notice a little decrease of $-0.66 \%$ of the throughput in classical cell zooming and $-5.07 \%$ in sleep mode. We can notice the same scenario in the cell-edge throughput, i.e., $-0.89 \%$ in classical cell zooming and $-8.30 \%$ in sleep mode. However, with the contribution of CoMP, the throughput improved in the classical cell zooming by $+1.09 \%$ and $+2.05 \%$ for the cell-edge throughput; while in the sleep mode, the throughput improved by $+1.15 \%$ and $+4.33 \%$ for the cell-edge throughput. In summary, CoMP contributes in the improvement of the quality of the network while cell zooming or sleep mode is applied.

* The percentage of the consumed power in classical cell zooming is greater than the sleep mode. There is $+69.75 \%$ of energy saving in sleep mode while in classical cell zooming, only $+1.03 \%$ of the total energy consumption has been saved. Therefore, sleep mode remains a better solution for the energy saving.

* The percentage of outage probability in sleep mode is greater than the classical cell zooming. There is an increase of $+42.10 \%$ of outage probability in classical cell zooming and $+59.12 \%$ in sleep mode. However, with the contribution of CoMP, the outage probability has been decreased by $-23.64 \%$ in sleep mode and $-11.96 \%$ in the classical cell zooming. In summary, CoMP contributes in the decrease of outage probability while improving the network quality, especially in sleep mode.

* We can notice that the UEs CoMP usage ratio in sleep mode is higher compared with the classical cell zooming because, in sleep mode, some cells are switched off. Therefore, most of the received power level are under the limit of the maximum received power (Prx ${ }_{\max }$ ) permitted by the CoMP requirements to enable the CoMP, especially in sleep mode where some UEs are not well covered. Then, we can notice an increase of $+40.21 \%$ of the UEs CoMP usage ratio in classical cell zooming, and $+69.44 \%$ in sleep mode. 


\section{CONCLUSIONS}

Energy efficiency in wireless systems is a hot topic nowadays. In this work, we are interested in the evaluation of the energy efficiency of sleep mode and classical cell zooming; and we propose the use of CoMP, as technique to improve the network quality.

After analyses of simulation results, comparing the standard simulation with the other modes, we can say that in terms of energy saving, sleep mode is more efficient than classical cell zooming at the cost of increasing the outage probability and decreasing the network quality. However, combining sleep mode with CoMP can be a better way to improve the network quality.

In point of view of energy saving, cell zooming alone is not very efficient, but its use with the sleep mode, can be advantageous, as zoom out scheme overcomes the coverage holes in sleep mode when bases stations are switched off.

However, to best of our knowledge, devices for dynamic physical antenna tilts adjustment are not already available, and we do not always have not always enough transmit power to increase. Thus, the use of the zoom out scheme remains an unfeasible technique to be implemented in the actual configuration of cellular networks systems.

CoMP, which is standardized for LTE cellular networks, proves to be an efficient technique to enable a sufficient received power level, to improve the network capacity and to decrease the outage probability. In summary, its use can improve the QoS of the network and QoE of UEs. However, it requires a higher complexity in the network level.

As mentioned in the introduction, the simulator is helpful do get rapidly some estimated results about the green commination concept before real implementation in actual LTE cellular networks.

Further research is needed in order to investigate the uplink transmission especially in CoMP technique.

In addition to that, as we consider only two base stations to serve UEs in CoMP, the possibility of more than two base stations and more realistic model of CoMP can be investigated in a further work. 


\section{REFERENCES \& LITERATURE}

[1] M. Nahas, S. Abdul-Nabi, L. Bouchnak and F. Sabeh, "Reducing Energy Consumption in Cellular Networks by Adjusting Transmitted Power of Base Station," Broadband Networks and Fast Internet (RELABRIA), pp. 39-44, 2012.

[2] C. Han, T. Harrold, S. Armour, S. Videv, P. M. Grant, H. Haas and J. S. Thompson, "Green Radio: Radio Techniques to Enable Energy-Efficient Wireless Networks," IEEE Communications Magazine, vol. 49, pp. 46-54, 2011.

[3] Z. Hasan, H. Boostanimehr and V. K. Bhargava, "Green Cellular Networks: A Survey, Some Research Issues and Challenges," IEEE Communications Surveys \& Tutorials, vol. 13, no. 4, pp. 524-540, 2011.

[4] M. Sawahashi, Y. Kishiyama, A. Morimoto, D. Nishikawa and M. Tann, "Coordinated multipoint Transmission/reception Techniques for LTE-Advanced [Coordinated and Distributed MIMO]," Wireless Communications, IEEE, vol. 17, pp. 26-34, 2010.

[5] GSMA, "GSMA Intelligence," December 2014. [Online]. Available: https://gsmaintelligence.com/research/?file=f51b086ec6c50fb8b374ef0e2f017e6e \&dow nload. [Accessed 2107 2014].

[6] X. Wang, P. Krishnamurthy and D. Tipper, "Cell Sleeping for Energy Efficiency in Cellular Networks: Is it viable?," IEEE Wireless Communications and Networking Conference: Mobile and Wireless Networks, vol. 10, p. 2509 - 2514, 2012.

[7] N. Zhisheng, W. Yiqun, G. Jie and Y. Zexi, "Cell Zooming for Cost-Efficient Green Cellular Networks," Communications Magazine, IEEE, vol. 48, pp. 74-79, 2010.

[8] T. Han and N. Ansari, "On Greening Cellular Networks via Multicell Cooperation," IEEE Wireless Communication, vol. 20, pp. 82-89, 2013.

[9] Jeanette Wannstrom (3GPP), "The Mobile Broadband Standard," 3GPP, June 2013. [Online]. Available: http://www.3gpp.org/technologies/keywords-acronyms/97-lteadvanced. [Accessed 2107 2013].

[10] S. K. A. Landou and A. N. Barreto, "Use of CoMP in 4G cellular networks for increased network energy efficiency," Telecommunications (IWT), International Workshop on, pp. $1-6,2015$.

[11] B. S. Carminati and M. F. Costa, "Gerenciamento de Potência em Redes Cellulares Sustentáveis de Quarta Geração," Undergraduate thesis, University of Brasilia, Brasilia, 2013. 
[12] Y. Bouguen, E. Hardouin and F.-X. Wolff, LTE et les réseaux 4G, Eyrolles, 2012.

[13] S. Sesia, I. Toufik and M. Baker, "LTE - The UMTS Long Term Evolution," Ed. Wiley, vol. 1st, 2009.

[14] O. Assou, "3gpp Lte Long Term Evolution Physical Layer and Associated Performances 4137," 09 June 2012. [Online]. Available: https://fr.scribd.com/doc/96551269/3gpp-LteLong-Term-Evolution-Physical-Layer-and-Associated-Performances-4137. [Accessed 27 June 2015].

[15] Agilent technologies, "Introducing LTE-Advancing, Application Note, Agilent Technologies," 08 March 2011. [Online]. Available: http://cp.literature.agilent.com/litweb/pdf/5990-6706EN.pdf. [Accessed 26 June 2015].

[16] B. Patil, Y. Saifullah and S. Faccin, "IP in Wireless Networks," February 2013. [Online]. Available: http://flylib.com/books/en/4.215.1.33/1/. [Accessed 27 June 2015].

[17] E. Oh, B. Krishnamachari, X. Liu and Z. Niu, "Toward Dynamic Energy-Efficient Operation of Cellular Network Infrastructure," IEEE Communications Magazine, pp. 5661, 2011.

[18] B. S. Carminati, M. F. Costa and A. N. Barreto, "Virtual Cell Zooming and Sleep Mode for 3GPP-LTE Green Cellular Networks," in Simpósio Brasileiro de Telecomunicaçoes (SBrT), 2013.

[19] S. Tombaz, A. Västberg and J. Zander, "Energy- and Cost-Efficient Ultra-High-Capacity Wireless Access," IEEE Wireless Communication, vol. 18, pp. 18-24, 2011.

[20] G. Cili, H. Yanikomeroglu and F. R. Yu, "Cell Switch Off Technique Combined with Coordinated Multi-Point (CoMP) Transmition for EnergyEfficiency in Beyond-LTE Cellular Networks," IEEE Workshop on Green Communications and Networking, pp. 5931-5935, 2012.

[21] Md. Shipon Ali, "On the Evolution of Coordinated Multi-Point (CoMP) Transmission in LTE-Advanced," International Journal of Future Generation Communication and Networking, vol. 7, no. 4, pp. 91-102, 2014.

[22] B.-S. Liao, W. R. Wu and H.-T. Hsieh, "Intra-Site CoMP in LTE-A Systems: an AntennaSelection-Based Solution," IEEE Wireless Communications and Networking Conference: PHY and Fundamentals, p. 832, 2012.

[23] F. Gunnarsson, M. N. Johansson, A. Furuskar, M. Lundevall, A. Simonsson, C. Tidestav and M. Blomgren, "Dowtilted Base Station Antennas - A Simulation Model Proposal and Impact on HSPA and LTE Performance," 2008. 
[24] T. S. Rapport, "Wireless Communications: Principles and Practice," in 2nd ed., Prentice Hall, 2001.

[25] J. Zhuang, L. Jalloul, R. Novak and J. Park, "Evaluation Methodology for P802.16m Advanced Air Interface," IEEE 802.16 Broadband Wireless Access Working Group, pp. 44-45, 2009.

[26] H. G. Myung, "Technical Overview of 3GPP Long Term Evolution (LTE)," 18 May February 2007. [Online]. Available: https://www.iith.ac.in/ tbr/teaching/docs/LTETutorial.pdf. [Accessed 3107 2015].

[27] M. L. Belhouchet and M. H. Ebdelli, "LTE Technology Performance Evaluation," Tunisia, 2010. 